\title{
Aldose Reductase, Ocular Diabetic Complications And the Development of Topical Kinostat ${ }^{\circledR}$
}

\author{
Peter F. Kador ${ }^{1,2}$, Milton Wyman ${ }^{1-3}$ and Peter J. Oates ${ }^{4}$
}

${ }^{1}$ College of Pharmacy and Department of Ophthalmology, University of Nebraska Medical Center, Omaha, NE,

${ }^{2}$ Therapeutic Vision, Inc. Omaha, NE,

${ }^{3}$ College of Veterinary Medicine, The Ohio State University, Columbus, $\mathrm{OH}$

${ }^{4}$ Oates Biomedical Consulting, LLC, Old Lyme, CT

Corresponding Author: Peter F. Kador, Ph.D., FARVO

College of Pharmacy

986025 Nebraska Medical Center

Omaha, NE 68198-6025

Tel: 402-559-9261

Email: pkador@unmc.edu 


\begin{abstract}
Diabetes mellitus (DM) is a major health problem with devastating effects on ocular health in both industrialized and developing countries. The control of hyperglycemia is critical to minimizing the impact of DM on ocular tissues because inadequate glycemic control leads to ocular tissue changes that range from a temporary blurring of vision to permanent vision loss. The biochemical mechanisms that promote the development of diabetic complications have been extensively studied. As a result, a number of prominent biochemical pathways have been identified. Among these, the two-step sorbitol pathway has been the most extensively investigated; nevertheless, it remains controversial. To date, long-term pharmacological studies in animal models of diabetes have demonstrated that the onset and development of ocular complications that include keratopathy, retinopathy and cataract can be ameliorated by the control of excess metabolic flux through aldose reductase (AR). Clinically the alleles of $A R$ have been linked to the rapidity of onset and severity of diabetic ocular complications in diabetic patient populations around the globe. In spite of these promising preclinical and human genetic rationales, several clinical trials of varying durations with structurally diverse aldose reductase inhibitors (ARIs) have shown limited success or failure in preventing or arresting diabetic retinopathy. Despite these clinical setbacks, topical ARI Kinostat ${ }^{\circledR}$ promises to find a home in clinical veterinary ophthalmology where its anticipated approval by the FDA will present an alternative treatment paradigm to cataract surgery in diabetic dogs. Here, we critically review the role of AR in diabetes mellitus-linked ocular disease and highlight the development of Kinostat ${ }^{\circledR}$ for cataract prevention in diabetic dogs. In addition to the veterinary market, we speculate that with further safety and efficacy studies in humans, Kinostat $^{\Theta}$ or a closely related product could have a future role in treating diabetic keratopathy.
\end{abstract}

Keywords: diabetic retinopathy; diabetic cataract; diabetic keratopathy; aldose reductase inhibitor; Kinostat ${ }^{\circledR}$ 


\section{Table of Contents}

The Biochemistry of Diabetic Complications 4

Aldose Reductase and the Rat Lens $\quad 8$

$\begin{array}{ll}\text { Diabetic Retinopathy } & 11\end{array}$

Diabetes-like Retinal Changes in Untreated Galactose-Fed Dogs 14

$\begin{array}{ll}\text { Initial Prevention Study } & 19\end{array}$

Expansion of the Prevention Studies $\quad 22$

Intervention Studies $\quad 26$

Galactose Diet Removal Studies $\quad 26$

Clinical Evaluation of Retinal Changes in Galactose-Fed Dogs 29

Transgenic Mouse Studies $\quad 33$

$\begin{array}{ll}\text { Development of Kinostat } & \\ & \end{array}$

Cataracts are Problematic in Dogs $\quad 38$

Identifying an Aldose Reductase inhibitor (ARI) Candidate 36

Intervention Study of Kinostat ${ }^{\circledR}$ in Galactose-Fed Dogs 39

Proof of Concept Clinical Study (Phase 1-2 Study) 42

$\begin{array}{ll}\text { FDA Approval Studies } & 46\end{array}$

Standardized Preparation of Topical Kinostat ${ }^{\circledR} \quad 46$

$\begin{array}{ll}\text { Drug Safety Study } & 47\end{array}$

Clinical Evaluation of Kinostat ${ }^{\circledR} \quad 48$

Aldose Reductase and Human Sugar Cataracts $\quad 50$

Aldose Reductase and Juvenile Cataracts $\quad 51$

Aldose Reductase and Adult Diabetic Cataracts 53

Localized Osmotic Changes $\quad 55$

Aldose Reductase and Corneal Changes 56

Aldose Reductase Inhibitors and Human Diabetic Keratopathy 59

$\begin{array}{ll}\text { Future Directions } & 63\end{array}$ 
Diabetes mellitus (DM) is a major health problem that can have devastating effects on ocular health in both industrialized and developing countries (Miyamoto et al., 2007; Paques et al., 1997). DM can adversely impact many parts of the eye ranging from the conjunctiva, cornea, iris, and lens in the anterior segment to the vitreous, retina and optic disk of the posterior segment. The clinical effects of DM on ocular tissues has been reviewed in detail (Skarbez et al., 2010). Central to minimizing the impact of DM on ocular tissues is the control of hyperglycemia, because inadequate glycemic control leads to ocular tissue changes that range from a temporary blurring of vision to permanent vision loss.

\section{The Biochemistry of Diabetic Complications}

The biochemical mechanisms by which relative insulin-deficiency and C-peptidopenia (Wahren and Larsson, 2015) and consequent hyperglycemia and hyperlipidemia promote the development of diabetic complications have been extensively studied in various tissues. As a result, several networks of biochemical pathways have been identified as being particularly prominent (Aronson, 2008; Oates, 2008). These include increased metabolic flux through the sorbitol pathway with consequent osmotic (Kinoshita, 1986), oxidative (Barnett et al., 1986), pseudohypoxic (Williamson et al., 1993), methylglyoxalic (Rabbani and Thornalley, 2012), and advanced glycation endproduct (AGE) (Yan et al., 2010) stresses; elevated activities of NADPH oxidase (Jha et al., 2014), diacyl glycerol/PKC (Geraldes and King, 2010), abnormal mitochondrial (Nishikawa et al., 2000) and endoplasmic reticulum metabolism (O'Brien et al., 2014), p66Shc activation (Yang et al., 2014), hexosamine synthesis (Schleicher and Weigert, 2000) and poly-ADP ribose polymerase activation (Pacher and Szabo, 2005). Common to increased metabolic flux through these interconnected pathways and enzymes is increased oxidative and nitrative stress with the excess generation of reactive oxygen/nitrogen species (ROS/RNS).

Among these various biochemical pathways, the two-step sorbitol pathway has been the most investigated; and yet, it remains controversial still. Briefly, in this pathway, excess glucose is reduced to the sugar alcohol sorbitol by the NADPH-dependent 
enzyme aldose reductase (AR). In the second step sorbitol, which is considered an osmolyte, is oxidized to fructose by the $N A D^{+}$-dependent enzyme sorbitol dehydrogenase $(\mathrm{SDH})$. $\mathrm{AR}$ has broad substrate specificity and can also reduce galactose to the sugar alcohol galactitol, but galactitol is only poorly further metabolized. In diabetic tissues that do not depend on insulin for glucose entry and that do not downregulate passive glucose transport or in galactosemic tissues, elevated extracellular hexose causes abnormally increased metabolic flux of hexose through AR, the first enzyme of the sorbitol pathway. In some tissues this leads to the intracellular elevation of the polyols sorbitol or galactitol, an event that has been shown to induce osmotic and oxidative stress through the various mechanisms mentioned above. Elevated metabolic flux through $A R$ also causes increased turnover of $\mathrm{NADPH}$, the obligatory cofactor of AR and a key component of cellular antioxidant systems (Kinoshita, 1986; Oka et al., 2012). In diabetic tissues, increased sorbitol levels also lead to increased flux through SDH which results in increased fructose levels and increased turnover of $\mathrm{NAD}^{+}$, the obligatory cofactor of $\mathrm{SDH}$. The consequent elevated cytosolic NADH/NAD ${ }^{+}$ratios inhibit nicotinamide phosphoribosyl transferase (NAMPT) which leads to reduced $\mathrm{NAD}^{+}$-dependent deacetylase Sirt-1 activity and prolonged acetylation and expression of Early growth response 1 (Egr1) activity (Vedantham et al., 2014). Erg1 controls the gene expression of a number of transcripts that are implicated in the pathogeneses of diabetes complications, including vascular cell adhesion molecules, matrix metalloproteinases, tumor necrosis factors, and tissue factors (Fig. 1). By preventing sorbitol accumulation, inhibitors of $A R$ (ARIs) also indirectly inhibit such downstream events resulting from increased sorbitol dehydrogenase activity. Studies on the specific inhibition of SDH with SDH inhibitors (SDHIs) have been limited in the eye because sorbitol accumulation accelerates cataract formation and because SDHIs should be irrelevant for efficacy in galactosemic animals since galactitol is poorly metabolized by SDH (Maret and Auld, 1988). 


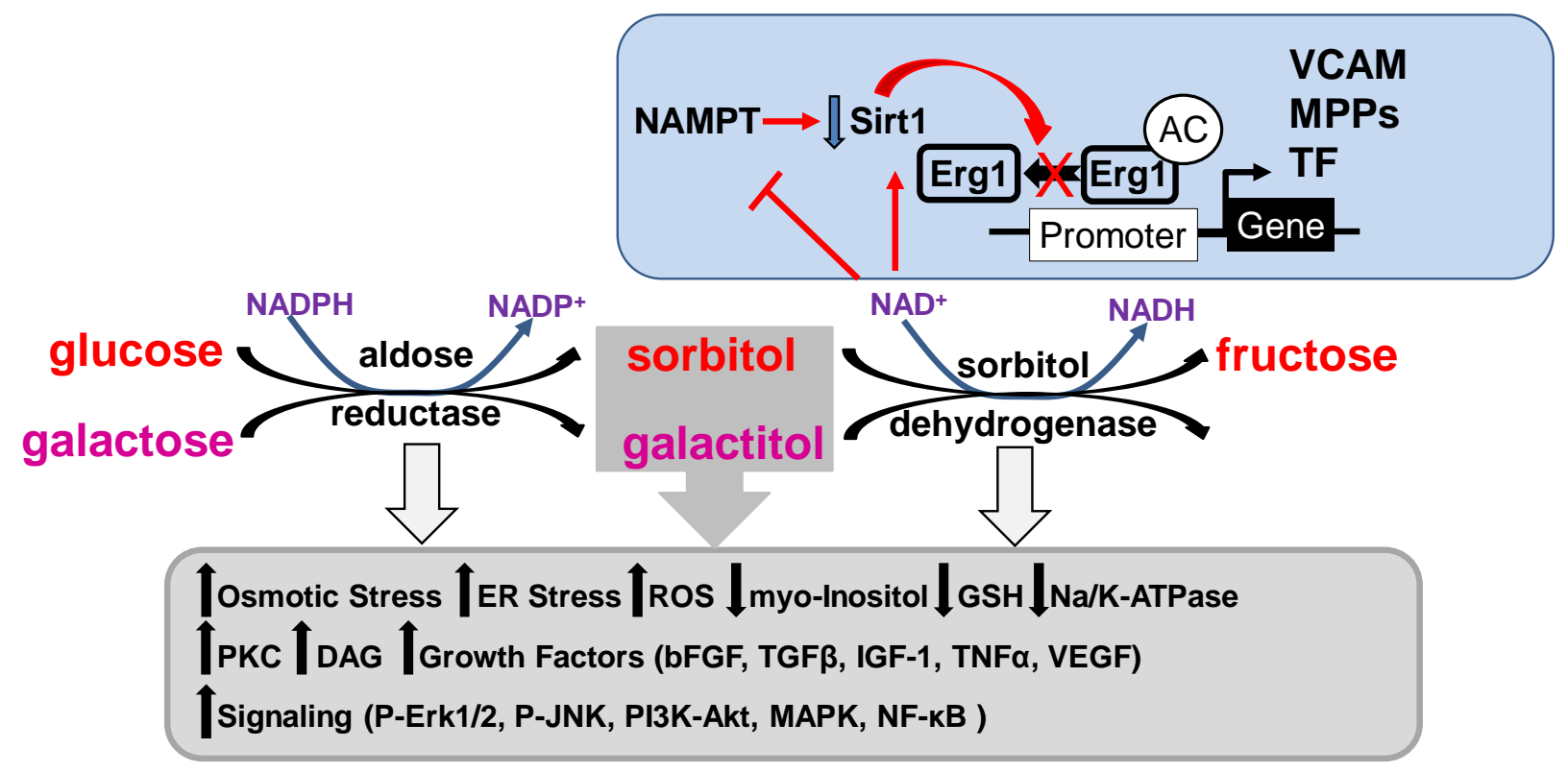

Figure 1. Summary of biochemical changes associated with increased Sorbitol Pathway activity. Increased "polyol" formation can result in cellular changes that result from osmotic stress, REDOX changes, the generation of ROS, and the induction of growth factors and signaling changes. The metabolism of sorbitol is linked to the activation, acetylation, and prolonged expression of Egr1 which leads to proinflammatory and prothrombotic changes. AC, acetylation; bFGF, basic fibroblast growth factor, DAG diacylglycerol; Erg 1, ETS-related gene1; GSH glutathione, MMPs, matrix metalloproteinases; NAMPT, Nicotinamide phosphoribosyl transferase; Na/K-ATPase, sodium-potassium ATPase; PKc, protein kinase c; REDOX, reduction and oxidation; ROS, reactive oxygen species; Sirt1, NAD-dependent deacetylase sirtuin-1; TF, tissue factor; TGF $\beta$, transforming growth factor beta; TNFa, tumor necrosis factor alpha; VEGF, vascular endothelial growth factor; VCAM, vascular cell adhesion molecule.

Since the observation in the early 1960's that galactosemic and diabetic cataracts are similarly linked to AR activity (Kinoshita, 1965, 1974), galactose feeding has often been used in animal studies to implicate AR in the onset and progression of diabetic complications. Although galactosemic animals are not diabetic, galactosemic animals develop certain ocular complications similar to those in diabetic animals but the lesions develop faster and are generally more advanced and severe. Similarly, feeding lactose to galactosemic newborns results in rapid cataract formation. Because galactitol is poorly further metabolized, studies in galactosemic animals require robust inhibition of $A R$ in order to demonstrate efficacy. A number of animal studies employing such robust AR inhibition to prevent sorbitol or galactitol formation have clearly demonstrated 
efficacy in preventing the onset and progression of diabetic or diabetic-like ocular complications including keratopathy, pupil function changes, cataract and retinopathy.

Moreover, following a seminal report from the Chung lab in 1995 (Ko et al., 1995), additional clinical evidence linking $A R$ gene polymorphisms to both AR activity and the development of diabetic complications has emerged. In the AR gene, the most common $(A C)_{n}$ microsatellite polymorphism, "Z," has an $n=24$. Shorter length $A R$ gene microsatellites, most often $n=23$ ("Z-2"), are associated with elevated AR transcriptional rates (Yang et al., 2003), enhanced expression level of AR (Shah et al., 1998), and increased AR activity levels. In contrast, the longer (AC)n microsatellites, most often $n=25$ ("Z+2"), are associated with reduced AR transcriptional rates (Yang et al., 2003) and relatively lower AR activity levels (Zou X-M et al., 2002). SNP C(-106)T in the basal promoter also interacts with the $(A C)_{n}$ element to determine the transcription rate of the AR gene (Yang et al., 2003). In many, but not all studies, the Z-2 allele ("high $A R$ expression") has been found to be associated with an elevated prevalence of diabetic microvascular complications, particularly diabetic retinopathy, nephropathy and neuropathy, as well as cataract formation. Conversely, the $Z+2$ allele ("low $A R$ expression") has been often, but not always, found to be associated with a lower prevalence of diabetic complications (Demaine et al., 2000; Demaine, 2003; dos Santos et al., 2006; Fujisawa et al., 1999; Heesom et al., 1997; Ichikawa et al., 1999; Ikegishi et al., 1999; Kao et al., 1999; Ko et al., 1995; Kumaramanickavel et al., 2003; Lee et al., 2001a; Lee et al., 2001b; Oates and Mylari, 1999; Olmos et al., 1999; Olmos et al., 2000; Park et al., 2002; Petrovic et al., 2005; Richeti et al., 2007; Wang et al., 2014; Wang et al., 2003). Such data are consistent with the concept that high tissue expression of AR might predispose interaction with elevated glucose levels to accelerate the progression of diabetic complications (Oates and Mylari, 1999).

In spite of these promising preclinical and human genetic rationales, multiple clinical trials of varying durations with several structurally diverse ARIs have shown limited success or overt failure in preventing and reversing long-term diabetic complications. The best-known ophthalmic example is the Sorbinil Retinopathy trial (Sorbinil Retinopathy Trial Research Group, 1990). ARIs have been orally administered in all 
major clinical trials with the dosage focused on minimizing any drug-induced potential safety concerns while at the same time reducing sorbitol levels in target tissues (Malone et al., 1984; Oates, 2002, 2008; Peterson et al., 1986). Repeated clinical failures, especially in retinopathy and neuropathy, resulted in loss of enthusiasm for the polyol pathway as a therapeutic target with sorbitol as an endpoint (Pfeifer et al., 1997; Polydefkis et al., 2015).

Despite these clinical setbacks, one ARI promises to find a home in clinical veterinary ophthalmology where its use will present an alternative treatment paradigm to cataract surgery in diabetic dogs. An FDA MUMS designation (equivalent to orphan drug in humans) has been granted for the development of the topical ARI Kinostat ${ }^{\circledR}$, which has passed a critical toxicology study and successfully finished its required clinical trial (see data below). With anticipated FDA approval in the next year, this will be the first ARI available for veterinary use in the US. The purpose of this article is to critically review the role of $A R$ in diabetes mellitus-linked ocular disease and the potential for ARI treatment to reduce diabetes mellitus-driven ocular disease in diabetic dogs.

\section{Aldose Reductase and the Rat Lens}

Studies on the role of AR in the diabetic eye began in the early 1960s when Kinoshita demonstrated that similar bilateral cataracts develop in both diabetic and galactosemic rats and that these cataracts are linked to the intracellular accumulation of sorbitol or galactitol which is catalyzed by the enzyme AR (Kinoshita, 1965, 1974). The lens changes appear osmotic in nature with hydration-associated histological changes present in the equatorial zone and cortical fiber cells (Kuwabara et al., 1969). However, the earliest hydration changes were later observed to begin at the central lens epithelial cells with the appearance of cell edema, aberrant intracellular vacuoles, and loss of normal tortuosity of cell boundaries (Robison et al., 1990b). These regional osmotic changes correspond to the lenticular distribution of AR which is primarily present in the metabolically active lens epithelial cells and equatorial region (Akagi et al., 1986a). This distribution is also consistent with the localized swelling observed by Raman Spectroscopy (Mizuno et al., 1990). This indicates that the hydration changes are 
localized and do not require the entire lens to be swollen, as often assumed, to initiate osmotic cataract formation. The abnormally hydrated lens cells undergo permeability changes followed by biochemical changes associated with cataract formation that include reductions in the levels of glutathione, myoinositol, $\mathrm{Na}^{+}, \mathrm{K}^{+}$-ATPase activity, loss of amino acids, altered electrolyte imbalance, and altered lens crystallin synthesis (Kador and Kinoshita, 1984; Kinoshita, 1974). These observations led Kinoshita to propose the Osmotic Hypothesis of sugar cataract formation which states that the intracellular accumulation of polyols in lens cells can result in hyperosmotic stress that draws water into these cells (Kinoshita, 1974; Kinoshita et al., 1979). This fluid accumulation initiates permeability changes that are then followed by the onset of a series of complex biochemical changes associated with cataract formation (Kador and Kinoshita, 1984; Kinoshita, 1974; Kinoshita et al., 1979). Subsequently, osmotic stress has also been linked to cell signaling changes, the induction of growth factors, and the generation of ROS resulting from the osmotic induction of endoplasmic reticulum (ER) stress in the lens epithelial cells (Kubo et al., 2004; Lee and Chung, 1999; Mulhern et al., 2006; Mulhern et al., 2007; Obrosova, 2002; Obrosova and Fathallah, 2000; Obrosova et al., 2003; Yeh and Ashton, 1990; Zatechka et al., 2003; Zhang et al., 2012a).

In the Osmotic Hypothesis, the AR catalyzed accumulation of polyols does not per se initiate biochemical changes associated with cataract formation. Rather, the elevated intracellular polyols indirectly initiate cataract formation via biophysical and biochemical cascades by drawing water into the cell through osmosis and causing cell and tissue swelling which causes detrimental permeability changes. Primary support for the Osmotic Hypothesis comes from in vitro lens organ

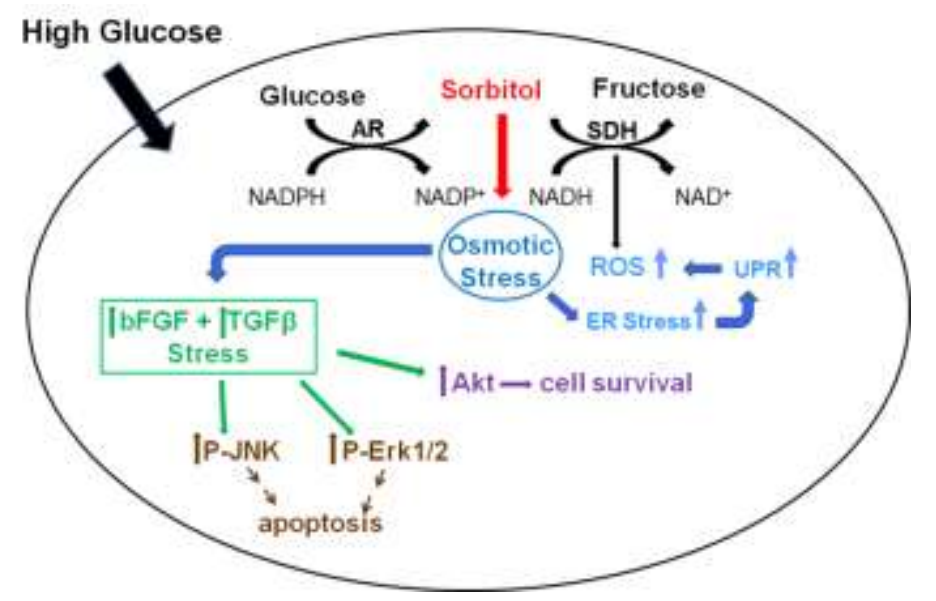

Figure 2 Relationship between osmotic changes resulting from sorbitol formation and the induction of growth factor and signaling changes, and the generation of ROS in the rat lens epithelial cell. 
culture studies which demonstrate that the development of sugar cataracts in experimental animals can be duplicated by culturing intact lenses in culture medium containing high levels of glucose, galactose or xylose. In these studies, the various biochemical changes associated with cataract formation can be minimized or prevented by the addition of ARIs to the culture medium (Kinoshita et al., 1979). Lens organ culture studies, conducted under iso-osmotic media conditions where increased osmotic pressure in media prevents cell swelling despite the intracellular accumulation of polyols, confirm that neither polyol formation per se nor increased AR activity by itself directly initiate the early biochemical changes associated with cataract formation in experimental animals. This includes the generation of ROS, growth factor and cell signaling changes that are currently being investigated as the cause of cataract formation by a number of laboratories (Fig. 2) (Obazawa et al., 1974; Randazzo et al., 2011; Zhang et al., 2012a).

The importance of AR as the cause of sugar cataract formation is further supported by in vivo animal studies where similar bilateral cataracts develop in either naturally diabetic or chemically induced diabetic rats or in rats fed a galactose diet. These sugar cataracts demonstrate similar osmotic changes (Friedenwald and Rytel, 1955) and their rates of formation are directly proportional to blood glucose or galactose levels (Patterson, 1954) as well as the lens levels of AR present (Chylack and Kinoshita, 1969; Kador et al., 1986; Kador and Kinoshita, 1984; Kinoshita, 1965, 1974; Kinoshita et al., 1969; Kinoshita et al., 1981; Kinoshita et al., 1965; Kinoshita et al., 1968; Obazawa et al., 1974; Robison et al., 1990a; Van Heyningen, 1959). The development of these sugar cataracts is also dose-dependently reduced or prevented by the administration of systemic or topical ARIs (Kador and Kinoshita, 1984). Animal models containing low lens AR levels further confirm the importance of $A R$ in sugar cataract formation. Mice do not develop sugar cataracts because their lens levels of AR are low (Varma and Kinoshita, 1974). However, when the lens AR levels are increased in transgenic mice, sugar cataracts rapidly develop after induction of DM or galactosemia (Cheung et al., 2005; Grossniklaus et al., 2010; Ho et al., 2006). Animal studies also diminish the proposed and often accepted central role for glycation in sugar cataract formation (Bron et al., 1993; Kandarakis et al., 2014). The absence of sugar cataracts in diabetic or 
galactosemic mice has not been correlated with any reduction of glycation. Moreover, ARIs inhibit sugar cataracts in both diabetic and galactosemic rats without reducing the levels of hyperglycemia or galactosemia, lens protein glycation, or AGE formation (Chiou et al., 1980; Hamada et al., 1996; Kador et al., 2000). The role of AR in cat, dog and human cataracts will be discussed below.

\section{Diabetic Retinopathy}

Diabetic retinopathy manifests as a vascular disease with ongoing neural retinal alterations where diabetes-induced changes in the neurons, glia and retinal capillaries eventually lead to the proliferation of new vessels that extend from the retina into the vitreous (Antonetti et al., 2006; Antonetti et al., 2012). Neovascularization is accompanied with secondary hemorrhage, retinal detachment, and eventual loss of visual function. Vascular changes begin with the selective degeneration of retinal capillary pericytes (mural cells) which Cogan proposed to be the hallmark of diabetic retinopathy (Cogan and Kuwabara, 1967). Capillaries with loss of pericytes dilate and the remaining endothelial cells proliferate. Capillaries adjacent to dilated capillaries carry less blood and gradually lose all of their cells to become nonperfused ghost vessels. This results in areas of nonperfused retina adjacent to areas of dilated capillaries that continue to perfuse the retina. As the endothelial cells proliferate, outpouchings of the capillary wall appear with the concomitant laying down of basement membrane and the development of typical diabetic microaneurysms with marked basement membrane thickening. In the late 1970's, support for a role for AR in these retinal microvascular changes began with the observations that $A R$ was immunohistochemically detected only in the pericytes of isolated human retinal capillaries (Akagi et al., 1983) and retinal capillary pericytes were isolated and found to produce sorbitol when cultured in high glucose media (Buzney et al., 1977). Subsequent work has also detected $A R$ in rat and human retinal endothelial cells, e.g., (Dagher 2004) and in other retinal cell types. Moreover, isolated intact retinal capillaries, when cultured in high glucose or galactose media, produced sorbitol or galactitol which was

reduced by the presence of ARIs in the culture media (Kennedy et al., 1983). When 
administered to diabetic or galactosemic rats, ARIs also reduced retinal capillary basement membrane thickening (Frank et al., 1983; Robison et al., 1983). Based on this emerging data, the National Eye Institute (NEI) and Pfizer Inc. in 1983 designed and initiated a joint clinical study, the Sorbinil Retinopathy Trial, to determine whether the ARI sorbinil could delay the onset or slow the progression of retinopathy from the early to the more advanced stages (Cogan et al., 1984).

Prior to the Sorbinil Retinopathy Trial, validation for the role of $A R$ in diabetic retinopathy was limited because of the lack of a practical experimental animal model that mirrored the retinal changes observed in human diabetic retinopathy. In the early 1960 's, Patz reported that spontaneously diabetic dogs developed early retinopathy that was similar to that in humans (Patz and Maumenee, 1962) and this was subsequently followed by a report that alloxan-induced diabetic dogs could also develop similar retinal microvascular changes (Engerman and Bloodworth, 1965). Requiring up to 60 months to develop, these diabetic dogs demonstrated retinal capillary microaneurysms, pericyte ghosts and obliterated vessels. Moreover, these vascular changes were reduced when similar diabetic dogs were placed in good glycemic control (Engerman et al., 1977). However, a major drawback of using diabetic dogs at the time was the high mortality of these animals both in the induction of diabetes and maintenance of their diabetes with insulin which made studies requiring a minimum of 60 dogs costly and work intensive to adequately maintain (Anderson et al., 1993). A breakthrough came in 1984 when dogs were documented to develop similar retinal changes after only 36 months of galactose diet despite normal insulin, glucose and lipid levels (Engerman and Kern, 1984). The similar but faster microvascular changes observed in the galactosemic dogs added support for the hypothesis that AR plays a central role in initiating diabetic retinopathy and reinforced the scientific premise for the sorbinil trial.

In planning the Sorbinil Retinopathy Trial, there were concerns over the study design. The time course of diabetic retinopathy development had not been established and the validity of intervening with an $\mathrm{ARI}$ at a time point where clinical microaneurysms were already present was unknown. Limited intervention studies in rats on cataract formation had suggested that there is a point where intervention with ARIs is no longer effective 
(Hu et al., 1983); however, similar retinal intervention studies could not be conducted because of the lack of a feasible animal model. More importantly, there was a concern that $A R$ inhibition in the retinal capillary target tissues would not be adequate. Therefore initial tests were done at what was believed to be the highest well tolerated drug dose. However, a percentage of patients receiving sorbinil metabolized the drug to a toxic intermediate and experienced adverse reactions characterized by fever, skin rash, and myalgia (Spielberg et al., 1991). In an attempt to minimize these adverse effects, the dosage of sorbinil was reduced to a level that was hoped to be both safe and efficacious; in the end, it was neither.

Because of these concerns over the clinical Sorbinil Retinopathy Study design, the NEI Intramural Research Program initiated an ARI prevention study in galactose-fed dogs to validate the premise that robust inhibition of $A R$ could prevent the onset and progression of retinal microvascular changes in that normoinsulinemic model of diabetic retinopathy. The study was also designed to document the onset and progression of retinal changes associated with diabetic-like retinopathy in untreated galactose-fed dogs. To minimize potential biological variations, young 9-month old male beagles were used. One group served as the normal, control group and was fed ca. $450 \mathrm{~g}$ of dog diet containing $30 \%$ non-nutrient filler daily while all other dogs received ca. 450 of dog diet containing $30 \%$ galactose. One galactose-fed group served as the untreated control while the other groups received either sorbinil (Pfizer Inc.) or its more potent analog, 2methyl sorbinil (M79175, Eisai Co., Ltd.). Since both ARIs contain the hydantoin ring, a third nonhydantoin ARI, zenarestat (FK366, Fujisawa Pharmaceutical Co., Ltd.), was subsequently evaluated (Fig. 3). The 36-month end points of the ARI studies were the anticipated clinical appearance of microaneurysms and histological appearance of vascular changes associated with diabetic retinopathy. All dogs received extensive eye examinations at 3-4 month intervals by a

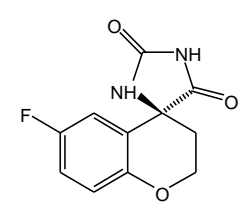

Sorbinil

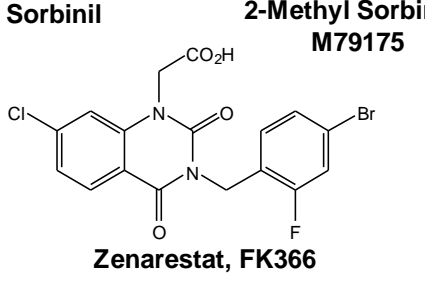

Figure 3. Structure of ARIs evaluated in galactose-fed dogs. diplomate veterinary ophthalmologist along with standard clinical blood chemistries. Eye 
enucleations from random dogs in the control and untreated galactose-fed groups were initiated at 12 months and in each drug-treated group beginning after 24 months of galactose-feeding.

\section{Diabetes-like Retinal Changes in Untreated Galactose-Fed Dogs}

The development and progression of diabetic retinopathy is a slow process that requires months to years in both patients and animal models. Since AR-linked lesions are accelerated in galactosemic animals, the untreated control galactose-fed dogs served not only as untreated controls for the ARI treatment studies but also as animal models for establishing the progression of diabetic retinopathy. By conducting enucleations at select time intervals beginning at 12 months after the onset of galactose-diet, a time-line for the histological development and clinical appearance of retinal changes associated with diabetic retinopathy was established (Fig.4).

The first histological change to be observed after 19 months of galactose-feeding in one of two dogs was retinal capillary pericyte degeneration, and by 24 months pericyte ghosts were present in all eyes of untreated dogs examined (Kador et al., 1990a; Kador et al., 1988). In addition to the pericyte ghosts, some retinal vessels from these eyes displayed a proliferation of endothelial cells in capillaries where pericytes were lost along with a number of acellular capillaries where both pericytes and endothelial cells were absent. By 27 months, microaneurysms appeared in the eyes of one of three untreated galactose-fed dogs and by 30-36 months this incidence increased to all eyes in untreated dogs examined. Initially, only saccular microaneurysms appeared and their numbers increased with the duration of galactose feeding. The formation of these microaneurysms appeared linked to endothelial cell proliferation associated with the presence of pericyte ghosts. By 33 months, some microaneurysms had become markedly enlarged while others appeared to degenerate. At the same time the first clinical sign of early retinopathy, the appearance of dot and blot hemorrhages was observed by limited fundus examinations through the cataractous lenses. Exudate formation was also present as miliary punctate lesions deep within the retina adjacent to the hemorrhages. Clinically, the microaneurysms appeared predominantly in the central 
area close to the optic disc; however, their number increased with the duration of galactose feeding and by 48 months, larger confluent hemorrhages were observed. By

19 Months Pericyte Ghost Formation

(G)

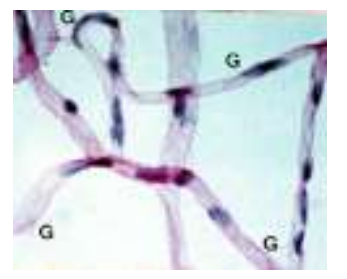

27 Months Saccular microaneurysms
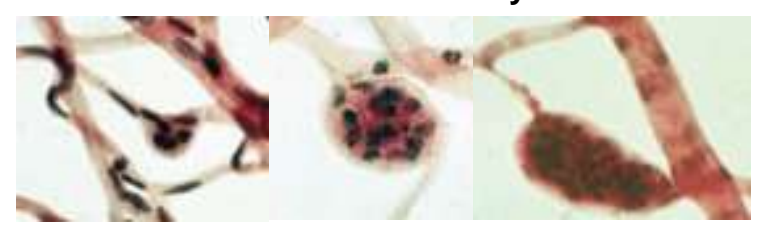

36-48 Months Varicose capillary enlargements confluent microaneurysms and confluent microaneurysms

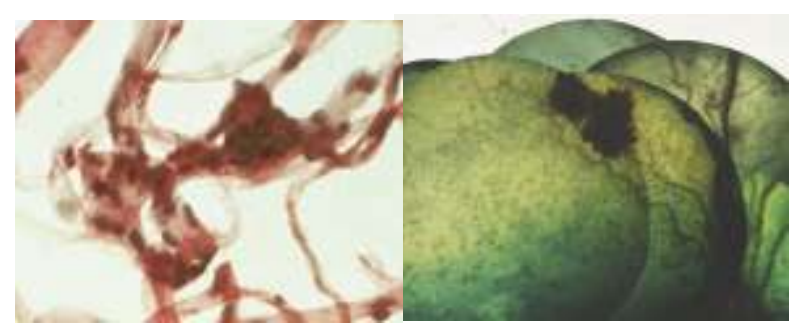

60 Months New vessel growth near optic disc
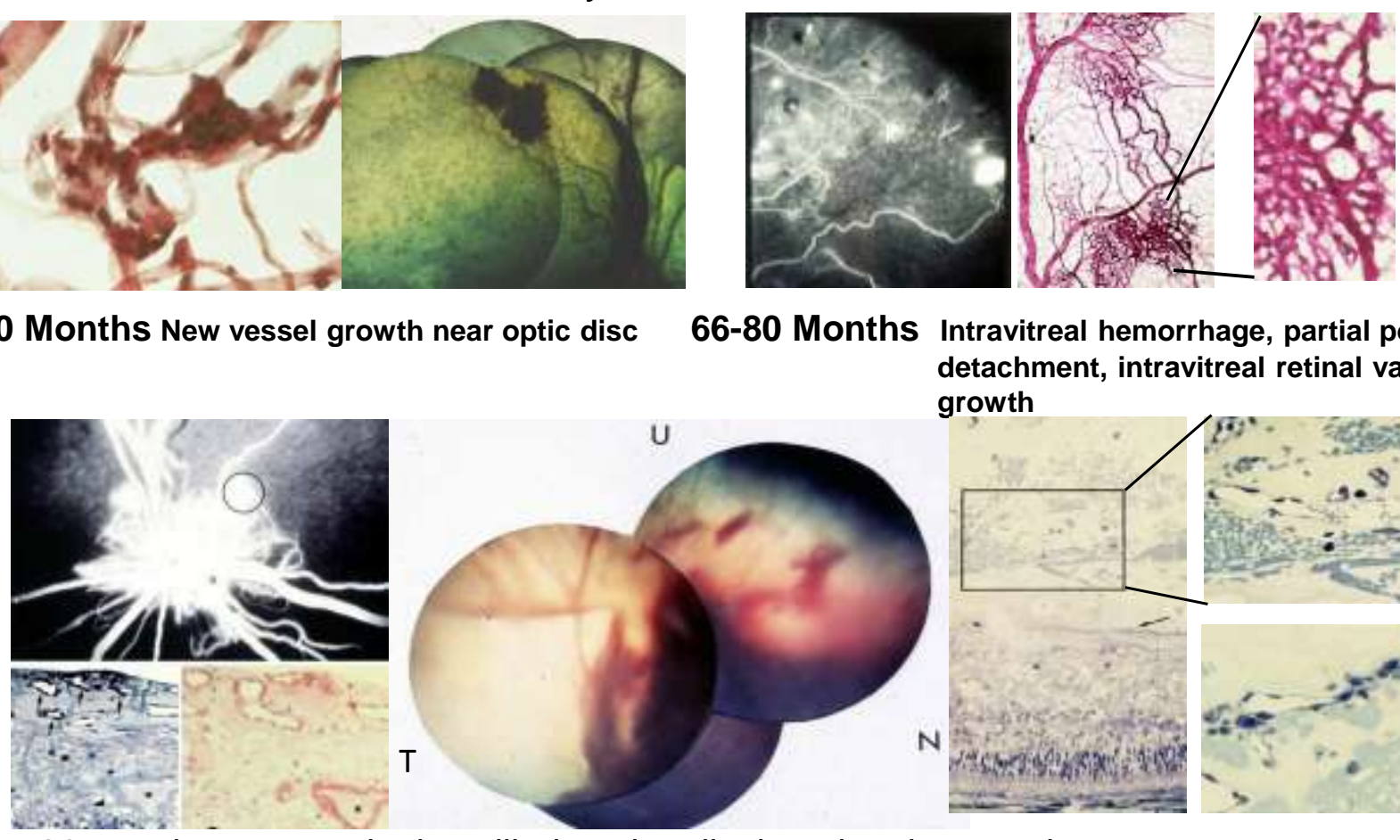

66-80 Months Intravitreal hemorrhage, partial posterior detachment, intravitreal retinal vascular growth

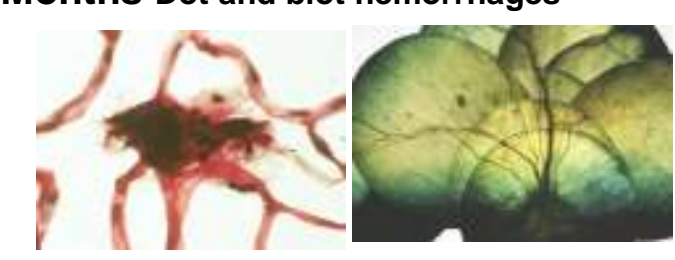

56 Months Areas of nonperfusion, shunt formation, IRMA

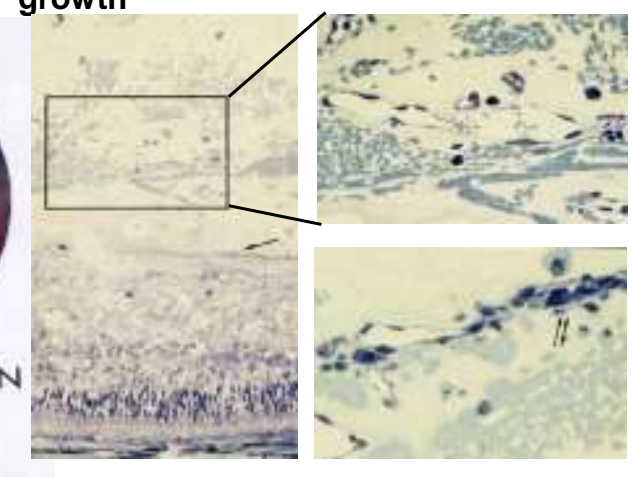

36 months some retinal capillaries also displayed varicose enlargements.

Figure 4 Time-frame of retinal changes in 9-month beagles fed 30\% galactose diet. Retinopathy progresses from the early background stage to the advanced proliferative stage. 
By 54 months of galactose feeding, cataracts in approximately 8 of 18 dogs cleared sufficiently to allow fluorescein angiography to be performed at 54, 56, 58 and 60 months. These revealed the presence of dot and blot hemorrhages, focal fluorescein leakage, occluded arterioles, intraretinal microvascular abnormalities (IRMA), and broad areas of nonperfusion (Takahashi et al., 1992). A striking feature of these angiograms was the development of broad areas of nonperfusion that demonstrated the chronic progression of capillary bed closure in these galactose-fed dogs. These observations were confirmed by trypsin digestion and histology of the subsequently enucleated eyes. For example, after isolation of the capillary beds by trypsin digestion, areas showing loss of blood flow corresponded to areas containing acellular capillary networks. Histologic examinations of cross sectioned retinas from areas of nonperfusion also demonstrated soft exudate (cytoid bodies) in the nerve fiber layer and some gliosis of the nerve fiber layer in the area of nonperfusion. By 60 months, vascular changes were also observed in the larger vessels (arteries and arterioles) of these dogs. Occluded arterioles, often with huge hemorrhages throughout the neuronal retina, were observed in areas adjacent to areas of nonperfusion. Trypsin digestion also revealed node-like protrusions of the vessel walls of arteries or arterioles. With fluorescein angiography, these nodes revealed vessel wall staining in the early filling stage with subsequent weak fluorescein leakage. The peripheral retina also showed the presence of large arteriovenous $(A-V)$ shunts. Portions of these $A-V$ shunts displayed increased cellularity and club-like structures that appeared to grow toward the inner limiting membrane. In three of eight 60-month dogs, fluorescein angiograms also revealed massive fluorescein leakage from the vascular networks surrounding the optic disc that appeared to be indistinguishable from fluorescein angiographic findings of neovascularization of the disc. Cross-sectioned histologic studies of one of the three eyes revealed the presence of a well-developed vascular plexus just beneath the inner limiting membrane. These vessels displayed characteristics associated with new vessels that included a higher density of endothelial nuclei, narrow lumina, and thickened basement membrane material that only weakly stained with periodic acid-Schiff. While dogs do not specifically have a macula and cannot develop macular edema, cystoid space formation in the outer plexiform layer, suggestive of retinal edema, was detected by histologic 
examinations of cross-sectioned retinas from dogs fed galactose diet for 60 months. Foamy histiocyte infiltration into the cystoid spaces, suggestive of hard-exudate formation, was also observed. Fundus photographs from dogs that were fed galactose diet for 66 months also demonstrated both intravitreal hemorrhages and partial posterior vitreous detachment. This suggested the presence of vessels outside of the retina and provided additional evidence for new vessel growth. By 74 to 80 months, proliferative retinopathy was observed with intravitreal retinal vascular growth (Kador et al., 1995).

In summary, dogs fed a galactose diet develop diabetes-like retinal vascular changes that corresponded to all clinical stages of diabetic retinopathy ranging from early background to the advanced, proliferative stage. Specific regional analyses, achieved by mathematically dividing each of the intact retinal vessel preparations into 24 distinct sub regions, indicated that there are specific regional differences in the formation and progression of retinal lesions with changes in pericyte density and microaneurysm formation developing predominantly in the central retina, especially at the temporal and nasal upper side(Takahashi et al., 1993). The onset and progression of retinal changes also appears linked to the age at onset of galactose feeding (or onset of diabetes) (Kador et al., 2007b). In comparing retinal changes in initially 2-month versus 9-month old beagles, significantly $(p<0.05)$ increased pericyte degeneration, expressed as either the number of pericytes/mm capillary length or the ratio of endothelial cells versus pericytes (E/P ratio) was observed in the retinas of the younger dogs. The number of microaneurysms per eye was also significantly increased in the younger dogs, but no difference in acellular capillary areas was observed (Fig 5). This correlates with the initial threefold higher level of AR activity in the retinas of the 2-month-old dogs. Clearly, these retinal vascular changes begin with the selective degeneration of pericytes which contain AR. This was confirmed by Northern blot analysis of cultured retinal capillary pericytes and endothelial cells isolated from the retina of beagles (Murata et al., 2002). When cultured separately in medium containing either $10 \mathrm{mM}$ D-galactose, $30 \mathrm{mM}$ Dglucose, or $2 \mathrm{mM}$ of 3-fluorodeoxyglucose, only pericytes but not endothelial cells accumulated sugar alcohols. Moreover, the prolonged accumulation of polyols induced apoptosis which was prevented by ARIs. More importantly, as discussed below, the 
administration of adequate doses of ARIs also prevented the onset and progression of retinal vascular changes in the galactose-fed dogs.

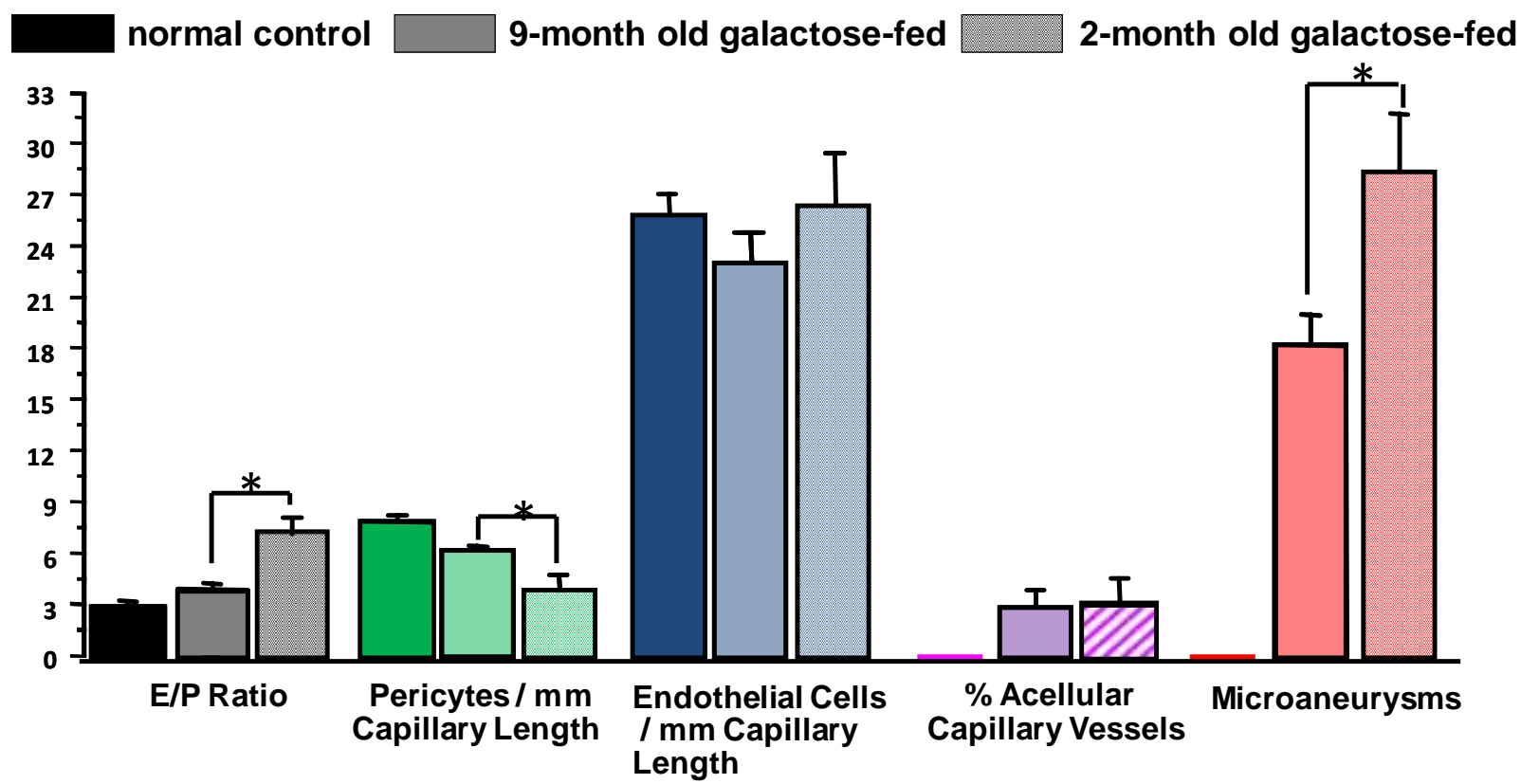

Figure 5 Comparison of retinal vascular changes in initially 2-month-old (diagonal bars) versus 9-month-old (vertical bars) male beagles fed a 30\% galactose diet for 36 months. Solid bars represent values obtained from 9-month old males fed only a control, fiber diet (values are the mean \pm standard error of the mean; $n 4-6) .{ }^{*}$ indicate significance $(p<0.05)$ between groups.

\section{Effect of ARI Treatment on the Progression of Diabetes-like Retinal Changes}

Preliminary Studies Compared to the retina, it is generally more difficult for orally administered drugs to reach the lens. Therefore, the lens polyol levels were examined as a surrogate biomarker for retinal polyol concentrations with the assumption that adequate administration of ARIs to prevent sugar cataracts should ensure that adequate levels of ARIs are also being delivered to the retina. Because both sorbinil and M79175 in man have tissue half-lives that are greater than 30 hours, no problem in drug availability in the dog was anticipated. Prior to beginning the initial NEI dog study, a small preliminary multi-dose trial was conducted in dogs to confirm that an oral dose of $50 \mathrm{mg} / \mathrm{kg}$ sorbinil adequately inhibited $A R$ in the lens and neural retina of the eye as well as sciatic nerve and kidney. After pre-dosing for 3 days, all dogs were fed a $30 \%$ galactose diet along with sorbinil for 7 days. Subsequent tissue analyses confirmed that 
the $50 \mathrm{mg} / \mathrm{kg}$ dose of sorbinil reduced galactitol levels $>90 \%$ in all target tissues examined compared to untreated galactose-fed dogs. This strengthened our assumption that drug half-life in this study would not be a problem.

Initial Prevention Study Based on the pilot dosing results, a prevention study was initiated with one group of 9-month old male beagles receiving an average single daily dose of $62 \mathrm{mg} / \mathrm{kg}$ of sorbinil administered one hour before feeding and a second group receiving $0.5 \mathrm{mg} / \mathrm{kg}$ of the $\mathrm{M} 79175$ administered one hour before feeding. Surprisingly, the first 4-month examination quickly proved to be problematic. Unexpectedly, lens vacuole formation, an early lens change in sugar cataract development, was observed in all ARI-treated as well as untreated dogs, suggesting little or no protective drug effects. Pharmacokinetic studies of blood drug levels quickly showed that the half-life of both drugs in dogs is less than $4 \mathrm{hr}$. Overall, these results clearly indicated that the levels of ARIs administered to the dogs to prevent lens galactitol formation were inadequate to prevent the early stages of cataractogenesis in this model. The ARI dosing regimen was subsequently changed to reflect the rapid metabolism of these drugs, with dosages of ARIs now divided around the daily galactose diet (Kador, 1990; Kador et al., 1990b). After 9 months, an additional group of fifteen 9-month old male beagles was added to the overall study, with this group receiving $5 \mathrm{mg} / \mathrm{kg}$ of M79175 (high dose). After 26 months this group was further divided with 8 dogs receiving M79175 now supplemented with an additional $250 \mathrm{mg}$ of sorbinil (M79175-sorbinil). Clinical blood chemistry profiles showed no apparent adverse effects related to ARI administration.

The development and progression of retinal changes was arrested to some degree in all ARI-treated dogs. Compared with untreated galactose-fed dogs, where a 100percent incidence of pericyte ghosts was observed in all eyes after 24 months of galactose feeding, a 100-percent incidence of pericyte ghosts was delayed in dogs treated with low-dose M79175 until 30 months; in sorbinil-treated dogs until 33 months; and in the high-dose-M79175-treated dogs until 36 months. In the M79175sorbinil group pericyte ghosts were present in only 50 percent of the dogs (2 of 4 dogs). In all eyes from ARI treated dogs that were free of pericyte ghosts, no other 
histologic abnormalities were detected, and the retinal capillaries were indistinguishable from those of the controls (Kador et al., 1990a).

The incidence and numbers of microaneurysms were also reduced in the ARI-treated dogs. All untreated galactose-fed dogs displayed microaneurysms after 30 months, while all dogs treated with low-dose M79175 and all dogs treated with sorbinil displayed microaneurysms at 33 months and 36 months, respectively. Some dogs from each of these three groups also displayed intraretinal hemorrhages by 33 months. In dogs receiving high-dose $\mathrm{M79175}$, a single microaneurysm was observed in one dog after 33 months of galactose feeding, and two microaneurysms were observed in one of two dogs after 36 months. No microaneurysms were present in M79175-sorbinil-treated dogs at 33 months of galactose feeding, but one of four dogs displayed one microaneurysm after 36 months. None of the high-dose M79175-treated or M79175sorbinil-treated dogs displayed intraretinal hemorrhages during the 36 -month period.

From these observations the time required to develop a $50 \%$ incidence of pericyte ghosts and microaneurysms was calculated and compared to the cataract severity observed in these dogs (Table 1). In addition, the adrenal gland galactitol levels were measured as an indicator of systemic ARI inhibition. The results indicate that the decrease in retinal changes and cataract development correlated with the adrenal gland galactitol levels in the order: no treatment > low-dose M79175 >sorbinil > high-dose M79175 > M79175-sorbinil.

\begin{tabular}{lccccc}
\hline $\begin{array}{l}\text { Biological } \\
\text { Marker }\end{array}$ & Untreated & Sorbinil & $\begin{array}{l}\text { M79175 } \\
\text { low dose }\end{array}$ & $\begin{array}{c}\text { M79175 } \\
\text { high dose }\end{array}$ & $\begin{array}{l}\text { M79175 } \\
\text { + Sorbinil }\end{array}$ \\
\hline Pericyte ghosts & 19.2 & 29.7 & 26.7 & 31.5 & 35.7 \\
$\begin{array}{l}\text { Microaneurysms } \\
\text { Cataract severity }\end{array}$ & 27.4 & 31.3 & 29.7 & 35.7 & $>36.0$ \\
$\begin{array}{l}\text { 36 Month adrenal gland } \\
\text { galactitol levels } \\
\text { (pg/mg protein) }\end{array}$ & 10.02 & 1.6 & 2.1 & 0.9 & $0.7^{*}$ \\
\hline
\end{tabular}


Table 1 Summary of ARI effects on retinal, lens and tissue biological markers observed in galactose-fed dogs. The values for pericyte ghosts and microaneurysms represent the time required in months to develop a $50 \%$ incidence of either pericyte ghosts or microaneurysms. Cataract severity (calculated as the mean score from 6-36 months) was subjectively classified on a scale of 0 to 4 , with 4 being the most advanced cataract according to the criteria: 1) an incipient cataract with some degree of vacuolization in the anterior or posterior cortex; 2) a progression of vacuoles and opacification to stria in the cortex with involvement of the sutures; 3) opacification of most of the visible cortex; and 4) a complete dense cataract. * calculated from 30-36 month values.

The retinal changes in all 36-month dogs were quantified with computer image analysis (Takahashi et al., 1993). Individual maps of each isolated intact retinal vasculature were constructed. Each map was divided into 24 distinct subregions and measurements of the endothelial cell to pericyte $(E / P)$ ratio were conducted in $0.1 \mathrm{~mm}^{2}$ areas surrounding the midpoints of 12 subregions associated with the highest incidence of microaneurysms. The E/P ratio of dogs on control diet was $3.01 \pm 0.12$ compared to the significantly $(p<0.05)$ higher ratio of $4.75 \pm 0.55$ in the untreated galactose-fed group. The E/P ratio of the sorbinil treated group was $4.09 \pm 0.61$, the low dose M79175 group was $5.40 \pm 1.20$, the high dose M79175 group was $3.94 \pm 0.31$, and the M79175sorbinil group was $3.57 \pm 0.19$. Of the $A R I$ treated galactose-fed dogs, only the E/P ratio of the M79175-sorbinil group was significantly $(p<0.05)$ lower than the $E / P$ value of the untreated galactose-fed dogs.

This initial study confirmed that retinal changes are linked to AR activity with the greatest delay in retinal changes observed with the highest systemic levels of AR inhibition. ARIs protected against the degeneration of retinal pericytes and the subsequent formation of microaneurysms in an apparent dose-dependent manner. The retinal changes also correlated with the degree of cataract development, supporting the premise that for systemically administered ARIs, inhibition of cataract formation can serve as a surrogate biomarker for AR inhibition in retinal pericytes. The results also raised the question of whether AR activity in this study had or had not been sufficiently reduced to achieve maximum possible protection. 
Expansion of the Prevention Studies Since no adverse effects were observed at the ARI doses administered, an additional study utilizing higher doses of M79175 was initiated along with two doses of the non-hydantoin ARI, zenarestat (FK366). Using a similar experimental design with 9-month old male beagles fed $30 \%$ galactose diet, eight dogs in each group received an average dose of either 10 or $16 \mathrm{mg} / \mathrm{kg} / \mathrm{day}$ of M79175 administered around the galactose diet for 38 months (Kador et al., 1994). In addition, groups of 12 galactose-fed beagles received either an average of 30 $\mathrm{mg} / \mathrm{kg} /$ day or $180 \mathrm{mg} / \mathrm{kg} / \mathrm{day}$ of FK366. These were similarly administered around the galactose diet as those receiving M79175. Appropriate controls were chosen from a concurrent study containing 12 similar age matched male beagles receiving only galactose diet (untreated galactose-fed group) and 12 control beagles receiving only standard diet containing $30 \%$ non-nutrient filler.

M79175 Treated Groups Administration of higher doses of M79175 resulted in an even greater reduction in pericyte ghost, microaneurysm, and visible hemorrhage formation. At 38 months pericyte ghosts were present in the eyes from 4 of 4 untreated galactosefed dogs examined, 2 of 4 dogs receiving $10 \mathrm{mg} / \mathrm{kg} / \mathrm{day}$ M79175 and in 1 of 4 dogs receiving $16 \mathrm{mg} / \mathrm{kg} /$ day $M 79175$. The 4 untreated dogs also had a mean number of 22 microaneurysms per eye examined compared to only a single microaneurysm in 1 of 4 eyes from dogs treated with $10 \mathrm{mg} / \mathrm{kg} / \mathrm{day}$ M79175 and 2 microaneurysms in 1 of 4 eyes from dogs treated with $16 \mathrm{mg} / \mathrm{kg} /$ day M79175. No clinically visible hemorrhages were present in either M79175 treated group compared to visible hemorrhages in 2 of 4 untreated galactose-fed dogs. When combined with the results from the first study, a dose-response effect in retinal vessel changes was apparent (Fig. 6) (Kador et al., 1994).
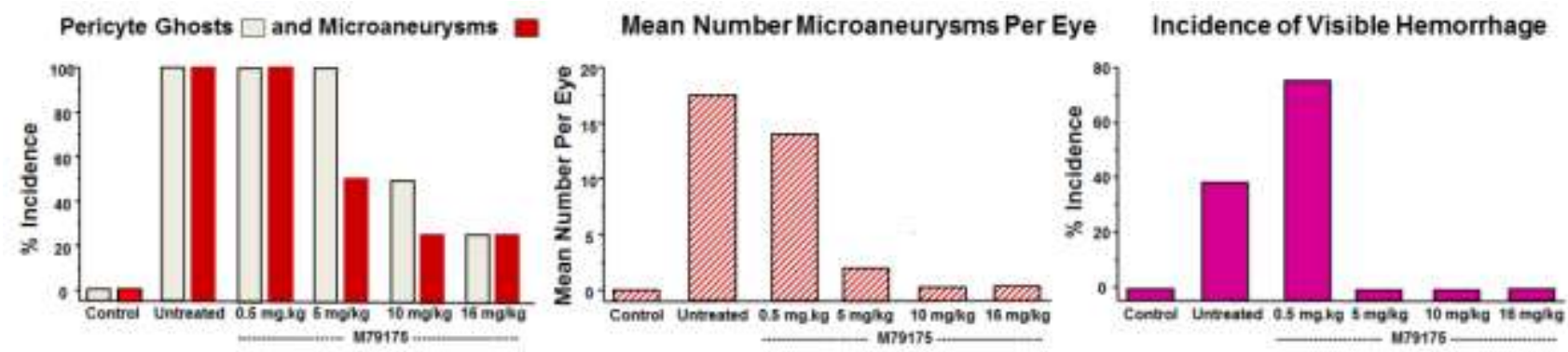

Figure 6 Dose dependent effect of M79175 on pericyte ghost and microaneurysm formation and clinical appearance of dot and blot hemorrhages in 36-38 month galactose-fed dogs. 
Cataract formation was also reduced by M79175 treatment. Compared to an average cataract severity of 2.2 in the untreated galactose-fed dogs, those treated with 10 and $16 \mathrm{mg} / \mathrm{kg} /$ day of M79175 had cataract severities of 0.5 and 0.3 , respectively. This dosedependent reduction of cataract formation correlated with the similar dose-dependent reduction of microaneurysms (Fig. 7).
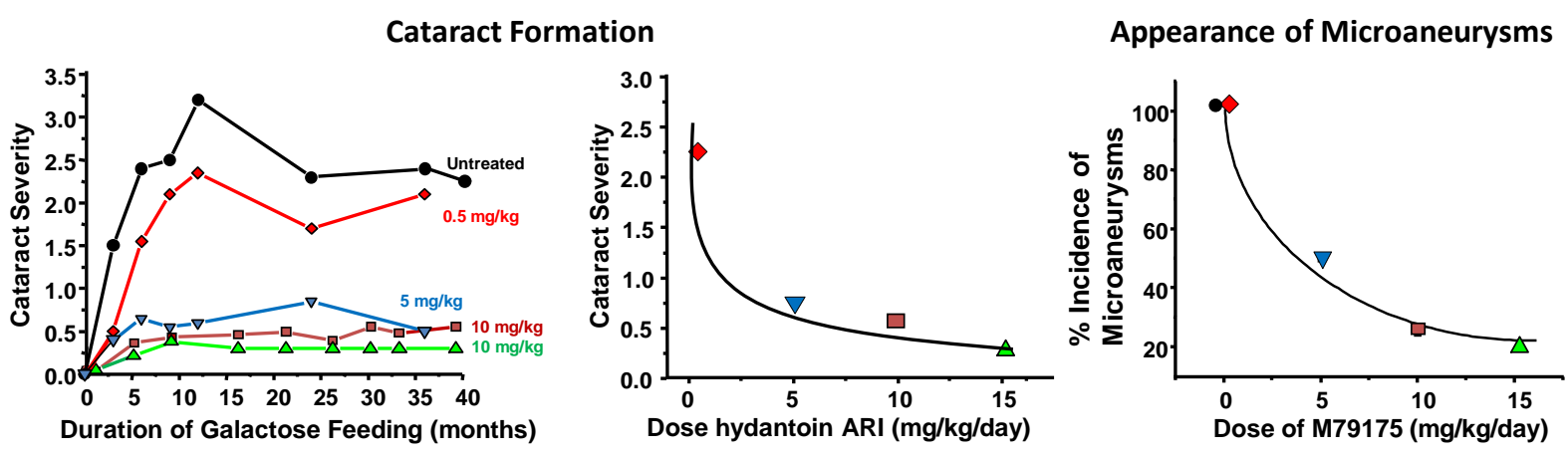

Figure 7 Dose-dependent prevention of cataract formation correlates with the prevention of microaneurysms. The center graph shows the average cataract severity (5-36/38 months) calculated from graph at the left. At right, the dose-dependent reduction in microaneurysm formation correlated with the observed reduction in cataract severity (center).

The retinal changes in all 38-month dogs were also quantified using computer image analysis to reveal a similar dose-dependent decrease in retinal changes (Neuenschwander et al., 1997). With the exception of endothelial densities which remained unchanged in the galactose-fed dogs, M79175 treatment reduced vascular changes in all parameters examined. The endothelial cell to pericyte $(E / P)$ ratio, a marker for pericyte destruction that increases with the duration of galactose feeding, was not significantly different in dogs treated with $16 \mathrm{mg} / \mathrm{kg} /$ day M79175 compared to age-matched non-galactose-fed dogs. These studies confirmed that adequate administration of ARIs can provide dose-dependent protection against pericyte degeneration and subsequent microaneurysm formation. In addition, these studies indicated that reduction of cataract formation was directly related to a reduction in retinal changes. 
FK366 Treated Groups While the ARI zenarestat (FK366) showed potential for clinical efficacy in reducing diabetic neuropathy (Brown et al., 2004; Greene et al., 1999), similar administration of this carboxylic containing ARI to galactose-fed dogs did not result in any reduction of either retinal or lens changes. As shown in Fig. 8, the administration of either $30 \mathrm{mg} / \mathrm{kg}$ (low dose) or $180 \mathrm{mg} / \mathrm{kg}$ (high dose) of FK366 had no effect on cataract formation. This lack of apparent drug activity was also observed in retinal vascular changes. No delay in the appearance of pericyte ghosts, microaneurysms, or hemorrhage was observed suggesting that FK366 did not adequately reach the retinal pericytes. Because of the apparent lack of a drug effect, select tissue analyses were

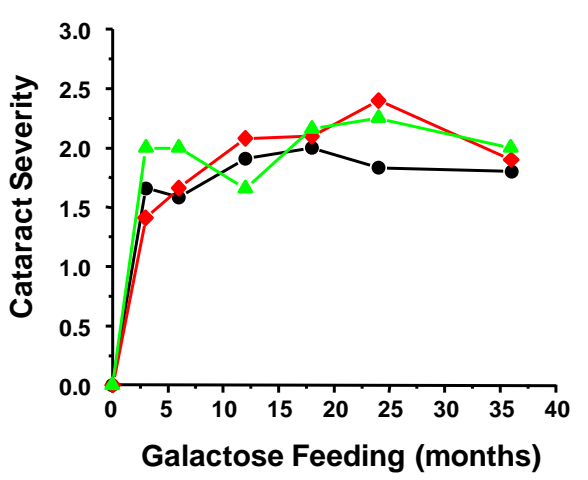

Figure 8 Comparison of cataract formation in untreated (black) versus $30 \mathrm{mg}$ (red) and $180 \mathrm{mg}$ (green) FK366 treated dogs fed galactose for 36 months. conducted at 30 months of galactose feeding (Fig. 9). Despite the lack of retinal activity, evaluation of galactitol levels indicated that FK366 dose-dependently inhibited galactitol formation in the whole retina. Similarly, FK366 inhibited galactitol levels in the sciatic nerve and kidney, but not in the lens. The degree of inhibition correlated with the observed drug levels in these tissues.
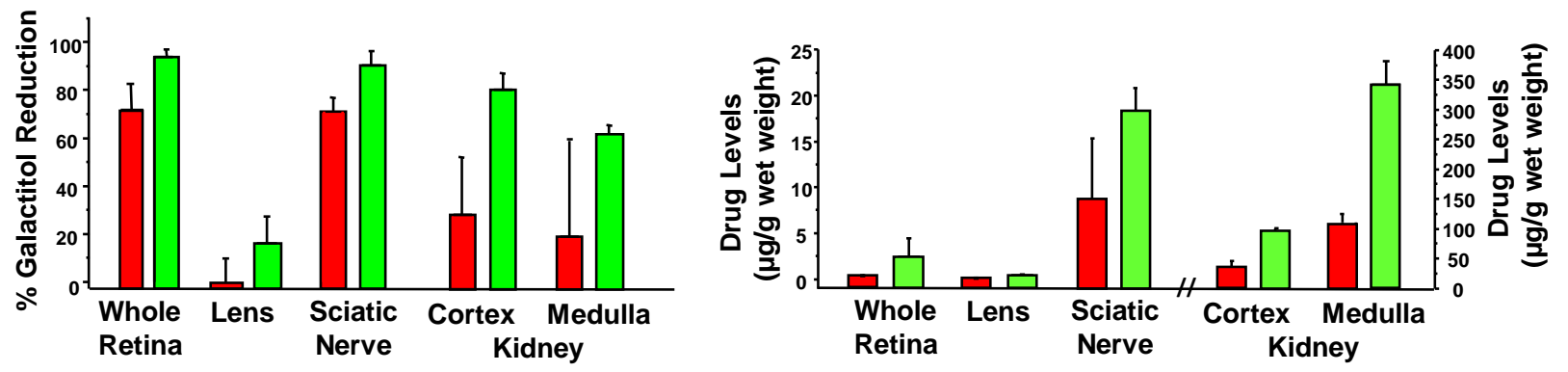

Figure 9 Analysis of galactitol (right) and FK366 levels (left) in select tissues from 30 month galactose-fed dogs. Red represents the $30 \mathrm{mg} / \mathrm{kg}$ dose and green represents the $180 \mathrm{mg} / \mathrm{kg}$ dose of FK366. The percent reduction of galactitol levels was calculated by comparing galactitol levels in tissues from drug treated dogs to galactitol levels from similar untreated dogs. Mean \pm SEM. 
While high dose FK366 inhibited $94 \%$ of galactitol formation in the whole retina, it failed to reduce either pericyte ghost or subsequent microaneurysm formation. AR is not only present in pericytes but also the Müller cells, ganglion cells and retinal pigmented epithelium cells of the retina (Akagi et al., 1986c; Akagi et al., 1984; Sato et al., 1993; Vinores et al., 1988). Specific galactitol or drug levels in retinal pericytes cannot be determined because of technical problems associated with small size and isolation of retinal pericytes. Since capillary pericytes make up less than $0.01 \%$ of the retinal mass, the observed galactitol inhibition in the whole retina may not reflect specific galactitol inhibition in the pericytes. Neutral hydantoin ARIs, in general, penetrate tissues better than ionized carboxylic acid-containing ARIs. The hydantoin M79175, in contrast to the carboxylic acid FK366, demonstrated both a dose dependent reduction in pericyte degeneration and cataract formation. However, the similar but less potent hydantoin sorbinil failed to prevent retinal changes in galactose-fed dogs despite an apparent 90$96 \%$ reduction of retinal galactitol levels (Kern and Engerman, 1991). Sorbinil also failed to inhibit cataract formation in these dogs (Kern, 1990). This negative study also failed to take into account the short half-life of this hydantoin. Therefore, a comparison the sorbinil study with the FK366, which also reduced retinal galactitol levels by $94 \%$, suggests that both sorbinil and FK366 levels were sufficient to lower galactitol by 94$96 \%$ but insufficient to inhibit AR enough in both the retinal pericytes and lens to successfully prevent pericyte degeneration and cataract formation.

These data raise once again the fundamental question of the link between tissue polyol levels vs. AR activity per se, e.g., (Oates, 2008). That is, these data in ocular tissues clearly indicate that an extremely high degree of reduction of tissue polyol is needed for ARI efficacy, very similar to findings reported in the diabetic nerve where $90 \%$ correction of nerve dysfunction requires $99 \%$ suppression of sorbitol (Cameron et al., 1994). Experimentally, the underlying basis for such a relationship remains unclear. As discussed above, it could relate to a small number of critical cell type(s) that are osmotically sensitive which happen(s) to be difficult for ARls to reach in high enough concentration. On the other hand, these data could indicate a fundamentally nonlinear linkage between tissue polyol content vs. AR enzyme turnover/utilization of NADPH (Oates, 2002). Such a situation could be envisaged if targeted ocular cells exhibited a 
relatively modest leak of polyol, perhaps connected with a volume regulatory response to osmotic stress. For example, P-glycoprotein is a modulator of volume-regulatory chloride channels that has been shown to upregulate two-fold in galactose-exposed rat lens and primary lens epithelial cells (Miyazawa et al., 2007). Theoretically, under conditions where the rate of product production by AR, e.g., galactitol, greatly exceeds the rate of metabolism or leakage of the AR product (e.g., galactitol), the steady-state relationship between the product concentration vs. the degree of inhibition of AR becomes strongly nonlinear - such that measured tissue polyol content can underestimate the degree of inhibition of AR flux and NADPH consumption (Oates, 2002). Good experimental data are lacking on this important point.

While FK366 failed to sufficiently inhibit retinal vascular changes and cataract formation in galactose-fed dogs, this compound did demonstrate beneficial AR inhibitory activity in corneal endothelial cells of the same dogs. Computer size measurements of 100 corneal endothelial cells were conducted on all images obtained by specular microscopy at 36 months. Analyses of these images indicated that the mean size of corneal endothelial cells increased from a value of $662.5 \pm 44.9$ (mean \pm S.D.) for the control, fiber-diet treated dogs to an average value of $732.8 \pm 31.7$ for the untreated galactose-fed dogs. In the low dose FK366 treated dogs, the size of the endothelial cells was significantly $(p<0.05)$ reduced to an average size of $694.3 \pm 67.9$. An even greater reduction was obtained with high dose FK366 where the average cell size of $668.8 \pm 50.4$ was similar to the $662.5 \pm 44.9$ value obtained for corneal endothelial cells from the fiber-fed controls.

Intervention Studies The NEI prevention studies in galactose-fed dogs confirmed the premise that AR activity is linked to the onset of diabetes-like retinal vascular changes and that administration of adequate doses of some, but not all, ARIs can prevent the onset and progression of retinal vascular changes. Meanwhile, the Sorbinil Retinopathy Trial, which assumed that the 36 month treatment with the ARI sorbinil would reduce the progression of retinal vascular changes after the initial clinical appearance of microaneurysms, failed to demonstrate a clinically significant reduction of the increase in microaneurysms (Sorbinil Retinopathy Trial Research Group, 1990). In comparison, a 
significant reduction in the progression of retinopathy was obtained by 48 months of intensive glycemic control in type 1 diabetics (Diabetes Complications Control Group, 1995). However, histopathologic studies conducted on 4 dogs which initially received galactose diet for 24 months followed by normal diet for 36 months, reported that the progression of some of the retinopathy endpoints were not halted by the removal of the galactose diet (Engerman and Kern, 1995). Since the removal of galactose substrate for AR by withdrawal of galactose diet might be equivalent to $100 \%$ inhibition of excess AR activity, this implied that the NEI prevention studies in galactose-fed dogs might not be relevant for providing insight into interventional trials such as the Sorbinil Retinopathy Trial. Therefore, NEI diet removal studies were next undertaken.

Galactose Diet Removal Studies These studies were again conducted with 9 month old male beagles (Kador et al., 2002). Ten dogs received control diet containing 30\% fiber while 50 dogs received standard diet containing 30\% galactose. After 24 months, the galactose diet was removed from 15 randomly selected dogs and the galactose diet was removed from an additional 15 randomly selected dogs at 31 months. These time points corresponded to the previously established onset of pericyte ghosts and microaneurysms, respectively. Eyes were periodically enucleated from dogs in each group and the intact isolated retinal vasculature from each eye was subjected to regional quantitative analysis as previously established.

In this study, the duration of galactose diet resulted in a steady decline in retinal pericytes per capillary length and this loss became significant $(p<0.05)$ by 42 months of duration, compared to similar measurements from $30 \%$ fiber-fed controls. On the other hand, the levels of endothelial cells per capillary length remained constant and did not significantly $(p<0.05)$ decline until the 60 month period which corresponded to the advanced, preproliferative retinopathy stage. In the control dogs, the levels of both pericytes and endothelial cells per capillary length remained constant. Similarly, after the 24 and 31 month galactose diet removal, the levels of pericytes and endothelial cells per capillary length remained constant from the time of galactose removal to 60 months. These results indicate that the removal of galactose diet prevented the further destruction of pericytes. This increase in pericyte loss can clearly be seen when 
expressed as E/P ratios (Fig. 10). In the continuous galactose fed dogs, the E/P ratio steadily increased, becoming significantly higher from 42-60 months compared to the controls. In contrast, the E/P ratios for dogs removed from the galactose diet at either 24 or 31 months remained essentially constant and did not significantly increase from the time of diet removal up to the 60-month period examined. Similar results were also observed in the subsequent development of microaneurysms and acellular capillaries. Moreover, the time-lines of the data confirmed that the destruction of pericytes precedes the formation of microaneurysms and the formation of areas containing acellular capillaries which correspond to the areas of nonperfusion.
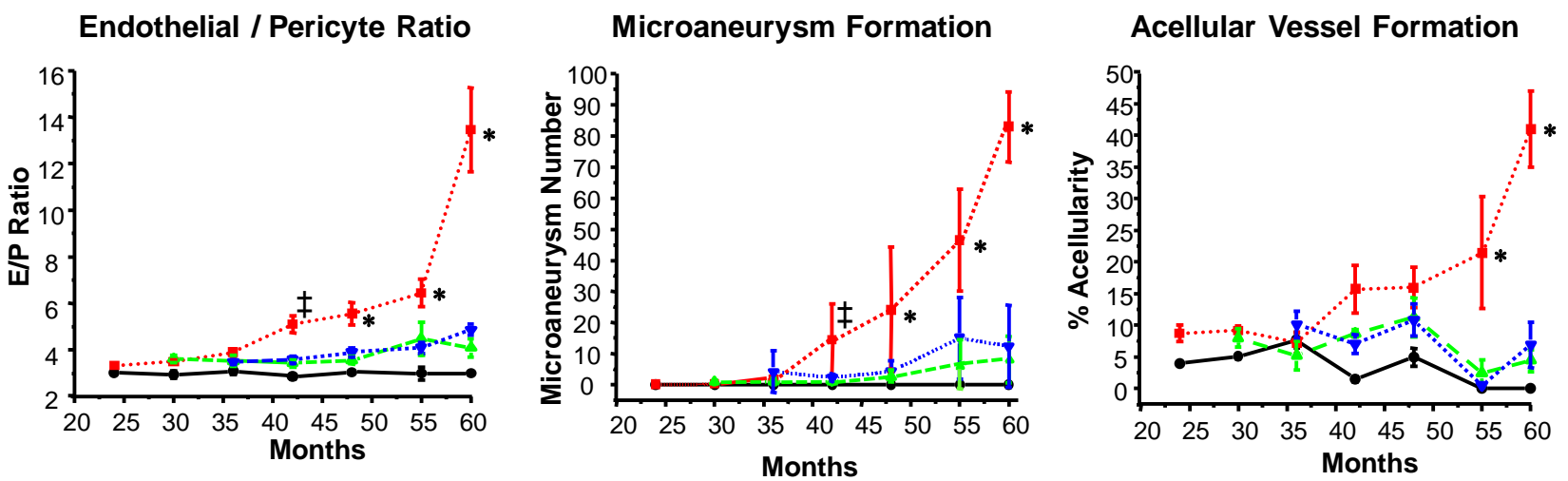

$\longrightarrow$ Control diet
$\cdots$.... Galactose diet

-- Galactose diet removed at 24 months

........ Galactose diet removed at 31 months

Figure 10 Effect of galactose diet removal on changes in endothelial cell to pericyte ratio, microaneurysm formation, and acellular vessel formation observed in the eyes from control $(\bullet)$, continuously galactose diet $(\square)$, galactose diet removed at 24 months $\left({ }^{\wedge}\right)$ and galactose diet removed at 31 months $\left({ }^{\nabla}\right)$ dogs. Results are from quantification of histological changes with each point representing $n=4-5$ eyes, mean \pm SD. Symbols indicate significant differences between the continuous galactose-fed group and all other groups at the $* p<0.01$ and $\ddagger p<$ 0.05 level. No significant differences between the control and either galactose-removed group were observed.

This study shows that retinal vascular changes are not readily reversible, because removal of the galactose diet when either pericyte destruction or microaneurysm formation has occurred did not result in any decrease of these vascular lesions. However, discontinuation of the diet at the initial stages of background retinopathy beneficially delayed the progression of retinal lesions. These results are consistent with reports that intensive hyperglycemic control delays the progression of retinopathy and 
confirm that the galactose-fed dog is a relevant animal model for investigating the progression of hexose-induced retinal lesions.

Clinical Evaluation of Retinal Changes in Galactose-Fed Dogs The galactose diet removal study demonstrated that retinal vascular changes observed by histology are not readily reversible, nor do they significantly increase with the absence of galactose diet (Kador et al., 2002). However, during the 60-month duration of galactose diet, retinal changes had progressed from an initial onset of retinopathy to the advanced preproliferative stage and this development could not be appropriately analyzed by histology alone. Therefore, a 74 month study was initiated employing the common clinical technique of fluorescein angiography to evaluate the effects of ARI treatment and galactose withdrawal on clinically observable retinal lesions, particularly retinal nonperfusion which precedes the development of retinal neovascularization in galactose-fed dogs (Cusick et al., 2003). These dogs were followed through all stages of retinopathy, including the advanced neovascular stage. Because cataracts induced by galactose feeding interfere with fundus photography, all dogs were required to be aphakic. Therefore, prior to the onset of the study, all male beagle dogs underwent bilateral lens removal by phacoemulsification at 3 months of age. YAG laser photocoagulation was subsequently performed on all aphakic dogs to improve the opening of the posterior capsules to facilitate fundus photography. At 9 months of age all dogs were randomly divided into four groups. The first group of 3 dogs (control) received 30\% non-nutrient fiber control diet. The second group of 11 dogs (continuous galactose) received $30 \%$ galactose diet for the entire duration of the study. The third group of 8 dogs (galactose withdrawal) received 30\% galactose for 36 months followed by replacement of the galactose diet with the $30 \%$ non-nutrient fiber control diet. The fourth group of 8 dogs (M79175-treated galactose withdrawal) received a daily dose of $16 \mathrm{mg} / \mathrm{kg} /$ day M79175 as described above along with $30 \%$ galactose diet. After 34 months, both the galactose diet and ARI were replaced with $30 \%$ non-nutrient fiber control diet for the duration of the study.

Stereoscopic fundus photographs and fluorescein angiograms were obtained during ophthalmoscopic examinations starting at baseline when diets were initiated, and twice 
yearly following the third annual exam. The photographic data was graded by a masked reader and assessed for the presence or absence of retinopathy, hyperfluorescence, nonperfusion, and retinal neovascularization at each individual visit. The severity of nonperfusion was graded according to the following predetermined levels: 1: no retinopathy; 2: hyperfluorescence; 3: nonperfusion < 2 optic disc areas; 4: nonperfusion $\geq 2$ and $<4$ disc areas; 5: nonperfusion $\geq 4$ and $<9$ disc areas; 6 : nonperfusion $\geq 9$ disc areas and $<1 / 2$ field; 7: nonperfusion $\geq 1 / 2$ field and $<1$ field; 8: nonperfusion $\geq 1$ field. The presence or absence of retinal neovascularization was noted and no side-by-side comparisons were performed. The outcome of nonperfusion of $\geq 1 / 2$ field or worse was considered to be a clinically meaningful outcome that may be similar to the severe nonproliferative diabetic retinopathy stage in human studies. This stage often triggers treatment.

For the first 27 months of the study, fluorescein angiograms indicated the absence of retinal lesions in all groups and retinal abnormalities remained absent in all control dogs throughout the 74 month course of the study. In the continuous galactose-fed dogs, hyperfluorescence and fluorescein leakage developed by 36 months. By 42 months, these dogs showed areas of nonperfusion that progressed by 53 months to sizes equal $\geq 1 / 2$ field. Neovascularization became apparent by 60 months and 7 out of 10 dogs showed proliferative disease at the 74 month study completion date. Fig 11 illustrates the progression of retinal lesions observed by fluorescein angiography. The first sign was the appearance of small areas of hyperfluorescence accompanied by fluorescein leakage. These areas of fluorescein leakage eventually disappeared and progressed into areas of nonperfusion, with these areas of nonperfusion increasing in size to greater than $1 / 2$ of the field size. Areas of nonperfusion are linked to retinal ischemia, and increasing ischemia is associated with the development of proliferative disease with neovascularization identified by the appearance of vessels that demonstrate fluorescein leakage that are located around the optic disc (Fig. 12).

A similar progression in the appearance of retinal lesions was observed in the 36 month galactose withdrawal group. However, the proportion of dogs demonstrating retinal lesions was consistently lower in this group compared to the continuously fed 
galactose diet dogs. Of the 6 dogs in the galactose withdrawal group examined at 74 months, 5 showed evidence of nonperfusion, 3 showed nonperfusion $\geq 1 / 2$ field, and 2 showed signs of neovascularization.
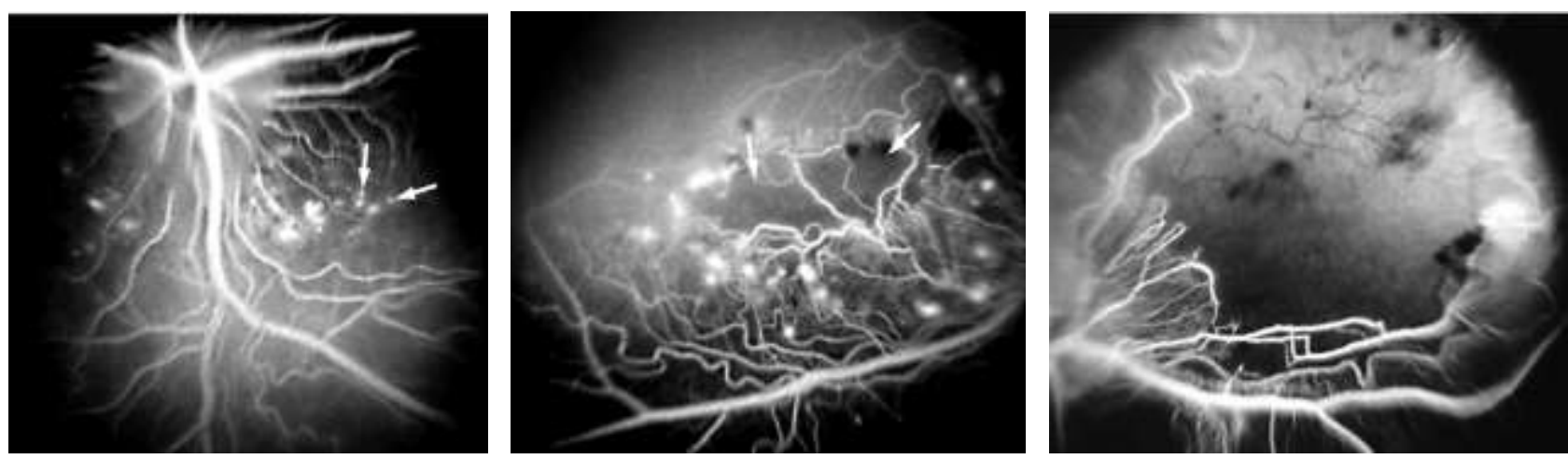

Figure 11 Fluorescein angiograms illustrating the development of retinal areas of nonperfusion in continuous galactose-fed dogs. Beginning at 36 months, focal areas of hyperfluorescence (arrows) developed (left) followed by areas of nonperfusion (arrows) that are characterized by a decreased amount of fluorescein leakage (center). This area of nonperfusion increases with the duration of galactose feeding (right).
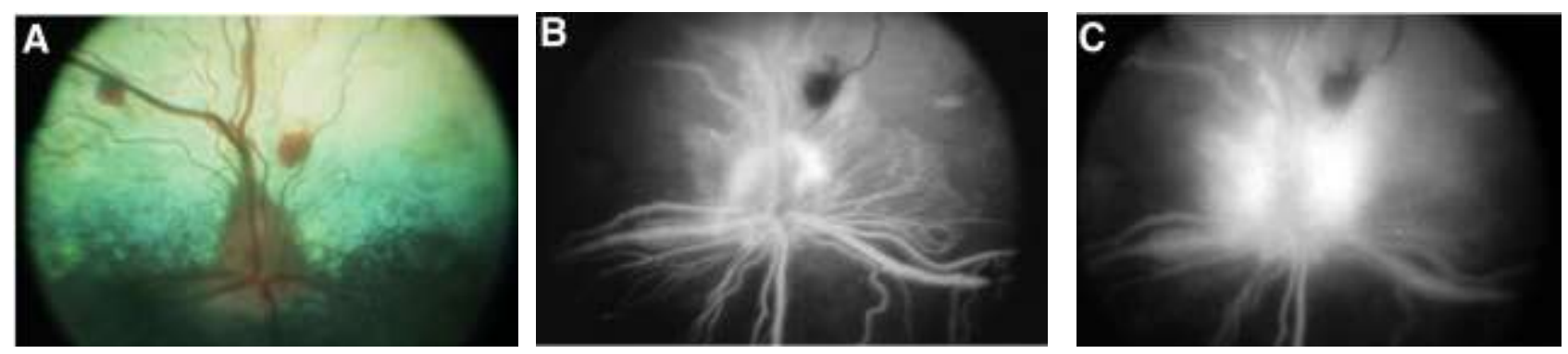

Figure 12 Fluorescein angiograms illustrating the presence of proliferative changes in the retina of continuous galactose-fed dogs. The fundus photograph taken near the optic disc (A) demonstrates in the early (B) and late (C) angiograms massive fluorescein leakage around the optic disc after the injection of fluorescein that is typically indicative of neovascularization. New vessel formation was subsequently confirmed by histology.

Compared to the continuous galactose-fed group, the M79175-treated galactose withdrawal group showed a delayed time until the first appearances of outcomes. Areas of hyperfluorescence developed after 47 months and nonperfusion was not observed until 53 months. In contrast to the continuous galactose-fed and the galactose withdrawal groups, none of these dogs developed areas of nonperfusion $\geq 1 / 2$ field nor retinal neovascularization at the 74 month study completion date. At 74 months, only 4 of 7 dogs showed signs of nonperfusion. 
In addition to the appearance of the fluorescence angiographic lesions, timing to the first appearances of hemorrhages and microaneurysms were also evaluated. In both the galactose withdrawal and M79175-treated galactose withdrawal groups, the appearance of hemorrhages and microaneurysms were similar to that of the appearance of hyperfluorescence; however, hemorrhages and microaneurysms developed last in the M79175-treated galactose withdrawal group.

The cumulative distribution functions for progression to any retinal nonperfusion, nonperfusion $\geq 1 / 2$ field, and retinal neovascularization, along with the median times to these outcomes derived from the estimated Weibull survival function, are shown in Fig. 13. Statistically significant differences in median survival times were seen between the galactose-withdrawal and M79175-treated galactose-withdrawal groups for development of nonperfusion $\geq 1 / 2$ field $(p=0.003)$ and neovascularization $(p=0.03)$, compared by data permutation. Median times to outcomes were longer for dogs in the galactose-withdrawal group compared to those in the continuous galactose-fed group.
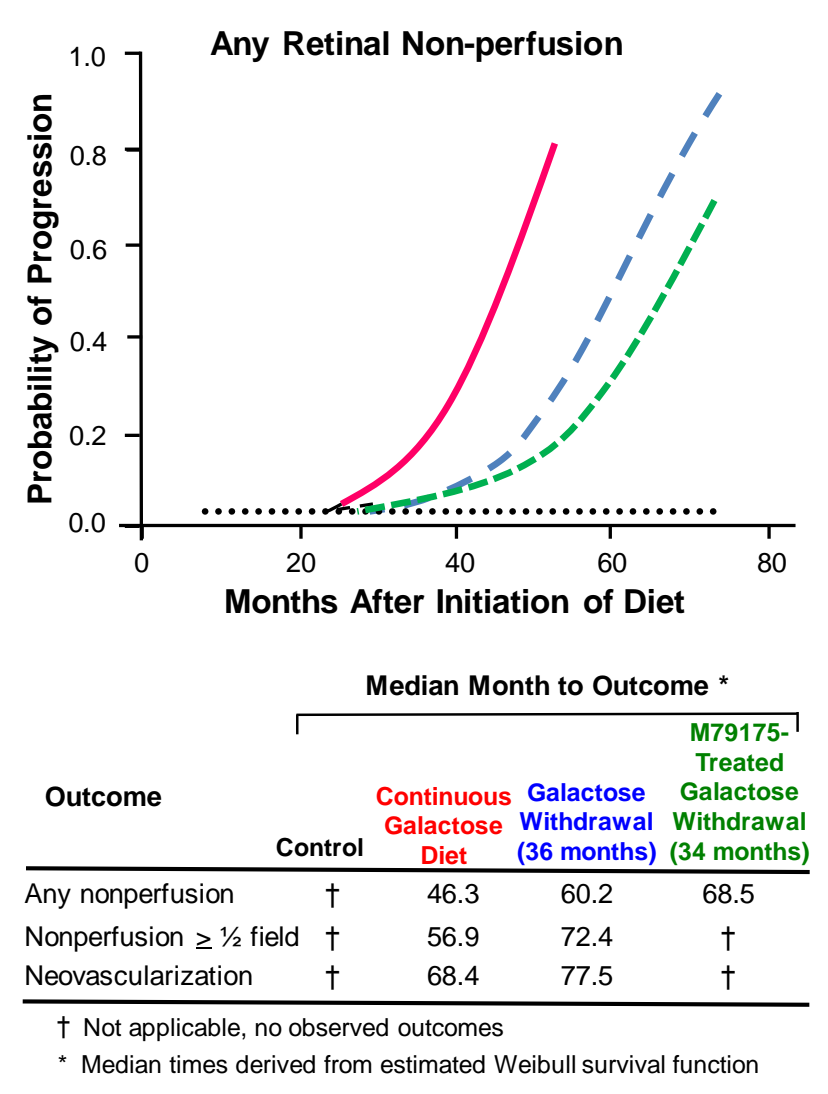
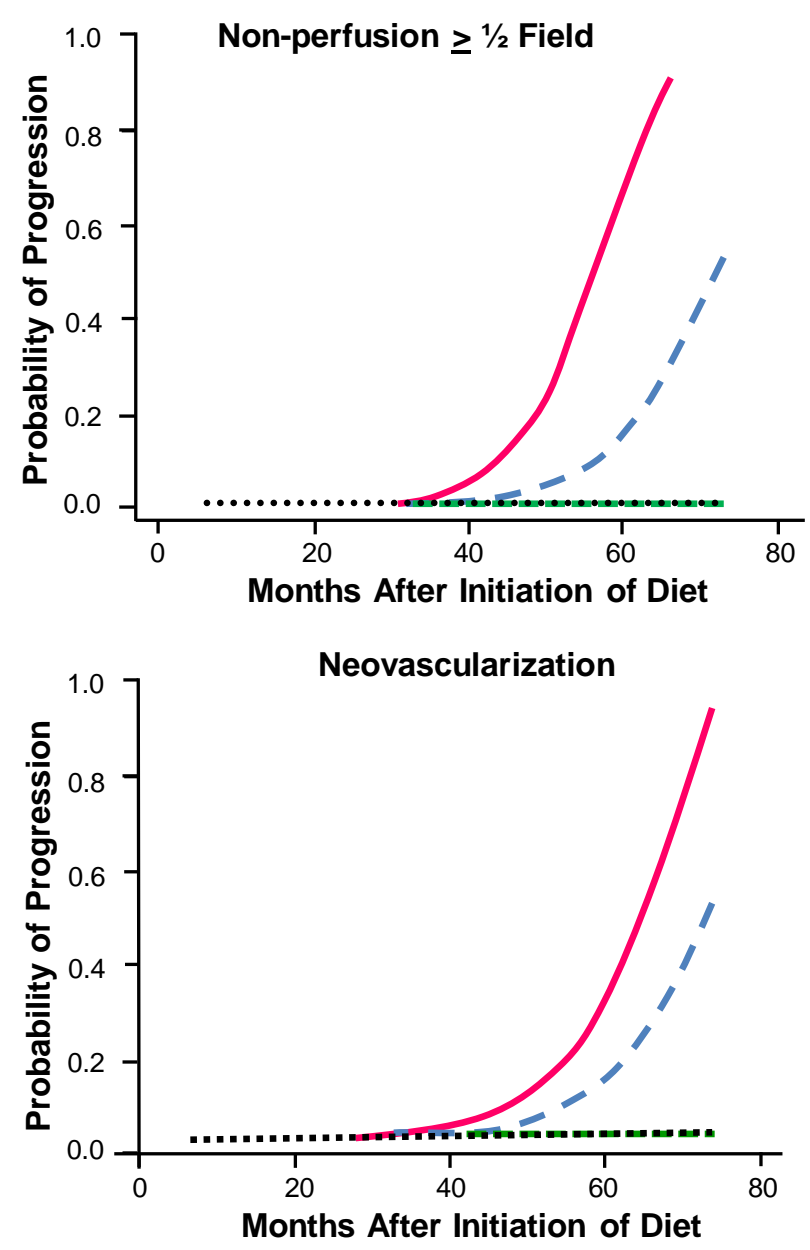
Figure 13 Estimated probability of progression to any retinal nonperfusion (top left), progression to nonperfusion $\geq 1 / 2$ field (top right), and progression to neovascularization (bottom right) among the control (black), continuous galactose fed (red), galactose withdrawal at 36 months (blue) and M79175-treated galactose withdrawal at 34 months (green) groups of dogs. The table (bottom left) lists the estimated month to outcome values for each group of dogs.

This study indicates that the combination of M79175 treatment during galactose feeding followed by withdrawal of both at 34 months is statistically more beneficial that withdrawing galactose diet alone in the primary outcomes of this study. Although M79175-treated galactose withdrawal group cannot be directly compared to the continuous galactose group due to the additional benefits associated with the withdrawal of galactose in the M79175-treated group, the results suggest that ARIs, when administered during galactose feeding, provide protection against the future development of retinal lesions. Nevertheless, the present study supports the previously reported beneficial effects of ARIs on delaying the onset and progression of retinal lesions in galactose-fed dogs. These results suggest a possible role for ARIs in the delaying the onset of key endpoints in human diabetic retinopathy. The results also demonstrate the importance of good glycemic control in slowing the progression of retinopathy and that retinopathy continues to progress for a period of several years, even after perfect control of glycemia. Consistent with recent data (Giacco et al., 2015; Kowluru et al., 2010) this is probably due to the fact that repeated hyperglycemic insults initiate a cascade of biochemical changes in retinal and vascular cells that cannot be readily reversed.

Transgenic Mouse Studies The Chung group, evaluating primarily retinal cross sections by light microscopy, has reported that an AR-deficient mouse does not develop signs of early diabetic retinopathy (Cheung et al., 2005). However, the development of advanced diabetic retinopathy in diabetic or galactosemic mice is controversial (Kern et al., 2010), and Obrosova reported that retinal sorbitol accumulation and oxidative stress in the mouse are much lower than in the rat, possibly due to low levels of $A R$ in the retina (Obrosova et al., 2006). This premise is in agreement with observations that mice do not form sugar cataracts because their lens levels of AR are low (Varma and Kinoshita, 1974). In fact, only transgenic mice where lens levels of AR are increased 
develop sugar cataracts (Ai et al., 2000; Lee et al., 1995). Therefore, new colonies of transgenic mice were established where AR levels were increased in tissues expressing smooth muscle actin (SMAA) which include retinal capillary pericytes (Kador et al., 2012). Colonies of transgenic C57BL/6 mice expressing green fluorescent protein (GFP) (SMAA-GFP), human AR (hAR) (SMAA-hAR) or both (SMAA-GFP-hAR) in their vascular tissues also expressing SMAA, were established. These were crossbred with C57BL/6-Ins2 ${ }^{\text {Akita/J }(A K) ~ m i c e ~ t o ~ p r o d u c e ~ n a t u r a l l y ~ d i a b e t i c ~ o f f s p r i n g ~ A K-S M A A-G F P ~}$ and AK-SMAA-GFP-hAR transgenic mice. GFP was introduced to aid in differentiating vascular pericytes from endothelial cells. The fluorescent appearance and fluorescent AR staining are illustrated in Fig 14 (left). The Akita transgenics develop DM by 8 weeks and the hAR expressing transgenics (AK-SMAA-GFP-hAR) have retinal sorbitol levels that are higher than transgenics not expressing hAR (Fig 14, right). The sorbitol levels in AK-SMAA-GFP and AK-SMAA-GFP-hAR retinas in Fig. 14 are very similar to the levels reported in fresh human and rat retinas exposed for 24 hours to elevated glucose levels, $15 \mathrm{nmol} / \mathrm{mg}$ protein (Lorenzi M and Oates PJ, 2008 ).
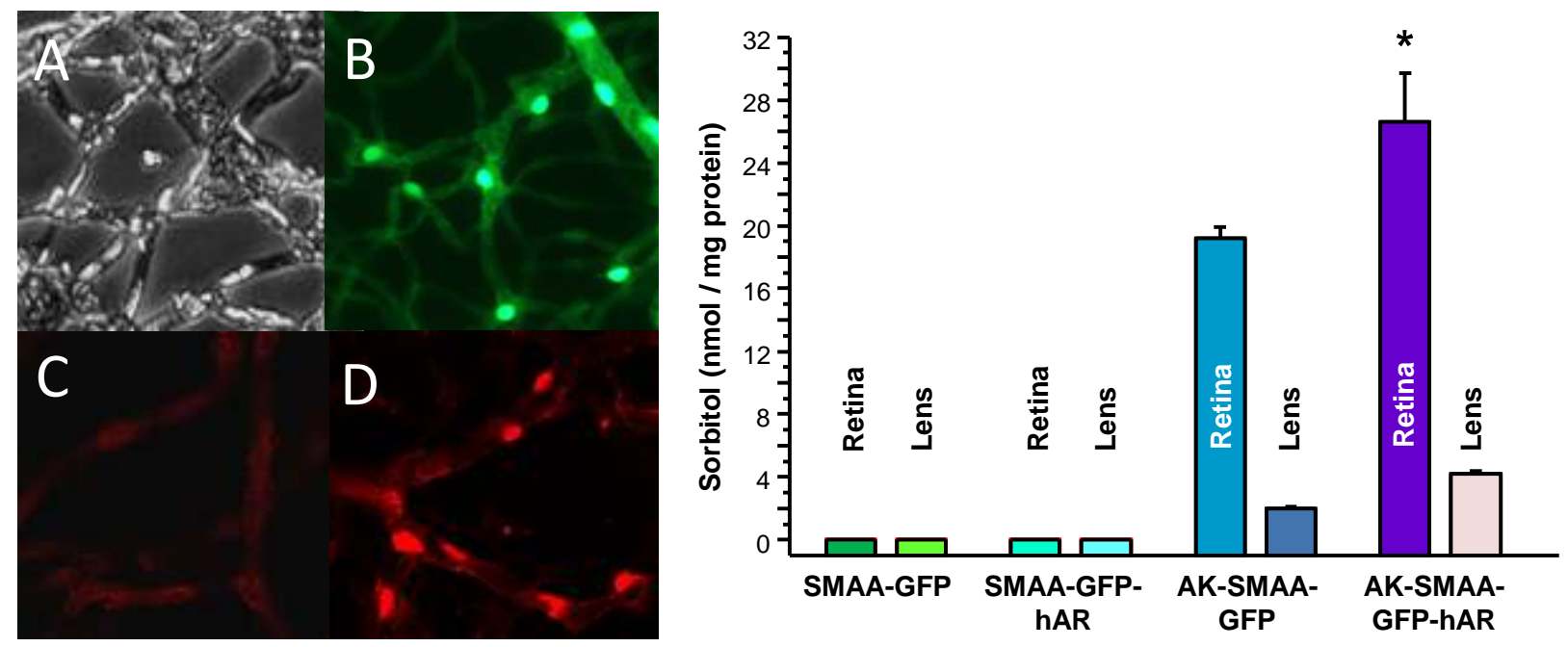

Figure 14 Appearance of retinal capillaries isolated from transgenic mice and comparison of retinal and lens polyol levels obtained from these mice. Left $A$ shows the confocal appearance of the isolated retinal vasculature from a SMAA-GFP mouse under white light and $B$ fluorescence indicating intense GFP localization in pericytes. Similarly, immunohistochemical staining of isolated capillaries from C57BL/6 control (C) and SMAA-GFP-HAR (D) mice with red staining Texas red conjugate of AR antibody from human placental AR (Akagi et al., 1983; Hohman et al., 1989) showed staining in pericytes. The capillaries from control mice (C) showed minimal immunohistochemical staining with $A R$ antibodies from either human or rat, indicating low levels of AR present. The graph on the right shows that when crossed with the naturally 
diabetic Akita mouse, significantly higher levels of sorbitol $(p<0.05)$ accumulate in the neural retina.

When hAR is introduced into these diabetic transgenic mice, they develop retinal changes that are similar to those in streptozotocin induced diabetic rats (Guo et al., 2014). The isolated retinal vessels from 18 week old diabetic hAR transgenics showed decreased capillary cell density and increased capillary acellularity that were prevented by ARIs similar to those in diabetic rats (Fig 15).
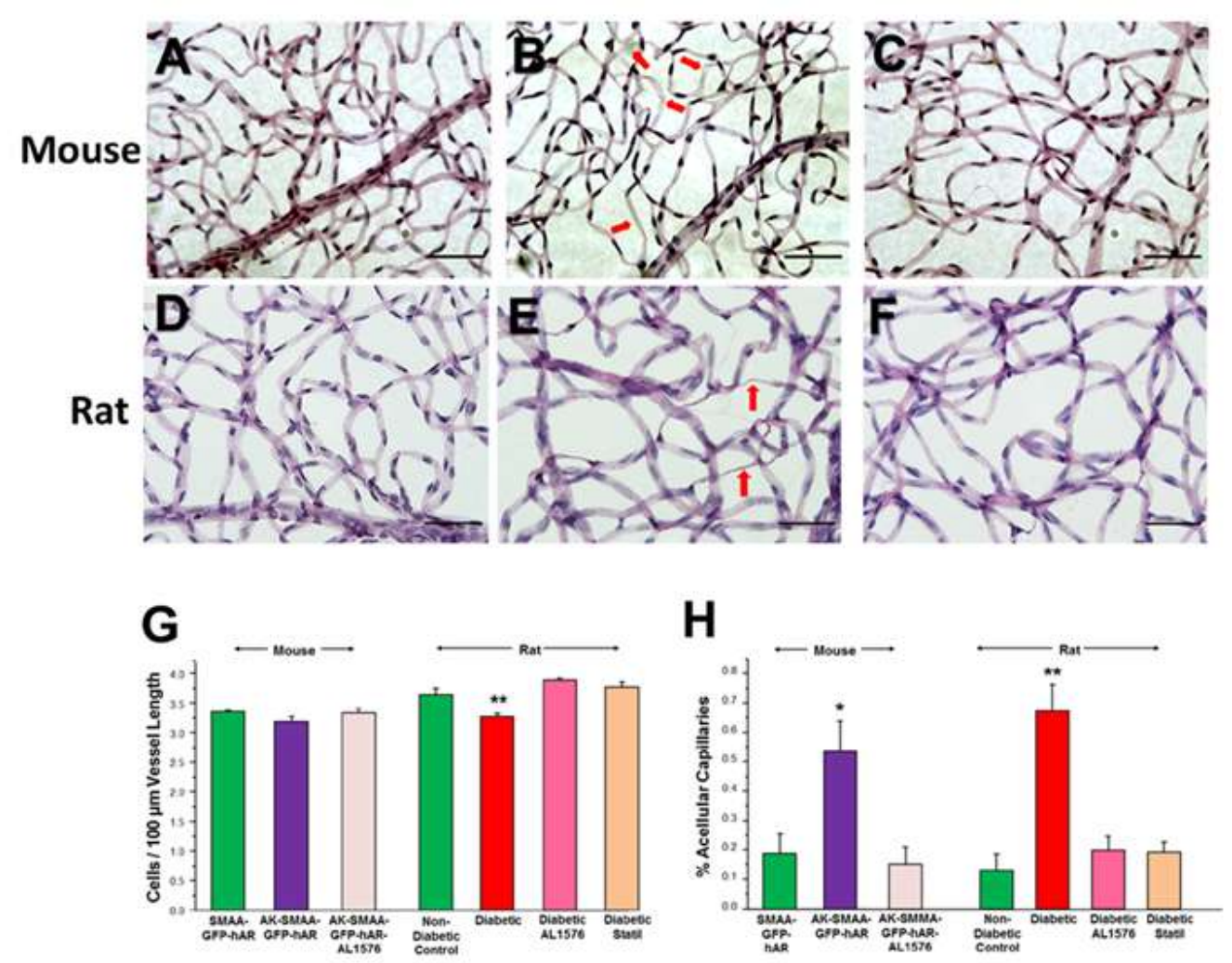

Figure 15 Appearance and changes of isolated retinal capillaries from 18 week non-diabetic SMAA-GFP-hAR mice and diabetic AK-SMAA-GFP-hAR mice treated with or without the hydantoin ARI AL1576 or carboxylic acid ARI statil and 10 week diabetic rats treated with or without the same ARIs. The representative appearances of retinal vessels from SMAA-GFPhAR mice (A), AK-SMAA-GFP-hAR mice (B) and AK-SMAA-GFP-hAR mice treated with AL1576 (C), control rat (D), diabetic rat (E) and diabetic rat treated with Al1575 (F) are shown. The red arrow indicates acellular vessels. The capillary cell density expressed as capillary nuclei per $100 \mu \mathrm{m}$ of capillary length for the mice and rats is summarized in (G) showing a small decrease in the number of nuclei per capillary length in the diabetic AK-SMAA-GFP-hAR mice compared to either the SMAA-GFP-hAR mice or AK-SMAA-GFP-hAR mice treated with AL1576. In the 10 week diabetic rats, the untreated diabetic rats showed a significant reduction in retinal capillary nuclei compared to either non-diabetic controls or diabetic rats treated with ARIs AL1576 or statil. The percent of acellular capillaries present in the examined neural retinal 
capillaries is summarized in $(\mathbf{H})$. A small, but significant increase in the percent acellular vessels present in the diabetic AK-SMAA-GFP-hAR mice compared to either AK-SMAA-GFP-hAR mice treated with AL1576 $(p<0.007)$ or non-diabetic SMAA-GFP-hAR $(p=0.03)$ mice. Mean \pm S.E.M. ${ }^{*} p<0.05$ compared to SMAA-GFP-hAR. ${ }^{* *} p<0.05$ compared to non-diabetic control. Bar $=50 \mu \mathrm{m}$. Figure from (Guo et al., 2014).

The hAR transgenics also show induction of retinal growth factors IGF-1, bFGF and TGF $\beta$, as well as signaling changes in P-Akt, P-SAPK/JNK, and P-44/42 MAPK that are normalized by ARIs. These changes are similar to the AR-related lens changes (Zhang et al., 2012b). Diabetic hAR expressing transgenics also have higher VEGF levels just like rats (Obrosova, 2003). Since all of these retinal changes are prevented by ARI administration in the transgenic mice, these studies confirm that the increased expression of $A R$ in mice contributes to the development of vascular changes associated with early diabetic retinopathy. Since the retinal changes in the hAR expressing transgenic are also similar to those observed in diabetic rats, this indicates that retinal $A R$ levels are critical for the early development of retinal changes. These changes are not limited to vascular tissue since AK-SMAA-GFP-hAR mice show reduced ERG scotopic b-wave function, which is normalized by ARIs.

In summary, the various NEI galactose-fed dog retinopathy studies demonstrate that $\mathrm{AR}$ is linked to pericyte degeneration and that, like diabetic retinopathy, pericyte loss begins a progression of retinal changes that ends in blinding proliferative retinopathy. These changes are reduced by the administration of doses of ARIs that are sufficient to inhibit $A R$ activity in the retinal capillary pericytes. The importance of the link between $\mathrm{AR}$ activity and pericytes is strengthened by transgenic mouse studies which also demonstrate that adequate cellular levels of pericyte $A R$ are critical for initiation of the vascular changes. AR allele correlations in humans further strengthen the clinical link of AR with acceleration of diabetic retinopathy. Despite early failures to demonstrate clinically significant effects of ARIs on endpoints of diabetic retinopathy (Feman et al., 1996; Sorbinil Retinopathy Trial Research Group, 1990; van Gerven et al., 1994), ARIs, to date, have demonstrated the most promising preclinical experimental evidence in preventing the onset and slowing the progression of the lesions of early diabetic and 
galactosemic retinopathy. However, the costs of a large long-term retinopathy trial along with the history of negative outcomes and the lack of a generally accepted biomarker make it difficult for researchers to conduct future diabetic retinopathy trials with any newer, more portent ARIs (Ferris III, 2005). Nevertheless, it is hoped that the lessons learned to date will help form a solid foundation for devising future novel and safe strategies to fully normalize metabolic flux through retinal AR and thereby markedly slow the progression of human diabetic retinopathy.

\section{Development of Kinostat ${ }^{\circledR}$}

The dog retinopathy studies at the NEI established not only that sugar cataracts can be dose-dependently inhibited or delayed by ARIs, but that this inhibition of cataract formation can serve as a surrogate marker for AR efficacy in preventing retinal capillary changes associated with diabetic-like retinopathy (Neuenschwander et al., 1997; Sato et al., 1998). Could this observation be transitioned to veterinary ophthalmology?

Diabetes Mellitus is an Increasing Problem in Veterinary Medicine Just as in humans, DM is an increasing problem with companion pets. At present, there are over 78 million dogs and 85 million cats in the United States and according to the American Veterinary Medical Association (AVMA), these companion pets are living longer due to better nutrition and preventive veterinary care (Hasuike et al., 2002). The risk of developing DM increases with age and currently $40 \%$ of all dogs and cats are at least seven years old (Organization, 2007). The prevalence of DM in dogs ranges from 1 in 400 to 1 in 500 (PetMD, 2011). A similar 1 in 500 prevalence has been reported for dogs between 5 and 12 years of age in the United Kingdom (Catchpole, 2007). The prevalence of DM in dogs has increased 3-fold between 1970 and 2000 (Guptill et al., 2003). These figures represent the incidence of DM in the general dog population; however, not all breeds equally develop DM, with smaller sized dogs which in general live longer, being more susceptible to DM. Females are also twice as likely to develop DM as males, but the risk of DM in males increases with castration (Marmor et al., 1982). In cats the incidence of DM ranges from 1 in 50 to 1 in 400 and again several breeds are associated with higher levels of DM (Rand et al., 2004). 
Cataracts are Problematic in Dogs DM in dogs, but not cats, is characterized by the rapid onset of blinding bilateral cataracts. These develop in diabetic dogs within 5-6 months of DM diagnosis (Gelatt, 1975). Cataracts seldom develop in diabetic cats because lens AR levels are much lower in age-matched cats than dogs (Richter et al., 2002). Often, DM is diagnosed in dogs only after their owners notice apparent changes in the appearance of their dog's eyes. As a result, early cataracts are already present in $21 \%$ of dogs at the time of DM diagnosis (Beam et al., 1999). As with humans, cataract formation leads to vision loss and blindness. Without surgical intervention, untreated cataracts can initiate lens-induced uveitis that results in intractable uveitis, and painful glaucoma. At present, the only treatment available is cataract surgery, and the general consensus of veterinary ophthalmologists is that the majority of cataract surgeries are being conducted on diabetic dogs. Phacoemulsification with intraocular lens implantation has a success rate of $85-90 \%$ (Lim et al., 2011) and complications include postoperative ocular hypertension $(22.9 \%)$, corneal lipid opacity $(19.0 \%)$, uveitis $(16.2 \%)$, intraocular hemorrhage $(12.3 \%)$, retinal detachment $(8.4 \%)$, and glaucoma (6.7\%) (Klein et al., 2011). Complications are higher in diabetic compared to nondiabetic dogs (Oliver et al., 2010).

The surgical expense for restoring vision for humans is easily justified A similar expenditure on dogs is less clear, especially to those without pets, because the cost of treatment outweighs the relative cost of replacing the pet. However, $80 \%$ of all households with companion pets describe them as family members and $70 \%$ include their pet's name on greeting cards. The majority also include their pets in family and holiday portraits (American Veterinary Medical Association, 2012). These strong emotional ties between owners and their pets is the reason why expensive cataract surgery is performed on diabetic and older, 12-14 year old pets to restore their vision. Similarly, many owners provide expensive glaucoma medication for their dogs for years rather than "replacing" these family members.

Identifying an Aldose Reductase inhibitor (ARI) Candidate Sugar cataract formation in galactose-fed animals is more rapid and severe than in diabetic animals because AR reduces galactose to galactitol more rapidly than glucose to sorbitol. Furthermore unlike 
sorbitol, galactitol is poorly metabolized by sorbitol dehydrogenase. As a result, galactose-induced cataracts are more difficult to inhibit. Therefore, using galactose-fed animals to identifying suitable drug candidates for inhibiting cataracts serves as the "acid test" for evaluating the in vivo efficacy of ARIs (Kador and Kinoshita, 1984). Based on studies conducted with a number of structurally diverse ARIs, M79175, also known as 2-methyl sorbinil or 2-MS, was found to be a promising candidate. Hydantoin rash is not associated with 2-MS in dogs and the compound also appeared to be safe when orally administered to dogs at $16 \mathrm{mg} / \mathrm{kg} /$ day for over 3 years. 2-MS successfully suppressed cataract formation in the galactose-fed dogs; however, because of its relatively short half-life in dogs, suitable efficacy could only be achieved through multiple oral doses per day (Fig. 16) (Sato et al., 1998; Sato et al., 1991). Since this required dosing would not be commercially feasible, topical administration of 2-MS was pursued because localizing the administration of 2-MS on the eye bypasses first-pass liver metabolism that results in the rapid excretion of 2-MS (Chiou, 1994). However, tear flow in dogs is more than 5-fold higher than in humans (Schirmer test 18-24 mm / min versus $\sim 3 \mathrm{~mm} / \mathrm{min}$, respectively) (Broadwater et al., 2010; Karampatakis et al., 2010). As a result, standard topical formulations with 2-MS proved to be unsatisfactory because of the rapid washout of 2-MS (Kador et al., 2007a). Nevertheless, a suitable viscous formulation resulting in the delivery of adequate levels of 2-MS to the lens was eventually developed and this topical formulation has been trade-named Kinostat ${ }^{\circledR}$.

Figure 16 Dose-dependent reduction of cataract formation in galactose-fed dogs by oral administration of 2-MS (M79175). The retro-illumination (A) and slit lamp (B) photograph of a lens from a galactose-fed dog administered 2-MS and receiving 30\% galactose diet for 38 months shows the absence of opacities. There is no demarcation line, confirming that cortical changes had not developed and that cataract formation had been arrested.
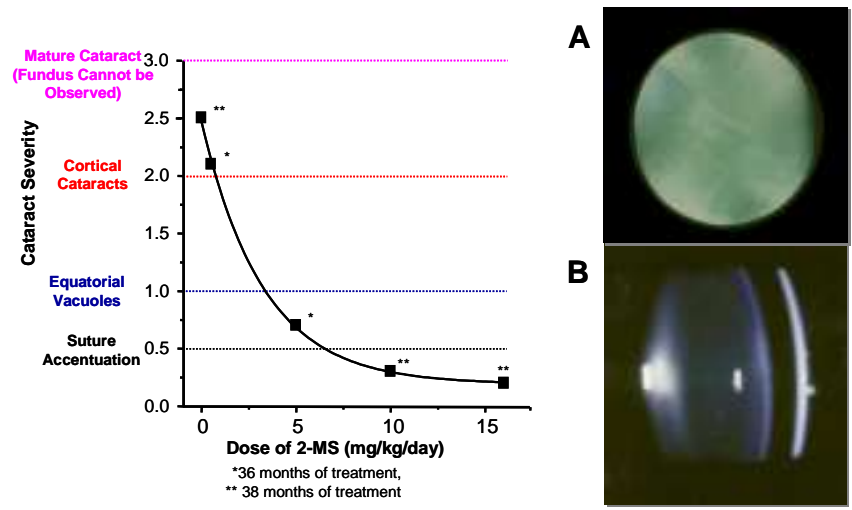

Intervention Study of Kinostat ${ }^{\circledR}$ in Galactose-Fed Dogs Prevention studies indicate that sugar cataracts can be prevented when administered at the onset of galactosemia or diabetes. However, limited intervention studies in rats suggest that reversing cataract 
formation can only be achieved at the early vacuolar stage of cataract formation and not when cortical cataracts have developed (Beyer-Mears and Cruz, 1985; Beyer-Mears et al., 1985; Beyer-Mears et al., 1997; Hu et al., 1983). Because early lens changes are often present in dogs at the time of DM diagnosis, a successful therapeutic treatment, administered at the time of diagnosis, is required to not only arrest the development of cataracts in diabetic dogs with no lens changes, but also beneficially halt or reverse the progression of sugar cataracts in their early stages of development. Therefore, a pilot study was initiated to evaluate the ability of Kinostat ${ }^{\circledR}$ to ameliorate the early stages of cortical cataract formation (Kador et al., 2006). For this study young, 6-month galactosefed beagles were utilized because they develop lens changes more rapidly than similar 9-month old beagles (Lackner et al., 1997). After ophthalmic examinations at the onset of the study to establish that all dogs were free of lens opacities or retinal lesions, all dogs were fed standard diet containing $30 \%$ galactose. Subsequently, all eyes were examined monthly in a masked fashion by indirect ophthalmoscope and hand-held slit lamp by veterinary ophthalmologists. As the study progressed, suture accentuation appeared after 4 months of galactose feeding as the earliest observed lens change. This was followed at 8 weeks by the appearance of vacuoles and at 12 weeks by the appearance of superficial cortical opacities in all dogs. At 16 weeks, bilateral cortical opacities were present in all dogs and by using the flash from the portable fundus camera, little tapetal reflex could be observed due to the density of the lens opacities (Fig. 17). At that time, 6 randomly selected dogs received 2 drops per eye twice daily of 2-MS with 1 drop per eye administered at 10 minute intervals at 8 AM and 4 PM (4 drops total/eye/day). The remaining 4 dogs similarly received placebo vehicle. After 10 weeks of Kinostat ${ }^{\circledR}$ administration, the tapetal reflex appeared to partially be restored, suggesting that the density of lens opacities was reduced or lens clearing had occurred. During the same time period, the apparent tapetal reflex in the 4 vehicle treated dogs was further reduced, with all vehicle treated dogs presenting with mature dense cataracts (Fig. 17). 


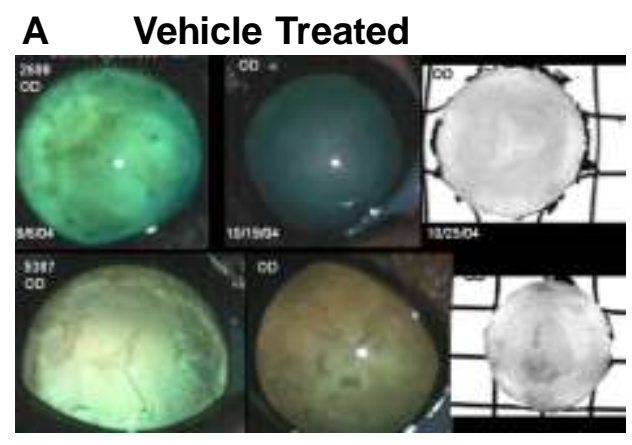

in vivo 15 weeks

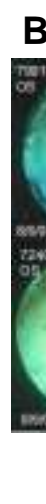

in vivo
25 weeks

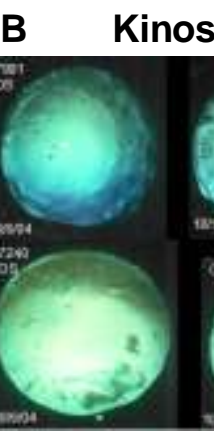

in vivo 15 weeks
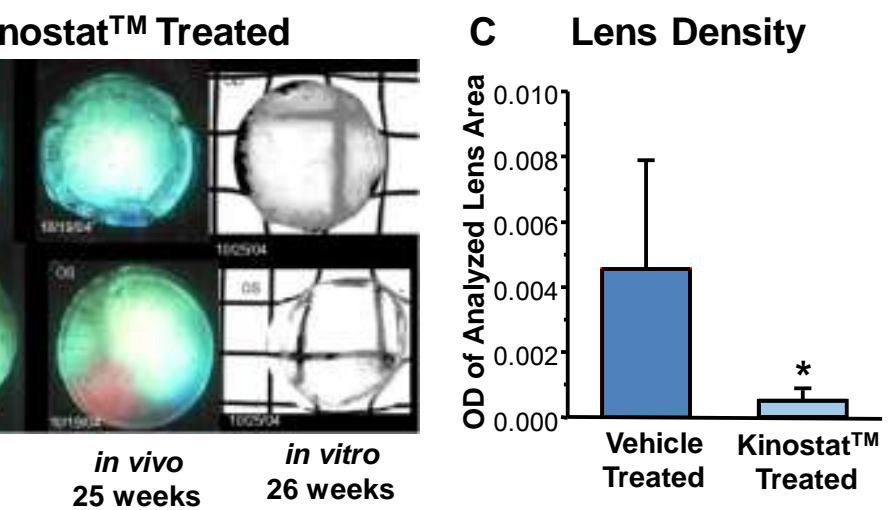

Figure 17. Representative appearance of lenses from dilated eyes from two beagles fed $30 \%$ galactose diet treated with or without Kinostat ${ }^{\circledR}$. The appearance 1 week prior to start of treatment (15 weeks), 9 weeks after treatment with vehicle ( 25 weeks) and the isolated lens at the termination of the study ( 26 weeks) is shown for the vehicle treated dogs in $\mathbf{A}$ and Kinostat ${ }^{\circledR}$ treated dogs in $\mathbf{B}$. Graph in $\mathbf{C}$ compares the means of the weighted average integrated optical density per $\mathrm{mm}^{2}$ area analyzed for the lenses from each group. ${ }^{*} \mathrm{P}<0.05$. Mean $\pm \mathrm{SD}$, vehicle treated $n=4$; Kinostat-treated $n=6$.

Following euthanasia at the 26 week study completion date, lenses were removed from each eye, placed over a lit surface containing a grid, and photodocumented (Fig. 17). Subjectively, the grid was more visible in lenses from Kinostat ${ }^{\circledR}$ treated dogs. Each lens was also photographed with the grid removed and the image was inverted to give greater detail. Lens density measurements on these inverted images were conducted with computer image analysis. As summarized in Fig. 17C, the optical density of lenses from the Kinostat ${ }^{\circledR}$ treated dogs were significantly ( $p \leq$ $0.05)$ lower than those from the vehicle treated dogs. Biochemical measurements of lens galactitol, myoinositol and 2-MS levels indicated that the lenses from the Kinostat ${ }^{\circledR}$ treated
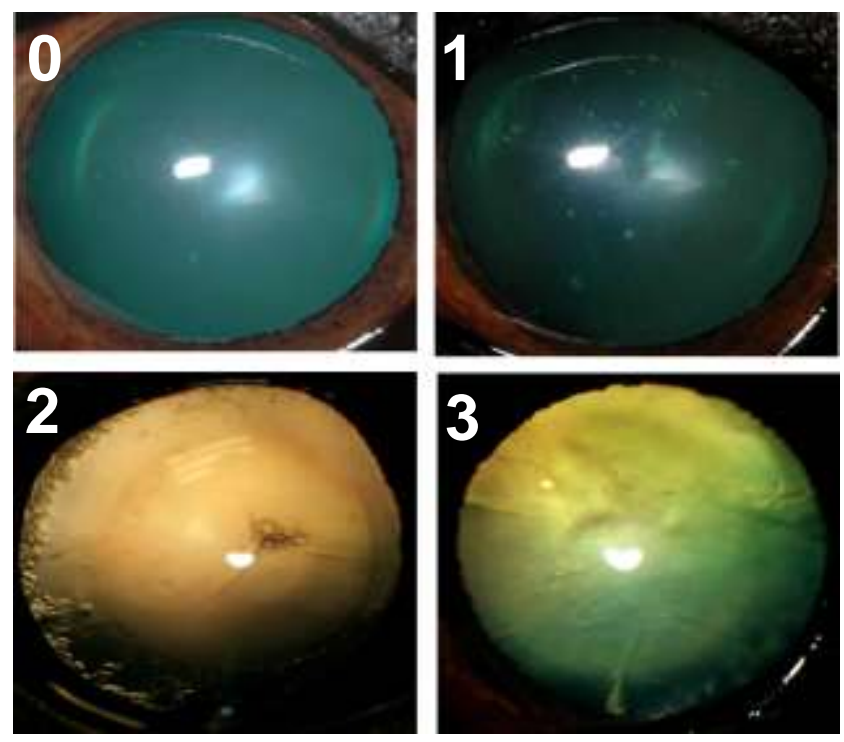

Figure 18 Cataract grading scale employed ranged from: 0 no lens opacity; 1 equatorial vacuoles only / punctate cortical opacities; 2 equatorial and cortical vacuoles / diffuse cortical opacities; 3 late immature to mature cataract. Suture accentuation was given a score of 0.5 . 
dogs which had lower optical densities also had lower galactitol levels and higher myoinositol levels than those from vehicle treated dogs (Kador et al., 2006).

Proof of Concept Clinical Study (Phase 1-2 Study) The intervention study suggested that Kinostat ${ }^{\circledR}$ could beneficially maintain or improve functional vision in diabetic dogs with early lens opacities. Based on these results, a proof of concept clinical study was initiated to investigate whether Kinostat $^{\mathrm{TM}}$ when administered three times daily (TID) by their owners could beneficially prevent or inhibit naturally occurring cataract progression in their diabetic companion dogs (Kador et al., 2010b). The endpoint of this study was cataract formation which was anticipated to occur within 1 year in the majority of placebo-treated diabetic dogs. This masked, multicenter clinical evaluation of topical Kinostat ${ }^{\circledR}$ versus placebo (vehicle) study consisted of 40 newly diagnosed diabetic dogs with no or minimal lens changes which were randomly assigned coded droptainer bottles containing either Kinostat ${ }^{\circledR}$ or vehicle for 1 year. The contents of the droptainer bottle (drug or placebo) were formulated and coded by SBH Medical, a commercial compounding laboratory, using 2-MS synthesized by the Kador Laboratory. The contents of the drug and placebo groups were similar in appearance. The study, in coordination with the Ohio State University College of Veterinary Medicine, was conducted at the MedVet Medical Center and Cancer Center for Pets, Worthington, Ohio, and at the All Animal Eye Clinic, Cincinnati, $\mathrm{OH}$. Examinations were done by board certified veterinary ophthalmologists at the onset and 1,2, 3, 6, and 12 months of the study. Documented lens changes were graded on a scale of $0-3$ as illustrated in Fig. 18.

Eligible dogs of any sex, breed or age with an initial or recent diagnosis of DM without clinical or laboratory data indicating concomitant liver, heart, adrenal or other organic diseases that could complicate cataract development were given compete eye examinations. All dogs with normal Schirmer tear test, normal intraocular pressures and no lens opacities or only equatorial vacuoles were then enrolled in the study. Owner consent was obtained at enrollment and each owner was instructed on how to administer the topical drops and document treatment compliance. Moreover, each owner was informed that there was at least a $33 \%$ chance that the agent used would be 
a placebo that would have no effect on delaying cataract formation. As compensation for the study, owners wishing to continue Kinostat ${ }^{\circledR}$ treatment after the study termination at 12 months received complimentary Kinostat ${ }^{\circledR}$ for the remaining life of their dog.

Study Results In the study 28 dogs received Kinostat ${ }^{\circledR}$ and 12 received placebo. All lens changes observed were bilateral. In the placebo group, lens changes developed within 12 months in 10 of 12 dogs (83\%). Seven dogs developed mature cataracts (scale 3), 2 dogs developed cortical opacities (scale 2), and 1 developed equatorial vacuoles / mild punctate cortical opacities (scale 1). Two dogs had no evidence of cataract formation. The progression of these lens osmotic changes is illustrated in Fig. 19.
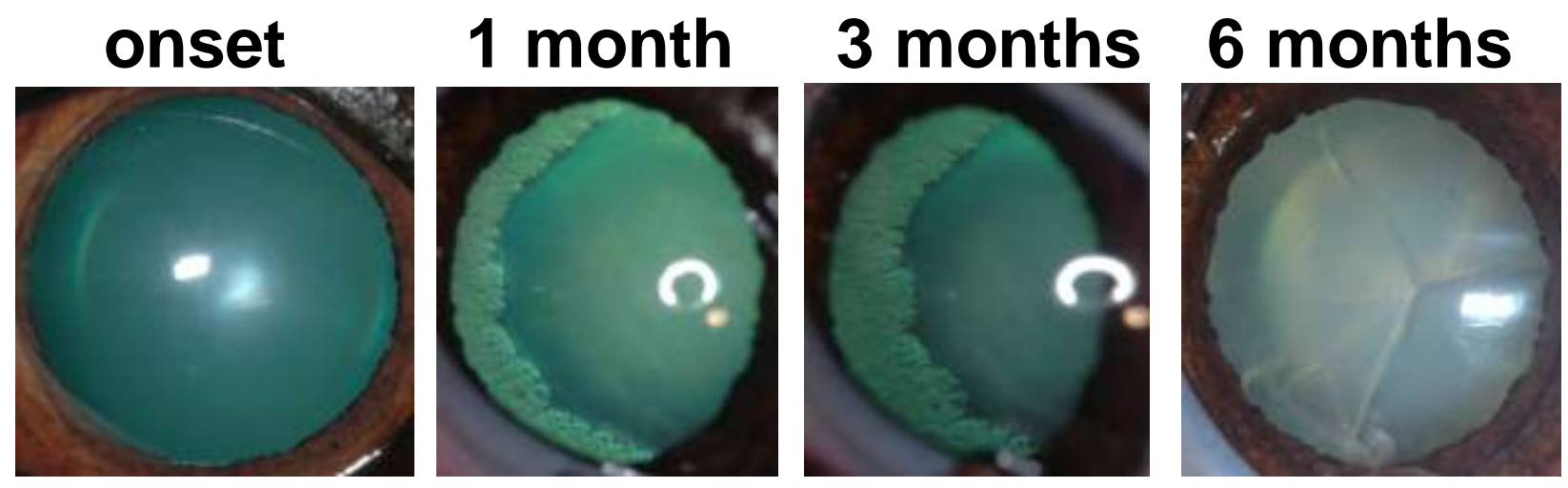

Figure 19 Osmotic lens changes observed in a placebo treated diabetic dog. While initially clear at the onset of the study, vacuoles rapidly developed resulting the appearance of a mature cataract within 6 months.

In contrast to the $83 \%$ of placebo-treated dogs developing lens changes, $46 \%$ of the Kinostat $^{\circledR}$ treated dogs (13 of 28 ) developed lens changes after 1 year. Anterior equatorial vacuoles (scale 1) were present in 7 dogs, cortical opacities (scale 2) were present in 2 dogs, and mature cataracts (scale 3) were present in 4 dogs. In the dogs with mature cataracts, these developed by 6 months in 3 dogs and by 12 months in 1 dog. More importantly, 15 of 28 dogs (54\%) showed no evidence of cataract development. At the time of enrollment 3 dogs also had age-related (but not osmotic DM related) incipient anterior and poster punctate opacities present and punctuate opacities were initially present in several other dogs. None of these progressed. Compared to the placebo treated group, the mean cataract severity score of the 
Kinostat ${ }^{\circledR}$ treated group was significantly $(p \leq 0.0016)$ lower at the 1 year completion date (Fig. 20).

The differences in cataract formation observed between the placebo- and Kinostat ${ }^{\circledR}$ treated groups were not due to differences in glycemic control since $\mathrm{HbA1c}$ values were not significantly different $(p=0.369)$ between the placebo $(6.7 \pm 0.95)$ and Kinostat $^{\circledR}$ (7.7 \pm 1.8$)$ groups. 2 -MS levels could not be detected in blood samples obtained from dogs after 12 months of treatment and complete blood chemistries showed no apparent adverse changes.

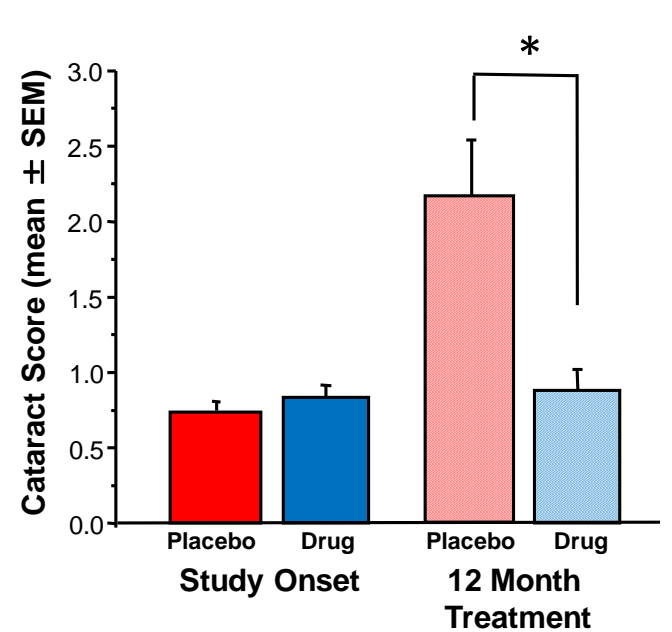

Figure 20 Comparison of mean cataract scores at the onset and at 12 months of placebo (vehicle, red) and Kinostat ${ }^{\circledR}$ (blue) treated diabetic dogs. The placebo treated group was composed of 24 eyes from 12 dogs and the Kinostat ${ }^{\circledR}$ treated dog was composed of 56 eyes from 28 dogs. (Mean \pm SEM) ${ }^{*} \mathrm{P} \leq 0.0016$.

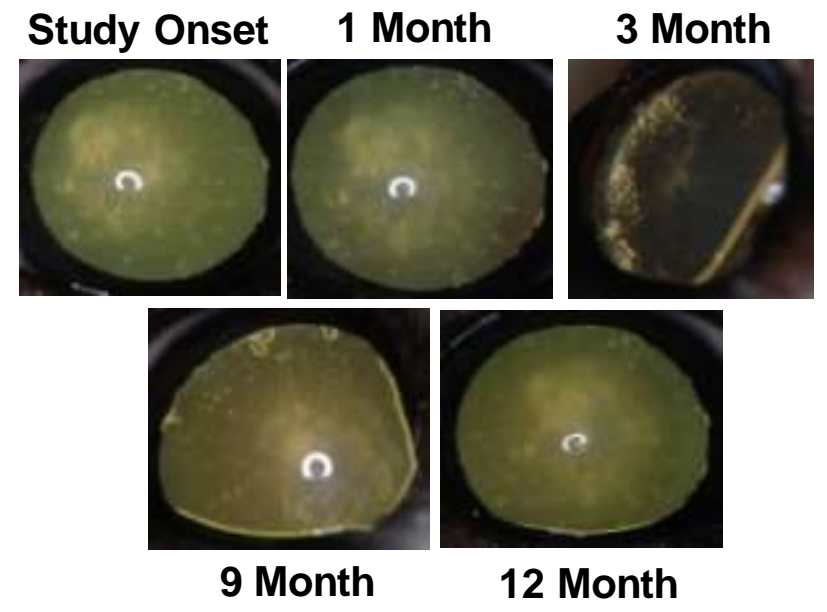

Figure 21 Wax and waning of osmotic lens changes in a Kinostat $^{\circledR}$ treated diabetic dog. While equatorial vacuoles formed and receded over the 12 month study period, the age-related anterior and posterior cortical opacities which were present from the onset of study did not progress and remained unchanged after 12 months.

This pilot clinical study confirmed that topical Kinostat ${ }^{\mathrm{TM}}$ when administered by owners could arrest the onset and/or progression of cataracts in their diabetic dogs. Because Kinostat $^{\circledR}$ is a preventive that requires continuous treatment, owner compliance was a critical factor in predicting whether Kinostat ${ }^{\circledR}$ could be commercially viable. Client compliance, however, was also a major factor in confounding the present results. For example, one owner placed his clear eyed, Kinostat ${ }^{\circledR}$ - treated pet in a kennel without treatment for two weeks while he went on vacation. After returning, the 
owner discovered that without treatment bilateral mature cataracts had rapidly developed. A waxing and waning of osmotic lens changes was also observed in some dogs during the study (Fig 21). This probably reflects changes in glycemic control rather than Kinostat ${ }^{\circledR}$ treatment which were monitored through the owner's daily dosing sheets.

Long-Term Treatment Owners of 20 dogs elected to continue Kinostat ${ }^{\circledR}$ treatment after completing the initial 12-month study. Of these, 13 dogs (65\%) had no lens changes, 6 $(30 \%)$ had cortical vacuoles and $1(5 \%)$ had a cortical opacity. With some, prolonged Kinostat $^{\Theta}$ treatment actually appeared to reverse osmotic changes. For example, equatorial vacuoles present at the initial examination in a cocker spaniel were absent after 29 months of Kinostat ${ }^{\circledR}$ treatment (Fig. 22). The number of dogs participating in the long-term Kinostat ${ }^{\circledR}$ treatment because their vision was being maintained is summarized in Fig 23. The decrease in numbers over time reflects the average 3-year lifespan generally observed for diabetic dogs. Of these, four dogs were still alive at the beginning of their 5 th year of Kinostat ${ }^{\circledR}$ treatment -- a 7 year old dachshund, a 13 year old chow mix, an 11 year old pomeranian, and a 16 year old medium mix. The dachshund who was diagnosed at age 2 with DM is still alive and on his 8 th year of treatment with no cataracts. As previously stated, Kinostat ${ }^{\circledR}$ is a preventive that requires continuous treatment for cataract prevention. In one case even after 4.5 years of continuous treatment, halting treatment resulted in bilateral cataract formation within one month.

Kinostat $^{\circledR}$ is the first drug to significantly prevent the clinical development of cataracts so that the need for cataract surgery can be reduced in dogs with DM. Based on this data, an Animal Investigational New Drug (AIND) application was issued for the clinical development of Kinostat ${ }^{\circledR}$. Subsequently, Kinostat ${ }^{\circledR}$ was given a Minimum Use in a Major Animal Species (MUMS) designation to fast track its development for the Veterinary Market based on the uniqueness of this drug. 


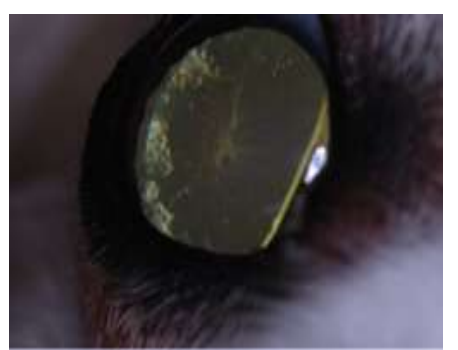

Study Onset

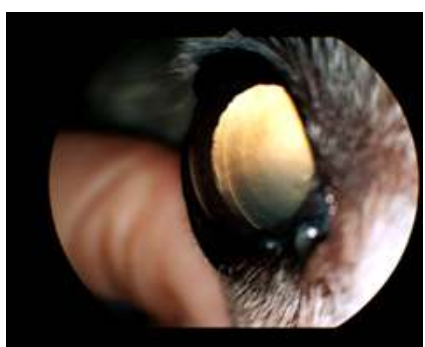

29 Month

Figure 22 Appearance of the lens from a diabetic Cocker Spaniel where equatorial vacuoles were noted at $360^{\circ}$. These disappeared after 29 months and the lens remained clear with continued topical treatment of Kinostat $\AA$ until the dog's death at 4 years.

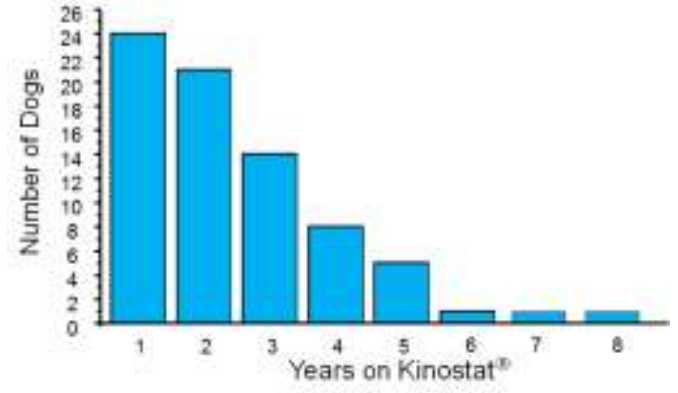

Figure 23 Number of dogs enrolled in long-term Kinostat ${ }^{\circledR}$ treatment following completion of the Proof of Concept trial.

\section{FDA Approval Studies}

Standardized Preparation of Topical Kinostat ${ }^{\circledR}$ For the studies required for FDA approval and commercialization, the active ARI 2-MS and its formulation into topical Kinostat $^{\circledR}$ had to be manufactured under GMP and validated under GLP guidelines in approved facilities. Because Kinostat ${ }^{\circledR}$ is a suspension, the preparation of $\operatorname{Kinostat}^{\circledR}$, required standardization with defined ranges of particle size and viscosity as well as validations of sample sterility and stability. To establish the baseline for the particle size of 2-MS, different batches of Kinostat ${ }^{\circledR}$ prepared by the SBH Medical compounding laboratory by grinding 2-MS in a mortar and pestle were analyzed by Field-Emission Scanning Electron Microscope (FE-SEM) to have an average particle size of $14.3 \pm 2.5$ $\mu \mathrm{m}$. To determine whether particle size differences in the range of 4-20 $\mu \mathrm{m}$ could significantly affect biological activity, 3 distinct preparations of 2-MS were jet milled to an average particle size of $7.7 \mu \mathrm{m}, 4.2 \mu \mathrm{m}$, and $19 \mu \mathrm{m}$ as measured by laser diffraction. These were then formulated with vehicle and the bioequivalence of these three formulations along with the SBH preparations were compared. All were evaluated in young rats fed $25 \%$ galactose diet that were divided into 6 groups with one group serving as the untreated control. Each rat received one drop of the assigned agent TID to each eye and signs of irritation were monitored daily by an ophthalmologist. Lens changes were monitored by slit lamp at 3-day intervals following dilation with $1 \%$ 
tropicamide. At the 3-week study completion, only rats in the untreated group developed cataracts while the lenses from all other treated groups remained clear. Galactitol, measured by HPLC (Kador et al., 2006), was only present in the lenses of untreated galactose-fed rats, confirming that all formulations adequately delivered 2-MS at levels required to inhibit AR. Surprisingly, lens levels of 2-MS, determined by HPLC (Kador et al., 2007a), were significantly higher in rats receiving 2-MS at particle sizes of less than 10 $\mu \mathrm{m}$ (Fig. 24). Therefore, Kinostat ${ }^{\circledR}$ prepared for all required FDA studies and commercialization contain 2-MS with particle sizes of $<10 \mu \mathrm{m}$ mean diameter.

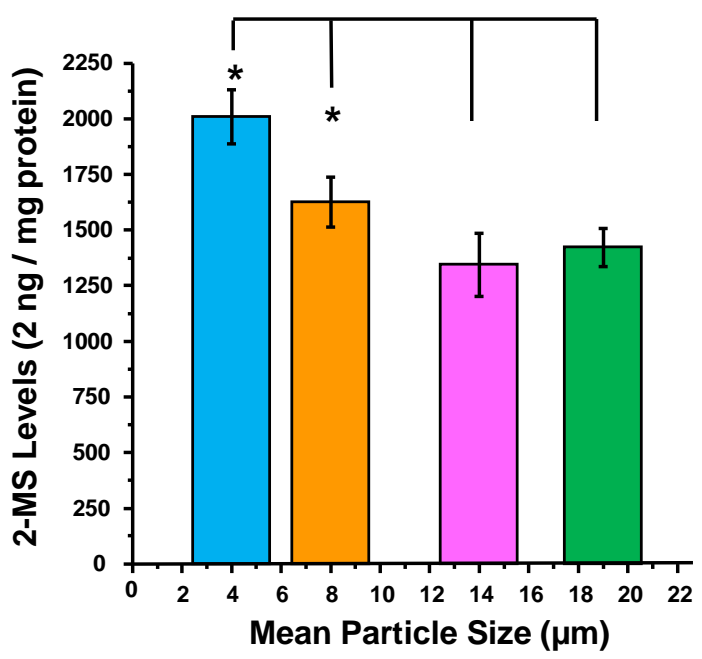

Figure 24 Effect of 2-MS particle size on lens uptake. Levels of 2-MS measured in the lenses of rats after 21 days of topical TID treatment. Mean $\pm S D * p<0.05$ compared to $14 \mu \mathrm{m}$ diameter.

Drug Safety Study A 6-month evaluation of Kinostat $^{\circledR}$ was conducted with FDA concurrence to assess the topical and systemic toxicity of Kinostat ${ }^{\mathrm{TM}}$. This required that Kinostat $^{\circledR}$ be topically applied to the eyes of non-diabetic dogs for 6 months at doses of up to five times the recommended dosage of 1 drop per eye TID. Therefore, dogs (4 males and 4 females beagles per group) received either $1 x$ ( 1 drop per eye, TID), $3 x$ ( 3 drops per eye, TID) or $5 x$ ( 5 drops per eye, TID) of Kinostat ${ }^{\circledR}$ or saline control (1 drop per eye, TID). Drops were directly applied to the cornea by technicians and washout from the eye was reduced by delivering each drop at approximately 30 second intervals.

Each dog was given a physical examination by a veterinarian during the initial acclimation period and then once weekly throughout the 26-week exposure period with the intent to establish baseline health status and subsequently to detect any abnormalities that may be product-related. The examinations assessed the ocular, musculoskeletal, cardiovascular, reproductive, lymphatic, nervous, integumentary, respiratory, urinary, and gastrointestinal systems. The examinations also determined body weight, behavior, body temperature, respiration rate, and heart rate. Each dog 
also received ophthalmic examinations of both eyes by a board-certified veterinary ophthalmologist during acclimation and then once monthly throughout the 26-week exposure period to establish baseline status and detect any product related abnormalities. Examinations included measurement of IOP, indirect ophthalmoscopy and slit-lamp biomicroscopy of the anterior segment, including evaluation of pupillary light reflex and examination of the conjunctiva, cornea (including fluorescein staining), anterior chamber, iris, lens, and anterior vitreous. After the initial biomicroscopic examination and evaluation of the pupillary light reflex, eyes were dilated with $1 \%$ tropicamide and the lens, anterior vitreous and retina were examined. Dogs were euthanized on Day 183 and postmortem evaluations included gross pathology, organ weights and histopathology.

The conclusion of the toxicology study was that the daily application of Kinostat ${ }^{\circledR}$ at doses of up to $5 x$ the recommended doses did not result in drug-related changes in ophthalmology findings or electrocardiography parameters. Kinostat ${ }^{\circledR}$ exposure did not induce any direct local or systemic toxic effects in any of the tissues examined by histopathology. Minor ocular observations (discharge, crusting, etc.) and increases in serum glucose within the normal physiologic range for beagles were noted, but although statistically significant, they were not considered to be an adverse treatment effect. FDA approval for the safety of Kinostat ${ }^{\circledR}$ was received in the spring 2015.

Clinical Evaluation of Kinostat ${ }^{\circledR}$ To determine the efficacy of topical Kinostat ${ }^{\circledR}$ in preventing cataract formation in dogs with well-controlled DM, a 9-month randomized, multicenter, prospective, double-masked placebo control study was conducted. While appearing similar to the initial 12 month Proof of Concept Clinical Study, this Clinical Trial was a more stringent 9-month study according to a protocol prepared with FDA concurrence. The study required that a total of 100 experimental $\left(\right.$ Kinostat $^{\circledR}$ ) treated and 33 control (placebo) treated dogs complete the primary endpoint as either a success or failure. The primary endpoint was the development or osmotic cataracts over a 9-month period whose progression was qualitatively graded on a scale of $0-3$ as summarized in Fig. 18. A failure was defined as a dog with grade 2 or higher cataract development in 
one or both eyes at any time point. A success was defined as a dog with no grade 2 or higher cataract development in either eye at 9 months. Secondary endpoints included: the incidence of corneal keratopathy and/or corneal defects; elevated intraocular pressure; abnormalities of blood chemistry; abnormalities of hematology; and presence of retinal changes. Time to development of Grade 1 and Grade 2 and Grade 3 cataracts were also evaluated.

All well controlled diabetic dogs of any age, breed or sex were enrolled based on their order of recruitment. Following an initial ophthalmic examination and blood chemistry profile, eligibility was based on the absence in both eyes of osmotic cataract and other ocular diseases, including retinal degenerations, detachments, overt corneal disease, anterior uveitis, glaucoma, or other diseases of the eye that may be associated with the development of cataracts and the absence of abnormalities in the blood profiles. Initial eligibility, with FDA concurrence, stipulated that both eyes must be free of any osmotic cataractous changes at the time of entry. With this restriction $50-60 \%$ of referred dogs at the initial examination were ineligible because lens vacuoles were present. Subsequently, the entry criterion was modified to include eyes with equatorial vacuoles encompassing less than 360 degrees (stage 1 cataract). Eligible dogs were enrolled only after owner consent, and continued study participation was contingent on owner treatment compliance and keeping examination appointments at 1, 2, 3, 6 and 9 months as outlined in the protocol.

To obtain the required number of animals, a total of 120 animals were randomized to the Kinostat ${ }^{\circledR}$ group and 60 to the placebo group (2:1 Kinostat ${ }^{\circledR}$ : placebo ratio). A stratified blocked random allocation scheme was generated with block sizes of 3 or 6 so that the number of patients assigned to each treatment allocation (2:1 Kinostat ${ }^{\mathrm{Q}}$ : placebo) was approximately balanced over time. The randomization was stratified to 5 original clinic sites with 36 treatment sets per site. To increase recruitment the study was subsequently expanded to 11 sites. Treatments sets with original codes were dispersed from the original to the newer sites in sets of 3 to maintain the blocked distribution. The study sites were located in Annapolis, Maryland; Fairfax, Virginia; Tampa and Largo Florida; Houston and Dallas Texas; Worthington, Ohio; Omaha, Nebraska; Tucson, Arizona; and San Diego and 
Tustin, California. At owner's request, all dogs successfully completing the 9 monthstudy with a cataract score of 1 or less were enrolled in a long-term study where they receive open label Kinostat ${ }^{\circledR}$ until the drug has been approved for commercial sale. To remain in the long-term study, each dog must receive at 6-month intervals a complete eye examination and blood chemistry evaluation at their original study sites.

The 9-month Efficacy Study has been completed and the study was closed in January 2016. Following FDA notification, the study code will be opened for statistical evaluation. Prior to closing the study, permission was obtained for an independent third party comparison of the initial proof of concept study with the current study results. In the current study, of the eyes not developing cataracts (stage 2 cataract) over the 9 month period, $70 / 98$ dogs were on drug (71.4\%). Moreover, in dogs successfully completing the study with either no change or improvement in lens score from the onset to completion of the study, 65 of 82 dogs were treated with drug (79.3\%). This compares to $62.5 \%$ ( 15 of 24 dogs) in the original 12 month study. These preliminary results suggest that efficacy similar to the initial proof of concept study is anticipated. In the current long-term Kinostat ${ }^{\circledR}$ treatment study, cataract development after treatment noncompliance has also been observed. For example, a neutered male Labrador retriever diagnosed at 5 years of age with DM successfully completed the study with no cataracts and normal (16-17 $\mathrm{mm} \mathrm{Hg}$ ) intraocular pressure. After entering long-term treatment he became noncompliant after 6 months and subsequently presented with progressive vision loss with pupils resistant to dilation, lens induced uveitis, hypotony (IOP 7-8 $\mathrm{mm} \mathrm{Hg}$ ), and bilateral mature cataracts. The prevention of cataracts with Kinostat ${ }^{\circledR}$ should reduce the risks of lens induced uveitis, secondary glaucoma, and other complications in diabetic dogs.

\section{Aldose Reductase and Human Sugar Cataracts}

Could Kinostat ${ }^{\circledR}$ be applied to humans? Finding a treatment for the ocular effects of DM is important for humans because $6.4 \%$ of the world's population is diabetic and this disease is expected to increase by $46.5 \%$ from 2000 to 2030 (Mathew, 2010). In both type 1 and 2 DM, poor hyperglycemic control results in vision loss due to the 
development of diabetic retinopathy and cataract. Cataracts can be surgically removed to restore vision; however, cataract surgery is associated with increased risk for complete posterior vitreal detachment and post-surgical worsening of diabetic retinopathy and macular edema (Gella et al., 2015; Haddad et al., 2014). In contrast to dogs, targeting AR in humans for these ocular diabetic complications is controversial. While osmotic sugar cataracts rapidly develop in both diabetic and galactosemic children and osmotic cataracts have been documented in cases of acute hyperglycemia in adolescent and adult diabetics, the lower levels of AR reported for the adult diabetic lens suggests that an osmotic mechanism affecting the entire lens is not likely. Moreover, as discussed earlier, in human diabetic retinopathy trials of up to 3 years with ARIs, only small effects have been observed. These effects have been judged to be, for example "unlikely... [of]... clinical importance" (Sorbinil Retinopathy Trial Research Group, 1990). Lens studies which will require even longer study times have not been conducted. The costs of such trials would be prohibitive.

Aldose Reductase and Juvenile Cataracts Since AR activity decreases with age (Lackner et al., 1997), tissue levels in young children are at greater risk for polyol accumulation as evidenced by the fact that sugar cataracts rapidly develop in galactosemic infants and in young diabetic children and adolescents with poor glycemic control (Awan et al., 2005; Florkowski et al., 2005; Gelvin and Thonn, 1993; LangMuritano et al., 1995; Orts Vila et al., 2003; Sharma and Vasavada, 2001; Suzuki et al., 2004; Vanderveen, 2008; Vinding and Nielsen, 1984). Galactosemic infants rapidly develop bilateral cataracts when fed a lactose diet. When caught at their early stage, these cataracts can generally be reversed by removal of galactose from the diet. Nevertheless, cataracts in some children can and do eventually develop because lactose-free diets, such as Isomil, are not totally galactose free and the diets of these children become less restrictive with age (Nischal, 2009; Segal, 2004). While galactosemia is rare, DM is one of the most common chronic diseases in pediatrics. In children with type $1 \mathrm{DM}$ there are two types - an early-onset form that appears at an average age of 2-3 years and a later-onset form at 9-10 years (Dabelea, 2009). 
Between 2005 and 2020, new cases of type 1 diabetes are predicted to double in European children $<5$ years of age and by $70 \%$ in those $<15$ years of age. Similar trends are suggested by the US Search for Diabetes in Youth Study Group (Dabelea et al., 2007). Little is known about the genetic background and the clinical and autoimmune status of children that develop type 1 diabetes before 5 years of age; however, these children are at high risk for developing long-term diabetic complications because tight control of hyperglycemia is not only hard to achieve but now also not advised so that brain development is not hindered (Hathout et al., 2003). The prevalence of type $2 \mathrm{DM}$ is also increasing in children as young as 2.5 years of age and adolescents worldwide. Linked with obesity, this is particularly prevalent in the US among African American, American Indian, Hispanic and Asian/Pacific Islander youth (Dabelea et al., 2007). Genetic defects associated with MODY (maturity onset diabetes of the young) which is an autosomal dominant form of DM has been documented in children as young as 8 months of age (Odem et al., 2009).

Cataracts are more likely in diabetic children that have prolonged poor control or prolonged hyperglycemia prior to diagnosis (Datta et al., 1997). In poorly controlled older children, the cataract incidence is $20 \%$ (Esteves et al., 2008). Children conventionally treated with insulin therapy for 3.5 years have a 5 -fold higher risk of cataracts (Florys et al., 2004). Depending on the age of the child and metabolic severity of the DM / galactosemia, the appearance of cataracts varies just like the appearance of sugar cataracts in dogs of various ages and levels of DM / galactosemia. Cataract development in children under the age of 5 is especially serious because this can result in permanent vision loss due to irreversible or untreated amblyopia (Vanderveen, 2008).

Vision can only be restored by cataract removal; however, cataract surgery in young children is problematic because their eyes are expected to undergo significant ocular growth after surgery. They also have a high rate of secondary cataracts due to posterior capsule opacification (PCO). PCOs generally appear within 6 months of postoperative surgery in approximately $71 \%$ of children younger than 1 year of age (Astle et al., 2009). Because of this high incidence of PCOs, cataract surgery in children younger than 2 years is often considered to be a 2-stage procedure. It has also been suggested that in 
children under the age of 5 years with intraocular lenses (IOLs) both an elective primary capsulotomy and elective vitrectomy are mandatory to keep a clear visual axis (Hussin and Markham, 2009).

In summary, osmotic cataracts similar to those observed described in diabetic and galactosemic dogs develop in both diabetic and galactosemic children. In these children it is beneficial to postpone cataract surgery until their eyes have properly grown and the administration of a topical AR inhibitor to delay the onset of cataracts should be beneficial. However, the small market size and the potential complexity and costs of the clinical trials required for efficacy suggest that it would not be feasible to develop topical ARIs specifically for children.

Aldose Reductase and Adult Diabetic Cataracts It is generally agreed that the two enzymes of the polyol pathway and their respective metabolites, sorbitol and fructose, are all present in adult human lens, e.g., (Jedziniak et al., 1981). The presence of the polyol pathway in human lenses accords with the findings that lenses extracted from adult human diabetics contain sorbitol and increased levels of fructose, and together the levels of these polyol pathway products were proportional to the blood glucose levels of the patients at the time of extraction (Varma et al., 1979).

Also reported is a trend for elevation of AR activity (Chylack et al., 1979) as well as elevated immunoreactive AR protein (Akagi et al., 1987) in the adult human diabetic lens vs. normal adult lens. For example, AR activity $\left(\Delta \mathrm{OD}_{340} / 5 \mathrm{~min} / \mathrm{mg}\right.$ protein) was found to be $5.0 \pm 1.7$ (6) in human adult diabetic lenses vs. $2.7 \pm 3.3$ (37) in normal adult human lens (mean $\pm S D, P<0.2)$ (Chylack et al., 1979). Consistent with this, sorbitol was slightly, but not significantly, elevated in adult diabetic cataractous lenses: $2.2 \mathrm{mM}$ in diabetic adult vs. $1.5 \mathrm{mM}$ in normal adult lenses $(P<0.2)$ which was reduced by the ARI alrestatin (Chylack et al., 1979). Jedziniak et al. later reported ranges of human diabetic lens polyol levels of 1.7-9.5 mM for sorbitol and 1.2-12.0 mM for fructose; mean values were not reported (Jedziniak et al., 1981). When incubated for 4 hours in 5 or $15 \mathrm{mM}$ glucose, lens from adult normal or diabetic cataract patients did not generate sufficient sorbitol to be detected by NMR (Lerman and Moran, 1988). However, when incubated 
for 24 hours in $35.5 \mathrm{mM}$ glucose, intact lenses from adult diabetics showed a significantly higher levels of sorbitol, $5.9 \mathrm{mM}$ compared to $2.7 \mathrm{mM}$ in nondiabetic lenses (Chylack et al., 1979; Lerman and Moran, 1988). Thus, there is clear evidence for the presence of the polyol pathway and its low molecular weight metabolites in normal and diabetic human adult lens.

However, controversy has surrounded the potential osmotic effects of the sorbitol levels in the lenses of humans vs. experimental animals. This is because the specific activity of $A R$ in the normal and diabetic adult human lens is $\sim 14-20 \mathrm{X}$ lower than that of adult rat lens, while the SDH specific activity in human lens is $\sim 5 \mathrm{X}$ higher, a situation that would not be conducive to substantial polyol accumulation (Jedziniak et al., 1981; Kador, 2010). Consistent with that notion, the absolute amount of sorbitol present in fresh adult human diabetic cataractous lenses, e.g., $2.2 \mathrm{mM}$, above (Chylack et al., 1979 ) is considerably less than found in experimental animal lenses, and the increase in adult human diabetic lens sorbitol was only about $50 \%$ (1.5 mM to $2.2 \mathrm{mM}$ ) and was not statistically significant, i.e., not $\mathrm{P}<0.05$ (Chylack et al., 1979). By contrast, diabetic rat lens sorbitol increases $\sim 37$-fold from a normal value of $0.33 \mathrm{mM}$ to $12.2 \mathrm{mM}$ in the first week of alloxan-induced diabetes (Gonzalez et al., 1983), while after 6 weeks of strepozotocin-induced diabetes, lens sorbitol increased $\sim 20$-fold from a normal value of $0.68 \mathrm{mM}$ to $13.4 \mathrm{mM}$ (Obrosova et al., 1998). Similarly, in 14-day 50\% galactose-fed rats, lens galactitol was $75 \mathrm{mM}$ (Obrosova et al., 1997). Likewise, rabbit lenses incubated 24 hours in $30 \mathrm{mM}$ glucose had $5.6 \mu$ mole sorbitol $/ 0.175 \mathrm{~g}$ lens, or $32.0 \mathrm{mM}$ sorbitol (Kinoshita et al., 1963). Therefore it has been argued that the much lower levels of $A R$ activity and sorbitol as well as higher levels of SDH in adult human versus rodent lenses makes it unlikely that sorbitol levels can rise high enough in the adult diabetic human lens to elicit a pathogenically significant osmotic effect (Bron et al., 1998). However, the combinatorial relationship between the observed lenticular increase of fructose in addition to sorbitol on osmotic stress in the human lens remains to be elucidated (Cheng et al., 1985; Chylack et al., 1986).

Alternative proposals for factors driving diabetic cataract formation in the adult human lens include protein glycation and oxidative stress (Bron et al., 1993; Harding, 1992; 
Kandarakis et al., 2014). However, at least in animals, glycation is not supported by observations that ARIs prevent cataracts in animals independent of increased lens protein glycation levels (Chiou et al., 1980; Kador et al., 2000; Obrosova and Kador, 2011). On the other hand, oxidative stress has been reported to be caused by high NADPH turnover in lenses cultured in high glucose media (Cheng and Gonzalez, 1986) and by endoplasmic reticulum (ER) stress resulting from generation of increased intracellular sorbitol levels in human lens epithelial cells cultured in very high glucose media (Mulhern et al., 2006). Unfortunately, biochemical studies of human lenses abruptly ended in the early 1980s because the availability of intact human diabetic lenses was dramatically reduced consequent to the widespread use of extracapsular cataract extraction with ultrasonic phacoemulsification.

Finally, human AR gene polymorphism studies have found, in addition to confirming age and hyperglycemia as risk factors for human diabetic cataracts, that compared to non-z-4 carriers with HBA1c < $8 \%$, carriers of Z-4 allele of the AR gene had increased susceptibility to cataract (Lee et al., 2001b). In type 2 diabetic patients with suboptimal glycemic control, the Z-4 allele of AR has also been independently associated with increased susceptibility to cataracts (Wang et al., 2014). However, the phenotypic expression associated with Z-4 allele of AR remains to be demonstrated.

\section{Localized Osmotic Changes}

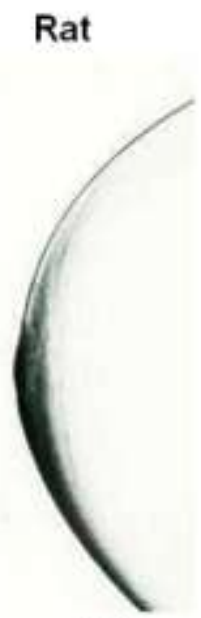

5.5

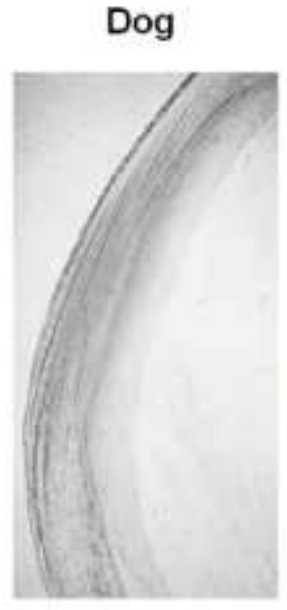

0.39
Human

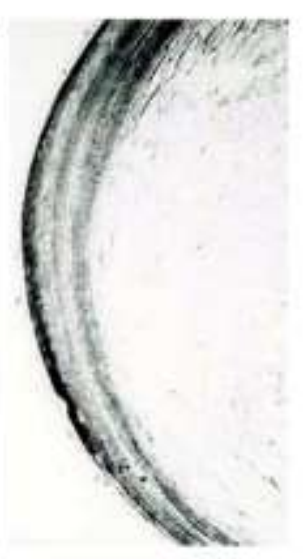

0.39 Specific Activity of AR ( $\mathrm{nmol} \mathrm{NADPH} / \mathrm{min} / \mathrm{mg}$ protein)

Figure 25 Immunohistochemical localization and specific activity of AR in rat, dog and human lenses. AR specific antibodies against rat lens, dog lens and human placental AR were used to demonstrate that the enzyme is primarily present in lens epithelium and superficial cortical fibers at the equator. From (Kador, 2010).

While sorbitol accumulation in the

older human diabetic lenses may not be adequate for initiating osmotic stress over the 
entire lens, localized osmotic stress cannot be ruled out. Bettelheim has reported that hydrational changes in diabetic human lenses precede cataract formation (Bettelheim et al., 1998). Despite differences in activity, AR is similarly localized in the epithelial cell layer and superficial fiber cells in the human, dog and rat (Fig. 25) (Kador, 2010; Kador et al., 2010a). The specific activity of AR in the adult dog and human lens is similar and both are 14-fold lower than in the rat lens (Fig. 25). The localization of AR also corresponds to where sorbitol production occurs. Studies with cultured dog lenses confirm that sorbitol primarily accumulates in the epithelial cells and superficial cortical fibers (Lizak et al., 1998), and this corresponds to localized osmotic changes observed by magnetic transfer contrast magnetic resonance imaging (MTC-MRI) in the dog lens (Kador, 2007, 2010; Lizak et al., 1996; Mori et al., 1995). These osmotic changes in the dog lens have also been confirmed by histology (Sato et al., 1991). In the diabetic adult rat lens hydration has also been localized to be primarily present in the lens epithelium, bow and superficial cortical regions, but not the nucleus by Raman spectroscopy (Mizuno et al., 1990). This is similar to the localized osmotic changes observed by histology in the rat lens where $A R$ is localized near the presence of vacuoles in the cortical layer and epithelium (Akagi et al., 1986a; Robison et al., 1990a). In human diabetic lenses, AR has also been similarly observed to be associated with the presence of vacuoles in both the anterior or posterior superficial cortical layers (Akagi et al., 1987). Human and dog lens epithelial cells both contain AR and they accumulate sorbitol (Ibaraki et al., 1998; Kubo et al., 2004; Lizak et al., 1998; Mulhern et al., 2006). Culture in high glucose or galactose medium induces apoptosis in lens epithelial cells and this apoptosis is inhibited by ARIs (Kubo et al., 2004; Mulhern et al., 2006; Murata et al., 2001). Similar apoptosis has been observed with TUNEL staining of lens capsules from humans and rats which show decreases in lens epithelial cell density with diabetes (Takamura et al., 2000). In diabetic rats, this decrease was prevented by treatment with ARIs (Takamura et al., 2003). Significant correlations of red blood cell AR levels with decreased lens epithelial cell densities have been observed in patients with DM when their $\mathrm{HbA1c}$ levels were above $6.5 \%$ or when diabetic retinopathy is present (Kumamoto et al., 2007). 


\section{Aldose Reductase and Corneal Changes}

DM affects corneal morphology, metabolism and physiology that result in clinical abnormalities that are referred to as diabetic keratopathy (Kaji, 2005). Documented diabetic corneal changes include epithelial defects, recurrent epithelial erosions, delayed reepithelialization, slower wound repair, increased epithelial fragility, reduced sensitivity, increased auto-fluorescence, altered epithelial and endothelial barrier functions, ulcers, edema, and increased susceptibility to injury due to the popularity of corneal refractive surgery and increase in cataract surgery, including LASIK among diabetics (Simpson et al., 2012; Skarbez et al., 2010). More than 70\% of diabetics develop diabetic keratopathy and demonstrate some morphological change of their cornea (Quadrado et al., 2006). While many physicians and scientists do not consider diabetes-linked corneal changes to be a serious clinical or pathological entity, numerous patients have visual loss secondary to diabetic keratopathy (Kaji, 2005).

Prior to the 1970's the effect of DM was believed to be limited to decreased corneal sensation; however, with the advent of vitreous surgery in diabetics, other corneal complications, as described above, became apparent (Foulks et al., 1979; Perry et al., 1978). During early intraocular surgery on diabetics, corneal edema sufficient enough to obscure the visualization of the surgery often occurred, necessitating the removal of the epithelium. This procedure often resulted in corneal epithelial defects that included corneal resurfacing and wound healing complications and stromal edema. Because the corneal epithelium from these diabetics showed increased sorbitol and fructose that suggested sorbitol pathway activation (Foulks et al., 1979), the focus of Kinoshita's laboratory at the National Eye Institute turned to the cornea where diabetic rats were observed to develop similar corneal problems. By totally denuding the corneal epithelium from diabetic rats and then following the resurfacing process with fluorescein stain, they documented both the delay in the rate of re-epithelialization and the hazy, edematous appearance of the healed corneas (Fukushi et al., 1980; Kinoshita et al., 1979). Moreover, they observed that topical or systemic treatment of similar diabetic rats with a number of structurally diverse ARIs, that included sorbinil, alrestatin, and 7-hydroxy-2-oxochromone-2-carboxylic acid, enhanced epithelial regeneration and the reduced appearance of edema. This observation 
that AR activity appeared to be linked to corneal changes was strengthened by the inability of the anti-inflammatory agents dexamethasone and indomethacin to demonstrate similar positive corneal effects (Fukushi et al., 1980).

Further support for a role for AR in the cornea came from the observation that similar corneal defects also occur in galactose-fed rats and that they are also prevented by the administration of ARls (Datiles et al., 1983). Subsequently, galactitol accumulation has been observed in both the corneal epithelial layer and endothelium with stroma and this accumulation was reduced by the topical ARI CT-112 (Awata et al., 1986) and the oral ARI SNK-860 (Kubo et al., 1999). These findings correlate with the immunohistochemically detected presence of AR in the epithelium and endothelium of the rat cornea (Akagi et al., 1986a). Topical CT-112 also improved corneal wound healing in galactosemic rats (Awata et al., 1988) as well as improving corneal epithelial barrier dysfunction caused by epithelial cell membrane disruption as detected by fluorescein uptake and horseradish peroxidase (HRP) penetration (Yokoi et al., 1997).

The corneal epithelium from diabetic and galactosemic rats both show that the epithelial cells have a distended appearance and an absence of filopodia that suggest that the corneal epithelial cells are osmotically altered (Fukushi et al., 1980; Piatigorsky et al., 1978). The regenerated epithelium also shows the presence of vacuoles and wide intercellular spaces. The corneal epithelium also appears thicker than normal with the basal cells of the epithelium containing considerable PAS - staining particles which have been confirmed to contain glycogen by electron microscopy. A breakdown of the basal cell membrane abutting the stroma has also been observed with the aggregation of glycogen particles in the anterior stroma. In addition to glycogen particle aggregation, glycogen-like substances that are surrounded by a thick membrane just underneath the wavy basal cell membrane have been observed. In these areas the cytoplasm of the basal cells also appears lucent and edematous. All of these histological changes have been reduced by the administration of oral ARIs that include sorbinil and AL1576 for periods of up to 17 months (Datiles et al., 1983; Fukushi et al., 1980; Mori et al., 2002).

DM changes in corneal nerve morphology and the presence of neuropathy have been documented in rats and humans (Davidson et al., 2014; Petropoulos et al., 2014). 
While numerous preclinical studies have linked AR with nerve morphological changes associated with peripheral neuropathy (Sima, 1994), no studies, to date, have been conducted on the relationship between $A R$ and corneal nerve morphology associated with loss of sensitivity. Nevertheless, the loss in corneal sensation observed in human diabetics has also been duplicated in both diabetic and galactosemic rats (Hosotani et al., 1996; Jacot et al., 1998), a loss also prevented by concomitant administration of either topical or systemic ARIs.

Corneal endothelial cells maintain corneal deturgescence required for optical transparency. Because these cells are post-mitotic and rarely divide, if at all, in the postnatal cornea, wounding of the corneal endothelium from trauma or metabolic insults prompts healing of the endothelial monolayer by sliding and enlargement of adjacent endothelial cells (polymegathism), rather than mitosis. Changes in the size and shape of corneal endothelial cells due to endothelial cell loss have been documented by specular microscopy in diabetic and galactosemic rats (Meyer et al., 1988) and dogs (Datiles et al., 1990; Yee et al., 1985) as well as diabetic humans (Cisarik-Fredenburg, 2001). Using transcorneal freezing to injure the corneal endothelium of normal and galactosemic rats, Akagi and coworkers (Akagi et al., 1986b) have demonstrated that endothelial repair was delayed in the untreated galactosemic rats and that this delay was prevented by ARI treatment. Combined with the observation that endothelial cells contain $A R$ and accumulated polyols, this is consistent with $A R$ involvement in experimental diabetic corneal endotheliopathy. The administration of topical or systemic ARIs from the onset of diabetes or galactosemia has also prevented increases in polymegathism of endothelial cells (Datiles et al., 1990; Matsuda et al., 1987; Schultz et al., 1984; Yee et al., 1985). These endothelial cell changes were also reversed by intervention with topical ARI treatment begun 8 weeks after induction of DM (Meyer et al., 1988). However, similar corneal endothelial changes were not significantly reversed in dogs when galactose-diet was replaced after 24 month of galactose feeding with 14 months of normal diet, indicating that amelioration of endothelial cell changes requires early therapy prior to the advent of significant endothelial morphologic changes (Neuenschwander et al., 1995). 


\section{Aldose Reductase Inhibitors and Human Diabetic Keratopathy Because AR has} also been localized in the epithelial and endothelial layers of the human cornea (Akagi et al., 1984) a number of studies have evaluated the potential clinical effects of ARIs on diabetic keratopathy. These began with initial findings that the topical application of sorbinil promoted corneal healing in diabetics with corneal epithelial disorders unresponsive to conventional treatment (Cogan et al., 1984). This beneficial effect was confirmed with the topical ARI CT-112 in two diabetics -- one with recurrent corneal erosion after vitrectomy and the other with spontaneous superficial punctate keratopathy. Clearing was observed within two months of treatment, but discontinuing CT-112 resulted in the reappearance of the corneal lesions. These changes again disappeared when drug was resumed (Ohashi et al., 1986; Ohashi et al., 1988). Subsequently, a randomized clinical study in diabetic patients was conducted to determine whether topically applied $0.5 \%$ CT-112 was capable of reversing both abnormal morphologic characteristics of corneal epithelial cells and reduced corneal sensitivity. Thirty-nine diabetic patients were randomly divided into two groups: one group treated for 6 months with topical CT-112 while the second control group was treated with vehicle alone. Using specular microscopy to analyze the morphologic characteristics of corneal epithelial cells before and after the treatment, the anterior surface area of superficial cells in the CT-112 treated group significantly decreased from a mean value of 881 to 728 microns $^{2}$ ( $p<0.0001$ ), while the control group showed no significant changes. Corneal sensitivity measurements, conducted using a CochetBonnet esthesiometer, were also significantly improved, decreasing from 5.36 to 1.37 $\mathrm{g} / \mathrm{mm}^{2}(\mathrm{p}<0.0001)$ in the CT-112 group while the control treated group remained unchanged. These results indicate that treatment with topical CT-112 is not only capable of reversing abnormal morphologic characteristics of corneal epithelial cells but also reducing corneal sensitivity, a form of neuropathy in diabetic patients (Hosotani et al., 1995). The ability of $0.5 \%$ CT-112 to preserve endothelial cell morphology was confirmed in a second, smaller study of 8 diabetic patients receiving CT-112 compared to 5 similar diabetic patients receiving placebo (Ohguro et al., 1995). Morphological variations of endothelial cell polymegathism and pleomorphism in 8 eyes from 8 patients 
resolved within 3 months of CT-112 treatment, while no change in endothelial morphology was noted in the 5 eyes of 5 placebo treated patients. CT-112 was also evaluated for its ability to alter corneal epithelial barrier function in a shorter, 8 week prospective, randomized, double masked placebo controlled study where 34 eyes of 34 diabetic patients were randomly assigned treatment with $0.25 \%$ topical CT-112 $(n=22)$ or a placebo $(n=12)$ (Nakahara et al., 2005). Corneal epithelial barrier measurements to fluorescein, which did not significantly differ for the CT-112 and placebo groups conducted before treatment, were significantly reduced after $4(p=0.0327)$ and $8(p=$ 0.0143 ) weeks of $0.25 \%$ CT-112 treatment. In contrast, average scores for superficial punctate keratopathy and corneal sensitivity did not significantly differ with the lower concentration of drug and the shorter time frame.

In addition to CT-112, a number of ARIs have been clinically evaluated in Japan. ARI epalrestat (Kinedak ${ }^{\circledR}$, ONO-2235), was approved in Japan and has been evaluated in a number of small trials. In fourteen aphakic or pseudophakic patients with diabetes orally administered epalrestat (150 mg/day) for 3 months, corneal sensation significantly recovered (from 4.1 to $3.0 \mathrm{~g} / \mathrm{mm}^{2} ; \mathrm{p}=0.015$ ), with parallel improvements in rose bengal and fluorescein staining scores $(p<0.05)$ (Fujishima et al., 1996). Tear break-up time also improved $(p=0.003)$. Results of Schirmer's test $(p=0.03)$ and the cotton-thread test $(p=0.0001)$ also showed significant improvement in tear production suggesting that improvement in the dynamics of tear production may be linked to an improvement in corneal sensitivity. Subsequently a small randomized, double blinded, placebo controlled study was conducted to evaluate the effect of oral administration of epalrestat on the ocular surface of diabetic patients after cataract surgery (Fujishima and Tsubota, 2002). Pseudophakic diabetics were randomly assigned to treatment with either oral epalrestat $(n=12)$ or placebo $(n=9)$ and after 12 weeks significant recovery of fluorescein staining scores (from 2.04 to $1.46 ; p=0.016$ ), conjunctival sensation (from 1.15 to 1.36; $\mathrm{p}=0.0006$ ), and symptom scores (from 5.38 to $4.00 ; \mathrm{p}=0.0002$ ) were observed. Fluorescein staining also decreased compared with placebo $(p=0.017)$. Minor improvement in rose bengal staining, tear clearance, and corneal sensation were observed but no significant changes in tear production, BUT, and specular microscopic evaluation of the corneal epithelium and endothelium were observed. 

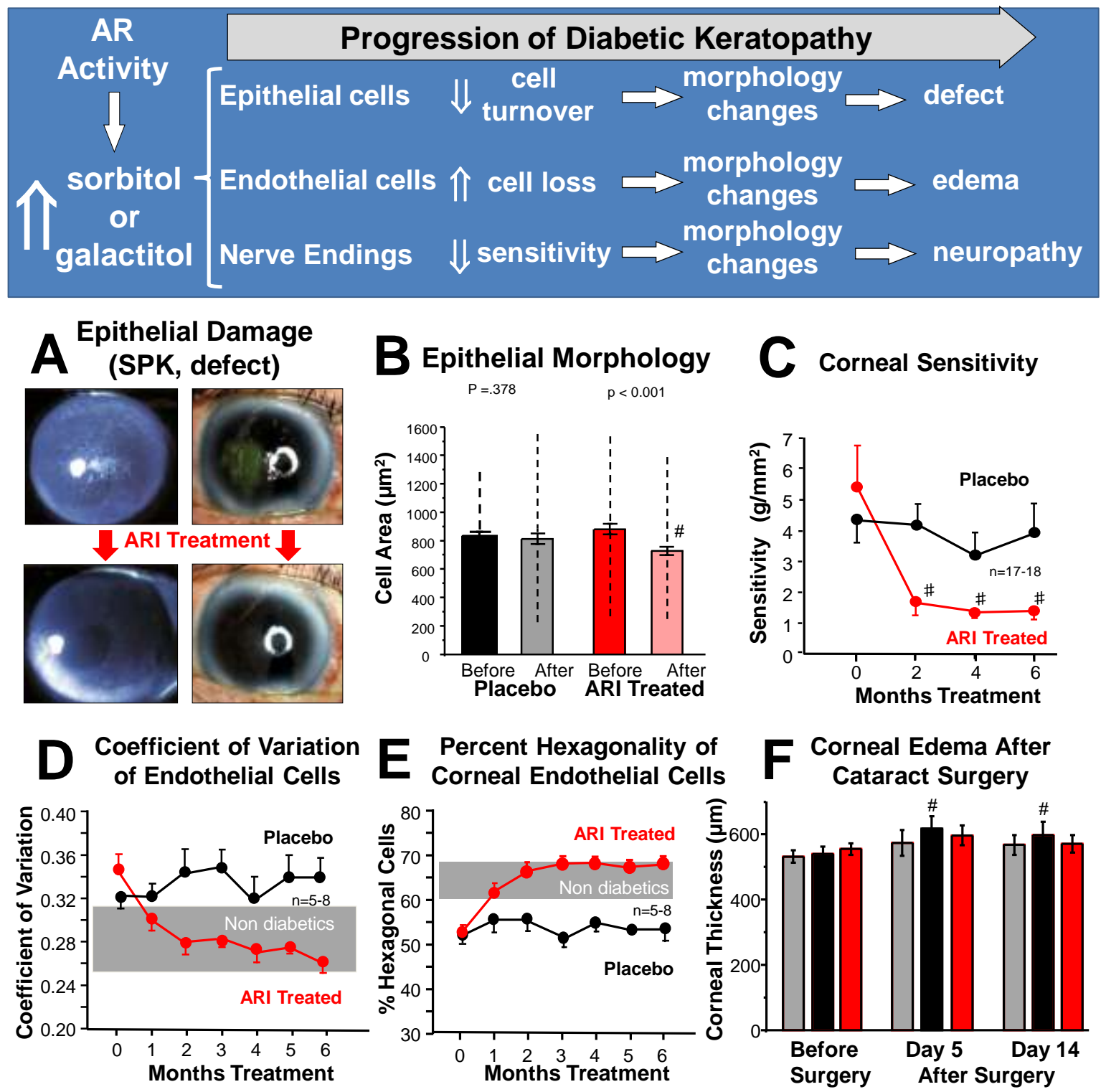

Figure 26 Diabetic corneal changes linked to AR activity include morphological changes in the epithelium and endothelium as well as nerve changes. ARIs have been clinically observed to reduce these changes. Illustrated here are the clinical effects of the ARI CT-112 which has been shown to $(\mathbf{A})$ reduce Superficial Punctate Keratitis (SPK) and surface defects (Hosotani et al., 1986) as well as (B) significantly reduce diabetes induced epithelial cell morphology measured by specular microscopy (mean \pm SE; dashed line represents range; $n=39$ patients) (Hosotani et al., 1995). (C) illustrates that CT-112 treatment resulted in significant improvement of corneal sensitivity in patients compared to placebo $(n=39$ patients $\# p<0.0001)$ (Hosotani et al., 1995). CT-112 treatment also reduced the corneal endothelial cell coefficient of variation (D) and increased the percent hexagonality (E) measured in diabetic patients by specular microscopy. (F) Persistent corneal edema observed to significantly increase in diabetics $(\# p<0,01)$ following cataract surgery was also reduced in similar patients treated with CT-112 ( $n=21)$ (Awata et al., 1990). 
Because current standard treatments regimens are often ineffective, a number of therapeutic approaches for the treatment of diabetic keratopathy are being investigated. Over the last decades these have focused on the use of various growth factors, cytokines, and opioid growth factor antagonists to aid in wound healing; however, few have translated to efficacy in humans (Abdelkader et al., 2011). In contrast, ARIs can ameliorate diabetic changes observed in the corneal epithelium, endothelium, and nerves of both animals and man. While some clinical studies have focused on uncontrolled case studies, it should be noted that several other controlled studies have demonstrated clinical efficacy of ARIs for diabetic keratopathy (Kaji, 2005).

\section{Future Directions}

The authors look forward to the pending FDA approval for Kinostat ${ }^{\circledR}$ and its use for cataract prevention in the diabetic dog population. Although the data available indicate Kinostat ${ }^{\circledR}$ is clearly clinically effective for inhibiting cataracts in diabetic dogs, at present there is not a compelling case to be made for the use of topical Kinostat ${ }^{\circledR}$ for treating diabetic retinopathy or for delaying human sugar cataract formation in adult diabetics. Nevertheless, with further efficacy and safety studies in humans, Kinostat ${ }^{\circledR}$ or a closely related product could have a future role in treating diabetic keratopathy.

\section{Acknowledgment}

This work was supported by NIH grant R91EY016730; R43EY018013-01A1; R44 EY018013-02A; R44 EY018013-2B; Nebraska SBIR Phase 2 Grant 16-01-054 


\section{References}

Abdelkader, H., Patel, D.V., McGhee, C., Alany, R.G., 2011. New therapeutic approaches in the treatment of diabetic keratopathy: a review. Clin Experiment Ophthalmol 39, 259-270.

Ai, Y., Zheng, Z., O'Brien-Jenkins, A., Bernard, D.J., Wynshaw-Boris, T., Ning, C., Reynolds, R., Segal, S., Huang, K., Stambolian, D., 2000. A mouse model of galactose-induced cataracts. Hum Mol Genet 9, 1821-1827.

Akagi, Y., Kador, P.F., Kinoshita, J.H., 1987. Immunohistochemical localization for aldose reductase in diabetic lenses. Invest Ophthalmol Vis Sci 28, 163-167.

Akagi, Y., Kador, P.F., Kuwabara, T., Kinoshita, J.H., 1983. Aldose reductase localization in human retinal mural cells. Invest Ophthalmol Vis Sci 24, 1516-1519.

Akagi, Y., Tasaka, H., Terubayashi, H., Kador, P.F., Kinoshita, J.H., 1986a. Aldose reductase localization in rat sugar cataracts. . Exerpta Medica Amsterdam.

Akagi, Y., Terubayashi, H., Ikebe, H., Kador, P.F., Kinoshita, J.H., 1986b. Repair of corneal endothelium in galactosemic rats. Exerpta Medica Amsterdam.

Akagi, Y., Terubayashi, H., Millen, J., Kador, P.F., Kinoshita, J.H., 1986c. Aldose reductase localization in dog retinal mural cells. Curr Eye Res 5, 883-886.

Akagi, Y., Yajima, Y., Kador, P.F., Kuwabara, T., Kinoshita, J.H., 1984. Localization of aldose reductase in the human eye. Diabetes 33, 562-566.

American Veterinary Medical Association, 2012. U.S. Pet Ownership and Demographics Sourcebook. American Veterinary Medical Association.

Anderson, H.R., Stitt, A.W., Gardiner, T.A., Lloyd, S.J., Archer, D.B., 1993. Induction of alloxan/streptozotocin diabetes in dogs: a revised experimental technique. Lab Anim 27, 281-285.

Antonetti, D.A., Barber, A.J., Bronson, S.K., Freeman, W.M., Gardner, T.W., Jefferson, L.S., Kester, M., Kimball, S.R., Krady, J.K., LaNoue, K.F., Norbury, C.C., Quinn, P.G., Sandirasegarane, L., Simpson, I.A., Group, J.D.R.C., 2006. Diabetic retinopathy: seeing beyond glucose-induced microvascular disease. Diabetes 55 , 2401-2411.

Antonetti, D.A., Klein, R., Gardner, T.W., 2012. Diabetic retinopathy. N Engl J Med $366,1227-1239$.

Aronson, D., 2008. Hyperglycemia and the pathobiology of diabetic complications. Adv Cardiol 45, 1-16.

Astle, W.F., Alewenah, O., Ingram, A.D., Paszuk, A., 2009. Surgical outcomes of primary foldable intraocular lens implantation in children: understanding posterior opacification and the absence of glaucoma. J Cataract Refract Surg 35, 1216-1222.

Awan, A., Saboor, T., Buchanan, L.M., 2005. Acute irreversible diabetic cataract in adolescence: a case report. Eye. 
Awata, T., Matsuda, M., Ohashi, Y., Fukuda, M., 1990. The effect of topical aldose reductase inhibitor on diabetic keratopathy. Exerpta Medica

Amsterdam.

Awata, T., Sogo, S., Yamagami, Y., Yamamoto, Y., 1988. Effect of an aldose reductase inhibitor, CT-112, on healing of the corneal epithelium in galactose-fed rats. J Ocul Pharmacol 4, 195-201.

Awata, T., Sogo, S., Yamamoto, Y., 1986. Effects of aldose reductase inhibitor, CT112 , on sugar alcohol accumulation in corneal epithelium of galactose-fed rats. Jpn J Ophthalmol 30, 245-250.

Barnett, P.A., Gonzalez, R.G., Chylack, L.T., Jr., Cheng, H.M., 1986. The effect of oxidation on sorbitol pathway kinetics. Diabetes 35, 426-432.

Beam, S., Correa, M.T., Davidson, M.G., 1999. A retrospective-cohort study on the development of cataracts in dogs with diabetes mellitus: 200 cases. Vet Ophthalmol 2, 169-172.

Bettelheim, F.A., Li, L., Zeng, F.F., 1998. Do changes in the hydration of the diabetic human lens precede cataract formation? Res Commun Mol Pathol Pharmacol 102, 3-14.

Beyer-Mears, A., Cruz, E., 1985. Reversal of diabetic cataract by sorbinil, an aldose reductase inhibitor. Diabetes 34, 15-21.

Beyer-Mears, A., Cruz, E., Varagiannis, E., 1985. Reversal of stage-I sugar cataract by Sorbinil, an aldose reductase inhibitor. Pharmacology 31, 88-96.

Beyer-Mears, A., Diecke, F.P., Mistry, K., Ellison, C., Cruz, E., 1997. Effect of pyruvate on lens myo-inositol transport and polyol formation in diabetic cataract. Pharmacology 55, 78-86.

Broadwater, J.J., Colitz, C., Carastro, S., Saville, W., 2010. Tear production in normal juvenile dogs. Vet Ophthalmol 13, 321-325.

Bron, A.J., Brown, N.A., Harding, J.J., Ganea, E., 1998. The lens and cataract in diabetes. Int Ophthalmol Clin 38, 37-67.

Bron, A.J., Sparrow, J., Brown, N.A., Harding, J.J., Blakytny, R., 1993. The lens in diabetes. Eye 7 ( Pt 2), 260-275.

Brown, M.J., Bird, S.J., Watling, S., Kaleta, H., Hayes, L., Eckert, S., Foyt, H.L., Zenarest, s., 2004. Natural progression of diabetic peripheral neuropathy in the Zenarestat study population. Diabetes Care 27, 1153-1159.

Buzney, S.M., Frank, R.N., Varma, S.D., Tanishima, T., Gabbay, K.H., 1977. Aldose reductase in retinal mural cells. Invest Ophthalmol Vis Sci 16, 392-396.

Cameron, N.E., Cotter, M.A., Dines, K.C., Maxfield, E.K., Carey, F., Mirrlees, D.J., 1994. Aldose reductase inhibition, nerve perfusion, oxygenation and function in streptozotocin-diabetic rats: dose-response considerations and independence from a myo-inositol mechanism. Diabetologia 37, 651-663. 
Catchpole, B., 2007. Canine diabetes mellitus, Society for Endocrinology BES 2007, . Endocrine Abstracts Birmingham, UK

p. S35.

Cheng, H.M., Gonzalez, R.G., 1986. The effect of high glucose and oxidative stress on lens metabolism, aldose reductase, and senile cataractogenesis. Metabolism 35, 1014.

Cheng, H.M., Gonzalez, R.G., Barnett, P.A., Aguayo, J.B., Wolfe, J., Chylack, L.T., Jr., 1985. Sorbitol/fructose metabolism in the lens. Exp Eye Res 40, 223-229.

Cheung, A.K., Fung, M.K., Lo, A.C., Lam, T.T., So, K.F., Chung, S.S., Chung, S.K., 2005. Aldose reductase deficiency prevents diabetes-induced blood-retinal barrier breakdown, apoptosis, and glial reactivation in the retina of $\mathrm{db} / \mathrm{db}$ mice. Diabetes 54 , 3119-3125.

Chiou, G.C., 1994. Systemic delivery of polypeptide drugs through ocular route. J Ocul Pharmacol 10, 93-99.

Chiou, S.H., Chylack, L.T., Jr., Bunn, H.F., Kinoshita, J.H., 1980. Role of nonenzymatic glycosylation in experimental cataract formation. Biochem Biophys Res Commun 95, 894-901.

Chylack, L.T., Jr., Henriques, H.F., 3rd, Cheng, H.M., Tung, W.H., 1979. Efficacy of Alrestatin, an aldose reductase inhibitor, in human diabetic and nondiabetic lenses. Ophthalmology 86, 1579-1585.

Chylack, L.T., Jr., Kinoshita, J.H., 1969. A biochemical evaluation of a cataract induced in a high-glucose medium. Invest Ophthalmol 8, 401-412.

Chylack, L.T., Jr., Tung, W., Harding, R., 1986. Sorbitol production in the lens: a means of counteracting glucose-derived osmotic stress. Ophthalmic Res 18, 313320.

Cisarik-Fredenburg, P., 2001. Discoveries in research on diabetic keratopathy. Optometry 72, 691-704.

Cogan, D.G., Kinoshita, J.H., Kador, P.F., Robison, G., Datilis, M.B., Cobo, L.M., Kupfer, C., 1984. NIH conference. Aldose reductase and complications of diabetes. Ann Intern Med 101, 82-91.

Cogan, D.G., Kuwabara, T., 1967. The mural cell in perspective. Archives of ophthalmology 78, 133-139.

Cusick, M., Chew, E.Y., Ferris, F., 3rd, Cox, T.A., Chan, C.C., Kador, P.F., 2003. Effects of aldose reductase inhibitors and galactose withdrawal on fluorescein angiographic lesions in galactose-fed dogs. Archives of ophthalmology 121, 17451751.

Dabelea, D., 2009. The accelerating epidemic of childhood diabetes. Lancet 373, 1999-2000. 
Dabelea, D., Bell, R.A., D'Agostino, R.B., Jr., Imperatore, G., Johansen, J.M., Linder, B., Liu, L.L., Loots, B., Marcovina, S., Mayer-Davis, E.J., Pettitt, D.J., Waitzfelder, B., 2007. Incidence of diabetes in youth in the United States. JAMA 297, 2716-2724.

Datiles, M.B., Kador, P.F., Fukui, H.N., Hu, T.S., Kinoshita, J.H., 1983. Corneal reepithelialization in galactosemic rats. Invest Ophthalmol Vis Sci 24, 563-569.

Datiles, M.B., Kador, P.F., Kashima, K., Kinoshita, J.H., Sinha, A., 1990. The effects of sorbinil, an aldose reductase inhibitor, on the corneal endothelium in galactosemic dogs. Invest Ophthalmol Vis Sci 31, 2201-2204.

Datta, V., Swift, P.G., Woodruff, G.H., Harris, R.F., 1997. Metabolic cataracts in newly diagnosed diabetes. Arch Dis Child 76, 118-120.

Davidson, E.P., Coppey, L.J., Holmes, A., Lupachyk, S., Dake, B.L., Oltman, C.L., Peterson, R.G., Yorek, M.A., 2014. Characterization of diabetic neuropathy in the Zucker diabetic Sprague-Dawley rat: a new animal model for type 2 diabetes. Journal of diabetes research 2014, 714273.

Demaine, A., Cross, D., Millward, A., 2000. Polymorphisms of the aldose reductase gene and susceptibility to retinopathy in type 1 diabetes mellitus. Invest Ophthalmol Vis Sci 41, 4064-4068.

Demaine, A.G., 2003. Polymorphisms of the aldose reductase gene and susceptibility to diabetic microvascular complications. Curr Med Chem 10, 1389-1398.

Diabetes Complications Control Group, 1995. Progression of retinopathy with intensive versus conventional treatment in the Diabetes Control and Complications Trial. Diabetes Control and Complications Trial Research Group. Ophthalmology 102, 647-661.

dos Santos, K.G., Canani, L.H., Gross, J.L., Tschiedel, B., Souto, K.E., Roisenberg, I., 2006. The -106CC genotype of the aldose reductase gene is associated with an increased risk of proliferative diabetic retinopathy in Caucasian-Brazilians with type 2 diabetes. Mol Genet Metab 88, 280-284.

Engerman, R., Bloodworth, J.M., Jr., Nelson, S., 1977. Relationship of microvascular disease in diabetes to metabolic control. Diabetes 26, 760-769.

Engerman, R.L., Bloodworth, J.M., Jr., 1965. Experimental Diabetic Retinopathy in Dogs. Archives of ophthalmology 73, 205-210.

Engerman, R.L., Kern, T.S., 1984. Experimental galactosemia produces diabetic-like retinopathy. Diabetes 33, 97-100.

Engerman, R.L., Kern, T.S., 1995. Retinopathy in galactosemic dogs continues to progress after cessation of galactosemia. Arch Ophthalmol 113, 355-358.

Esteves, J.F., Dal Pizzol, M.M., Sccoco, C.A., Roggia, M.F., Milano, S.B., Guarienti, J.A., Rodrigues, T.C., Canani, L.H., 2008. Cataract and type 1 diabetes mellitus. Diabetes Res Clin Pract 82, 324-328. 
Feman, S.S., Leonard-Martin, T.C., Redman, J.R., 1996. The Vanderbilt Classification System in the evaluation of diabetic retinopathy patients treated with Alredase. Trans Am Ophthalmol Soc 94, 433-447; discussion 447-450.

Ferris III, F.L., 2005. Emerging therapies for diabetic retinopathy. Johns Hopkins Advanced Studies in Ophthalmology 2, 26030.

Florkowski, A.R., Golden, R., Sooch, Y., Krishna, R., 2005. Sudden bilateral visual loss in a diabetic man. Am J Med Sci 329, 99-101.

Florys, B., Oldytowska, A., Glowinska, B., Peczynska, J., Urban, M., 2004. [Prevalence of chronic diabetes complications depending on the method of insulin therapy in children and adolescents with type 1 diabetes]. Endokrynol Diabetol Chor Przemiany Materii Wieku Rozw 10, 31-39.

Foulks, G.N., Thoft, R.A., Perry, H.D., Tolentino, F.I., 1979. Factors related to corneal epithelial complications after closed vitrectomy in diabetics. Arch Ophthalmol 97, 1076-1078.

Frank, R.N., Keirn, R.J., Kennedy, A., Frank, K.W., 1983. Galactose-induced retinal capillary basement membrane thickening: prevention by Sorbinil. Invest Ophthalmol Vis Sci 24, 1519-1524.

Friedenwald, J.S., Rytel, D., 1955. Contributions to histopathology of cataract. Arch. Ophthalmol. 53, 825-831.

Fujisawa, T., Ikegami, H., Kawaguchi, Y., Yamato, E., Nakagawa, Y., Shen, G.Q., Fukuda, M., Ogihara, T., 1999. Length rather than a specific allele of dinucleotide repeat in the $5^{\prime}$ upstream region of the aldose reductase gene is associated with diabetic retinopathy. Diabet Med 16, 1044-1047.

Fujishima, H., Shimazaki, J., Yagi, Y., Tsubota, K., 1996. Improvement of corneal sensation and tear dynamics in diabetic patients by oral aldose reductase inhibitor, ONO-2235: a preliminary study. Cornea 15, 368-375.

Fujishima, H., Tsubota, K., 2002. Improvement of corneal fluorescein staining in post cataract surgery of diabetic patients by an oral aldose reductase inhibitor, ONO2235. Br J Ophthalmol 86, 860-863.

Fukushi, S., Merola, L.O., Tanaka, M., Datiles, M., Kinoshita, J.H., 1980. Reepithelialization of denuded corneas in diabetic rats. Exp Eye Res 31, 611-621.

Gelatt, K.N., 1975. Spontaneous cataract resorption and lens-induced uveitis in the dog. Mod Vet Pract 56, 331-335.

Gella, L., Raman, R., Pal, S.S., Ganesan, S., Sharma, T., 2015. Incidence, Progression, and Associated Risk Factors of Posterior Vitreous Detachment in Type 2 Diabetes Mellitus: Sankara Nethralaya Diabetic Retinopathy Epidemiology and Molecular Genetic Study (SN-DREAMS II, Report No. 7). Semin Ophthalmol, 1-7.

Gelvin, J.B., Thonn, V.A., 1993. The formation and reversal of acute cataracts in diabetes mellitus. J Am Optom Assoc 64, 471-474. 
Geraldes, P., King, G.L., 2010. Activation of protein kinase C isoforms and its impact on diabetic complications. Circ Res 106, 1319-1331.

Giacco, F., Du, X., Carratu, A., Gerfen, G.J., D'Apolito, M., Giardino, I., Rasola, A., Marin, O., Divakaruni, A.S., Murphy, A.N., Shah, M.S., Brownlee, M., 2015. GLP-1 Cleavage Product Reverses Persistent ROS Generation After Transient Hyperglycemia by Disrupting an ROS-Generating Feedback Loop. Diabetes 64, 3273-3284.

Greene, D.A., Arezzo, J.C., Brown, M.B., 1999. Effect of aldose reductase inhibition on nerve conduction and morphometry in diabetic neuropathy. Zenarestat Study Group. Neurology 53, 580-591.

Grossniklaus, H.E., Kang, S.J., Berglin, L., 2010. Animal models of choroidal and retinal neovascularization. Prog Retin Eye Res 29, 500-519.

Guo, C., Zhang, Z., Zhang, P., Makita, J., Kawada, H., Blessing, K., Kador, P.F., 2014. Novel transgenic mouse models develop retinal changes associated with early diabetic retinopathy similar to those observed in rats with diabetes mellitus. Exp Eye Res 119, 77-87.

Guptill, L., Glickman, L., Glickman, N., 2003. Time trends and risk factors for diabetes mellitus in dogs: analysis of veterinary medical data base records (1970-1999). Vet J 165, 240-247.

Haddad, N.M., Sun, J.K., Abujaber, S., Schlossman, D.K., Silva, P.S., 2014. Cataract surgery and its complications in diabetic patients. Semin Ophthalmol 29, 329-337.

Hamada, Y., Araki, N., Horiuchi, S., Hotta, N., 1996. Role of polyol pathway in nonenzymatic glycation. Nephrol Dial Transplant 11 Suppl 5, 95-98.

Harding, J.J., 1992. Pharmacological treatment strategies in age-related cataracts. Drugs Aging 2, 287-300.

Hasuike, Y., Nakanishi, T., Otaki, Y., Nanami, M., Tanimoto, T., Taniguchi, N., Y., Y.T., 2002. Plasma 3-deoxyglucosone elevation in chronic renal failure is associated with increased aldose reductase in erythrocytes. Am J Kidney Dis 40, 464-471.

Hathout, E.H., Hartwick, N., Fagoaga, O.R., Colacino, A.R., Sharkey, J., Racine, M., Nelsen-Cannarella, S., Mace, J.W., 2003. Clinical, autoimmune, and HLA characteristics of children diagnosed with type 1 diabetes before 5 years of age. Pediatrics 111, 860-863.

Heesom, A.E., Hibberd, M.L., Millward, A., Demaine, A.G., 1997. Polymorphism in the 5 '-end of the aldose reductase gene is strongly associated with the development of diabetic nephropathy in type I diabetes. Diabetes 46, 287-291.

Ho, E.C., Lam, K.S., Chen, Y.S., Yip, J.C., Arvindakshan, M., Yamagishi, S., Yagihashi, S., Oates, P.J., Ellery, C.A., Chung, S.S., Chung, S.K., 2006. Aldose reductase-deficient mice are protected from delayed motor nerve conduction velocity, increased c-Jun $\mathrm{NH} 2$-terminal kinase activation, depletion of reduced glutathione, increased superoxide accumulation, and DNA damage. Diabetes 55, 1946-1953. 
Hohman, T.C., Nishimura, C., Robison, W.G., Jr., 1989. Aldose reductase and polyol in cultured pericytes of human retinal capillaries. Exp Eye Res 48, 55-60.

Hosotani, H., Ohashi, Y., Kinoshita, S., Matsumoto, T., Awata, T., 1996. Effects of topical aldose reductase inhibitor CT-112 on corneal sensitivity of diabetic rats. Curr Eye Res 15, 1005-1007.

Hosotani, H., Ohashi, Y., Yamada, M., Tsubota, K., 1995. Reversal of abnormal corneal epithelial cell morphologic characteristics and reduced corneal sensitivity in diabetic patients by aldose reductase inhibitor, CT-112. Am J Ophthalmol 119, 288294.

Hosotani, H., Tano, Y., Tamada, R., 1986. Treatment of diabetic keratopathy with a topical aldose reductase inhibitor. olia Japonica de Ophthalmologica Clinica 37, 1359-1365. .

Hu, T.S., Datiles, M., Kinoshita, J.H., 1983. Reversal of galactose cataract with Sorbinil in rats. Invest Ophthalmol Vis Sci 24, 640-644.

Hussin, H.M., Markham, R., 2009. Long-term visual function outcomes of congenital cataract surgery with intraocular lens implantation in children under 5 years of age. Eur J Ophthalmol 19, 754-761.

Ibaraki, N., Chen, S.C., Lin, L.R., Okamoto, H., Pipas, J.M., Reddy, V.N., 1998. Human lens epithelial cell line. Exp Eye Res 67, 577-585.

Ichikawa, F., Yamada, K., Ishiyama-Shigemoto, S., Yuan, X., Nonaka, K., 1999. Association of an (A-C)n dinucleotide repeat polymorphic marker at the 5'-region of the aldose reductase gene with retinopathy but not with nephropathy or neuropathy in Japanese patients with Type 2 diabetes mellitus. Diabet Med 16, 744-748.

Ikegishi, Y., Tawata, M., Aida, K., Onaya, T., 1999. Z-4 allele upstream of the aldose reductase gene is associated with proliferative retinopathy in Japanese patients with NIDDM, and elevated luciferase gene transcription in vitro. Life Sci 65, 2061-2070.

Jacot, J.L., Hosotani, H., Glover, J.P., Lois, N., Robison, W.G., Jr., 1998. Diabetic-like corneal sensitivity loss in galactose-fed rats ameliorated with aldose reductase inhibitors. J Ocul Pharmacol Ther 14, 169-180.

Jedziniak, J.A., Chylack, L.T., Jr., Cheng, H.M., Gillis, M.K., Kalustian, A.A., Tung, W.H., 1981. The sorbitol pathway in the human lens: aldose reductase and polyol dehydrogenase. Invest Ophthalmol Vis Sci 20, 314-326.

Jha, J.C., Gray, S.P., Barit, D., Okabe, J., El-Osta, A., Namikoshi, T., Thallas-Bonke, V., Wingler, K., Szyndralewiez, C., Heitz, F., Touyz, R.M., Cooper, M.E., Schmidt, H.H., Jandeleit-Dahm, K.A., 2014. Genetic targeting or pharmacologic inhibition of NADPH oxidase nox4 provides renoprotection in long-term diabetic nephropathy. $J$ Am Soc Nephrol 25, 1237-1254.

Kador, P.F., 1990. Prevention of Ocular Diabetic Complications by Aldose Reductase Inhibitors. Swiss Pharma. 12, 33-38. 
Kador, P.F., 2007. Ocular Pathology of Diabetes Mellitus, in: Tasman, W., Jaeger, E. (Eds.), Duane's Ophthalmology. Wolters Kluwer / Lippicott Williams and Wilkins, Philadelphia, pp. 1-84.

Kador, P.F., 2010. Diabetes-associated cataracts. Saunders Elsevier.

Kador, P.F., Akagi, Y., Kinoshita, J.H., 1986. The effect of aldose reductase and its inhibition on sugar cataract formation. Metabolism 35, 15-19.

Kador, P.F., Akagi, Y., Takahashi, Y., Ikebe, H., Wyman, M., Kinoshita, J.H., 1990a. Prevention of retinal vessel changes associated with diabetic retinopathy in galactose-fed dogs by aldose reductase inhibitors. Archives of ophthalmology 108, 1301-1309.

Kador, P.F., Akagi, Y., Terubayashi, H., Wyman, M., Kinoshita, J.H., 1988. Prevention of pericyte ghost formation in retinal capillaries of galactose-fed dogs by aldose reductase inhibitors. Archives of ophthalmology 106, 1099-1102.

Kador, P.F., Betts, D., Wyman, M., Blessing, K., Randazzo, J., 2006. Effects of topical administration of an aldose reductase inhibitor on cataract formation in dogs fed a diet high in galactose. Am J Vet Res 67, 1783-1787.

Kador, P.F., J.S, Z., Clark, J., Datiles, M.i.D.s.O.T.W.a.J.E., ed.) on DVD-ROM, Philadelphia: Lippincott Williams \& Wilkins, 2010., 2010a. Medical Treatment of Cataracts. Lippincott Williams \& Wilkins,, Philadelphia.

Kador, P.F., Kinoshita, J.H., 1984. Diabetic and galactosaemic cataracts. Ciba Found Symp 106, 110-131.

Kador, P.F., Lee, J.W., Fujisawa, S., Blessing, K., Lou, M.F., 2000. Relative importance of aldose reductase versus nonenzymatic glycosylation on sugar cataract formation in diabetic rats. J Ocul Pharmacol Ther 16, 149-160.

Kador, P.F., Randazzo, J., Babb, T., Koushik, K., Takamura, Y., Zhu, W., Blessing, K., Kompella, U.B., 2007a. Topical aldose reductase inhibitor formulations for effective lens drug delivery in a rat model for sugar cataracts. J Ocul Pharmacol Ther 23, 116123.

Kador, P.F., Takahashi, Y., Akagi, Y., Blessing, K., Randazzo, J., Wyman, M., 2007b. Age-dependent retinal capillary pericyte degeneration in galactose-fed dogs. J Ocul Pharmacol Ther 23, 63-69.

Kador, P.F., Takahashi, Y., Akagi, Y., Neuenschwander, H., Greentree, W., Lackner, P., Blessing, K., Wyman, M., 2002. Effect of galactose diet removal on the progression of retinal vessel changes in galactose-fed dogs. Invest Ophthalmol Vis Sci 43, 1916-1921.

Kador, P.F., Takahashi, Y., Sato, S., Wyman, M., 1994. Amelioration of diabetes-like retinal changes in galactose-fed dogs. Prev Med 23, 717-721.

Kador, P.F., Takahashi, Y., Wyman, M., Ferris, F., 3rd, 1995. Diabeteslike proliferative retinal changes in galactose-fed dogs. Archives of ophthalmology 113, 352-354. 
Kador, P.F., Takahashi, Y., Wyman, M., J.H., K., 1990b. The role of aldose reductase in retinal vessel changes associated with diabetic retinopathy in galactose-fed dogs. , National Eye Institute - Juvenile Diabetes Foundation Workshop on Aldose Reductase Inhibitors. Department of Health and Human Services, Bethesda, MD, pp. 75-107.

Kador, P.F., Webb, T.R., Bras, D., Ketring, K., Wyman, M., 2010b. Topical KINOSTAT ameliorates the clinical development and progression of cataracts in dogs with diabetes mellitus. Vet Ophthalmol 13, 363-368.

Kador, P.F., Zhang, P., Makita, J., Zhang, Z., Guo, C., Randazzo, J., Kawada, H., Haider, N., Blessing, K., 2012. Novel diabetic mouse models as tools for investigating diabetic retinopathy. PLoS One 7, e49422.

Kaji, Y., 2005. Prevention of diabetic keratopathy. Br J Ophthalmol 89, 254-255.

Kandarakis, S.A., Piperi, C., Topouzis, F., Papavassiliou, A.G., 2014. Emerging role of advanced glycation-end products (AGEs) in the pathobiology of eye diseases. Prog Retin Eye Res 42, 85-102.

Kao, Y.L., Donaghue, K., Chan, A., Knight, J., Silink, M., 1999. An aldose reductase intragenic polymorphism associated with diabetic retinopathy. Diabetes Res Clin Pract 46, 155-160.

Karampatakis, V., Karamitsos, A., Skriapa, A., Pastiadis, G., 2010. Comparison between normal values of 2- and 5-minute Schirmer test without anesthesia. Cornea 29, 497-501.

Kennedy, A., Frank, R.N., Varma, S.D., 1983. Aldose reductase activity in retinal and cerebral microvessels and cultured vascular cells. Invest Ophthalmol Vis Sci 24, 1250-1258.

Kern, T.S., 1990. Dog model for diabetic retinopathy and nephropathy. , National Eye Institute - Juvenile Diabetes Foundation Workshop on Aldose Reductase Inhibitors. Department of Health and Human Services, Bethesda, MD, pp. 65-72.

Kern, T.S., Engerman, R.L., 1991. Retinal polyol and myo-inositol in galactosemic dogs given an aldose-reductase inhibitor. Invest Ophthalmol Vis Sci 32, 3175-3177.

Kern, T.S., Tang, J., Berkowitz, B.A., 2010. Validation of structural and functional lesions of diabetic retinopathy in mice. Mol Vis 16, 2121-2131.

Kinoshita, J.H., 1965. Cataracts in galactosemia. The Jonas S. Friedenwald Memorial Lecture. Invest Ophthalmol 4, 786-799.

Kinoshita, J.H., 1974. Mechanisms initiating cataract formation. Proctor Lecture. Invest Ophthalmol 13, 713-724.

Kinoshita, J.H., 1986. Aldose reductase in the diabetic eye. XLIII Edward Jackson memorial lecture. Am J Ophthalmol 102, 685-692.

Kinoshita, J.H., Barber, G.W., Merola, L.O., Tung, B., 1969. Changes in the levels of free amino acids and myo-inositol in the galactose-exposed lens. Invest Ophthalmol $8,625-632$. 
Kinoshita, J.H., Fukushi, S., Kador, P., Merola, L.O., 1979. Aldose reductase in diabetic complications of the eye. Metabolism 28, 462-469.

Kinoshita, J.H., Futterman, S., Satoh, K., Merola, L.O., 1963. Factors Affecting the Formation of Sugar Alcohols in Ocular Lens. Biochim Biophys Acta 74, 340-350.

Kinoshita, J.H., Kador, P., Datiles, M., 1981. Aldose reductase in diabetic cataracts. Jama 246, 257-261.

Kinoshita, J.H., Merola, L.O., Hayman, S., 1965. Osmotic Effects on the Amino AcidConcentrating Mechanism in the Rabbit Lens. J Biol Chem 240, 310-315.

Kinoshita, J.H., Merola, L.O., Tung, B., 1968. Changes in cation permeability in the galactose--exposed rabbit lens. Exp Eye Res 7, 80-90.

Klein, H.E., Krohne, S.G., Moore, G.E., Stiles, J., 2011. Postoperative complications and visual outcomes of phacoemulsification in 103 dogs (179 eyes): 2006-2008. Vet Ophthalmol 14, 114-120.

Ko, B.C., Lam, K.S., Wat, N.M., Chung, S.S., 1995. An (A-C)n dinucleotide repeat polymorphic marker at the $5^{\prime}$ end of the aldose reductase gene is associated with early-onset diabetic retinopathy in NIDDM patients. Diabetes 44, 727-732.

Kowluru, R.A., Zhong, Q., Kanwar, M., 2010. Metabolic memory and diabetic retinopathy: role of inflammatory mediators in retinal pericytes. Exp Eye Res 90, 617-623.

Kubo, E., Nakamura, S., Tsuzuki, S., Takahashi, Y., Akagi, Y., Mizuno, K., Matsubara, A., 1999. Inhibitory effect of orally administered aldose reductase inhibitor SNK-860 on corneal polyol accumulation in galactose-fed rats. Graefes Arch Clin Exp Ophthalmol 237, 758-762.

Kubo, E., Urakami, T., Fatma, N., Akagi, Y., Singh, D.P., 2004. Polyol pathwaydependent osmotic and oxidative stresses in aldose reductase-mediated apoptosis in human lens epithelial cells: role of AOP2. Biochem Biophys Res Commun 314, 1050-1056.

Kumamoto, Y., Takamura, Y., Kubo, E., Tsuzuki, S., Akagi, Y., 2007. Epithelial cell density in cataractous lenses of patients with diabetes: association with erythrocyte aldose reductase. Exp Eye Res 85, 393-399.

Kumaramanickavel, G., Sripriya, S., Ramprasad, V.L., Upadyay, N.K., Paul, P.G., Sharma, T., 2003. Z-2 aldose reductase allele and diabetic retinopathy in India. Ophthalmic Genet 24, 41-48.

Kuwabara, T., Kinoshita, J.H., Cogan, D.G., 1969. Electron microscopic study of galactose-induced cataract. Invest Ophthalmol 8, 133-149.

Lackner, P.A., Rodriguez, L., Sato, S., Lizak, M.J., Wyman, M., Kador, P.F., 1997. Age-dependent lens changes in galactose-fed dogs. Exp Eye Res 64, 431-436.

Lang-Muritano, M., La Roche, G.R., Stevens, J.L., Gloor, B.R., Schoenle, E.J., 1995. Acute cataracts in newly diagnosed IDDM in five children and adolescents. Diabetes Care 18, 1395-1396. 
Lee, A.Y., Chung, S.K., Chung, S.S., 1995. Demonstration that polyol accumulation is responsible for diabetic cataract by the use of transgenic mice expressing the aldose reductase gene in the lens. Proc Natl Acad Sci U S A 92, 2780-2784.

Lee, A.Y., Chung, S.S., 1999. Contributions of polyol pathway to oxidative stress in diabetic cataract. FASEB J 13, 23-30.

Lee, S.C., Wang, Y., Ko, G.T., Critchley, J.A., Ng, M.C., Tong, P.C., Cockram, C.S., Chan, J.C., 2001a. Association of retinopathy with a microsatellite at $5^{\prime}$ end of the aldose reductase gene in Chinese patients with late-onset Type 2 diabetes. Ophthalmic Genet 22, 63-67.

Lee, S.C., Wang, Y., Ko, G.T., Ma, R.C., Critchley, J.A., Cockram, C.S., Chan, J.C., 2001b. Risk factors for cataract in Chinese patients with type 2 diabetes: evidence for the influence of the aldose reductase gene. Clin Genet 59, 356-359.

Lerman, S., Moran, M., 1988. Sorbitol generation and its inhibition by Sorbinil in the aging normal human and rabbit lens and human diabetic cataracts. Ophthalmic Res 20, 348-352.

Lim, C.C., Bakker, S.C., Waldner, C.L., Sandmeyer, L.S., Grahn, B.H., 2011. Cataracts in 44 dogs (77 eyes): A comparison of outcomes for no treatment, topical medical management, or phacoemulsification with intraocular lens implantation. Can Vet $J$ 52, 283-288.

Lizak, M.J., Mori, K., Ceckler, T.L., Balaban, R.S., Kador, P.F., 1996. Quantitation of galactosemic cataracts in dogs using magnetization transfer contrast-enhanced magnetic resonance imaging. Invest Ophthalmol Vis Sci 37, 2219-2227.

Lizak, M.J., Secchi, E.F., Lee, J.W., Sato, S., Kubo, E., Akagi, Y., Kador, P.F., 1998. 3$\mathrm{FG}$ as substrate for investigating flux through the polyol pathway in dog lens by $19 \mathrm{~F}-$ NMR spectroscopy. Invest Ophthalmol Vis Sci 39, 2688-2695.

Lorenzi M, PJ, O., 2008 The polyol pathway and diabetic retinopathy, in: E, D. (Ed.), Diabetic retinopathy. Totowa, NJ,, Totowa, NJ,, pp. 159-186.

Malone, J.I., Leavengood, H., Peterson, M.J., O'Brien, M.M., Page, M.G., Aldinger, C.E., 1984. Red blood cell sorbitol as an indicator of polyol pathway activity. Inhibition by sorbinil in insulin-dependent diabetic subjects. Diabetes 33, 45-49.

Maret, W., Auld, D.S., 1988. Purification and characterization of human liver sorbitol dehydrogenase. Biochemistry 27, 1622-1628.

Marmor, M., Willeberg, P., Glickman, L.T., Priester, W.A., Cypess, R.H., Hurvitz, A.I., 1982. Epizootiologic patterns of diabetes mellitus in dogs. Am J Vet Res 43, 465470.

Mathew, B., 2010. Worldwide Prevalence of Diabetes, healthguideinfo.com.

Matsuda, M., Awata, T., Ohashi, Y., Inaba, M., Fukuda, M., Manabe, R., 1987. The effects of aldose reductase inhibitor on the corneal endothelial morphology in diabetic rats. Curr Eye Res 6, 391-397. 
Meyer, L.A., Ubels, J.L., Edelhauser, H.F., 1988. Corneal endothelial morphology in the rat. Effects of aging, diabetes, and topical aldose reductase inhibitor treatment. Invest Ophthalmol Vis Sci 29, 940-948.

Miyamoto, N., de Kozak, Y., Jeanny, J.C., Glotin, A., Mascarelli, F., Massin, P., BenEzra, D., Behar-Cohen, F., 2007. Placental growth factor-1 and epithelial haemato-retinal barrier breakdown: potential implication in the pathogenesis of diabetic retinopathy. Diabetologia 50, 461-470.

Miyazawa, T., Kubo, E., Takamura, Y., Akagi, Y., 2007. Up-regulation of P-glycoprotein expression by osmotic stress in rat sugar cataract. Exp Eye Res 84, 246-253.

Mizuno, A., Toshima, S., Mori, Y., 1990. Confirmation of lens hydration by Raman spectroscopy. Exp Eye Res 50, 647-649.

Mori, K., Lizak, M.J., Ceckler, T.L., Balaban, R.S., Kador, P.F., 1995. Magnetic resonance imaging of the galactosemic dog eye using magnetization transfer contrast. Curr Eye Res 14, 1035-1040.

Mori, K., Takahashi Y., Akagi, Y., Kador, P.F., 2002. Effects of aldose reductase inhibitors on galactose-induced changes in corneal epithelium basal cells and basement membrane: A quantitative analysis on long-term galactose-fed rat corneas, in: Patil, P.N., Puri, V.N. (Eds.), Frontiers of Ocular Pharmacology and Therapeutic. Allied Publishers PVT Limited, New Dehli.

Mulhern, M.L., Madson, C.J., Danford, A., Ikesugi, K., Kador, P.F., Shinohara, T., 2006. The unfolded protein response in lens epithelial cells from galactosemic rat lenses. Invest Ophthalmol Vis Sci 47, 3951-3959.

Mulhern, M.L., Madson, C.J., Kador, P.F., Randazzo, J., Shinohara, T., 2007. Cellular osmolytes reduce lens epithelial cell death and alleviate cataract formation in galactosemic rats. Mol Vis 13, 1397-1405.

Murata, M., Ohta, N., Fujisawa, S., Tsai, J.Y., Sato, S., Akagi, Y., Takahashi, Y., Neuenschwander, H., Kador, P.F., 2002. Selective pericyte degeneration in the retinal capillaries of galactose-fed dogs results from apoptosis linked to aldose reductase-catalyzed galactitol accumulation. J Diabetes Complications 16, 363-370.

Murata, M., Ohta, N., Sakurai, S., Alam, S., Tsai, J., Kador, P.F., Sato, S., 2001. The role of aldose reductase in sugar cataract formation: aldose reductase plays a key role in lens epithelial cell death (apoptosis). Chem Biol Interact 130-132, 617-625.

Nakahara, M., Miyata, K., Otani, S., Miyai, T., Nejima, R., Yamagami, S., Amano, S., 2005. A randomised, placebo controlled clinical trial of the aldose reductase inhibitor CT-112 as management of corneal epithelial disorders in diabetic patients. $\mathrm{Br} \mathrm{J}$ Ophthalmol 89, 266-268.

Neuenschwander, H., Julia, C., Wyman, M., Kador, P.F., 1995. Endothelial changes in galactose-fed dogs. Curr Eye Res 14, 319-322.

Neuenschwander, H., Takahashi, Y., Kador, P.F., 1997. Dose-dependent reduction of retinal vessel changes associated with diabetic retinopathy in galactose-fed dogs by the aldose reductase inhibitor M79175. J Ocul Pharmacol Ther 13, 517-528. 
Nischal, K.F., 2009. Personal communication on surgery on galactosemic children., in: Kador, P.F. (Ed.).

Nishikawa, T., Edelstein, D., Du, X.L., Yamagishi, S., Matsumura, T., Kaneda, Y., Yorek, M.A., Beebe, D., Oates, P.J., Hammes, H.P., Giardino, I., Brownlee, M., 2000. Normalizing mitochondrial superoxide production blocks three pathways of hyperglycaemic damage. Nature 404, 787-790.

O'Brien, P.D., Hinder, L.M., Sakowski, S.A., Feldman, E.L., 2014. ER stress in diabetic peripheral neuropathy: A new therapeutic target. Antioxid Redox Signal 21, 621-633.

Oates, P.J., 2002. Polyol pathway and diabetic peripheral neuropathy. Int Rev Neurobiol 50, 325-392.

Oates, P.J., 2008. Aldose reductase, still a compelling target for diabetic neuropathy. Curr Drug Targets 9, 14-36.

Oates, P.J., Mylari, B.L., 1999. Aldose reductase inhibitors: therapeutic implications for diabetic complications. Expert Opin Investig Drugs 8, 2095-2119.

Obazawa, H., Merola, L.O., Kinoshita, J.H., 1974. The effects of xylose on the isolated lens. Invest Ophthalmol 13, 204-209.

Obrosova, I., Cao, X., Greene, D.A., Stevens, M.J., 1998. Diabetes-induced changes in lens antioxidant status, glucose utilization and energy metabolism: effect of DLalpha-lipoic acid. Diabetologia 41, 1442-1450.

Obrosova, I., Faller, A., Burgan, J., Ostrow, E., Williamson, J.R., 1997. Glycolytic pathway, redox state of $\mathrm{NAD}(\mathrm{P})$-couples and energy metabolism in lens in galactose-fed rats: effect of an aldose reductase inhibitor. Curr Eye Res 16, 34-43.

Obrosova, I.G., 2002. How does glucose generate oxidative stress in peripheral nerve? Int Rev Neurobiol 50, 3-35.

Obrosova, I.G., Drel, V.R., Kumagai, A.K., Szabo, C., Pacher, P., Stevens, M.J., 2006. Early diabetes-induced biochemical changes in the retina: comparison of rat and mouse models. Diabetologia 49, 2525-2533.

Obrosova, I.G., Fathallah, L., 2000. Evaluation of an aldose reductase inhibitor on lens metabolism, ATPases and antioxidative defense in streptozotocin-diabetic rats: an intervention study. Diabetologia 43, 1048-1055.

Obrosova, I.G., Kador, P.F., 2011. Aldose reductase / polyol inhibitors for diabetic retinopathy. Curr Pharm Biotechnol 12, 373-385.

Obrosova, I.G., Minchenko, A.G., Vasupuram, R., White, L., Abatan, O.I., Kumagai, A.K., Frank, R.N., Stevens, M.J., 2003. Aldose reductase inhibitor fidarestat prevents retinal oxidative stress and vascular endothelial growth factor overexpression in streptozotocin-diabetic rats. Diabetes 52, 864-871.

Odem, J., Munzinger, E., Violand, S., Van Morlan, A., Rife, D., Bachrach, B., 2009. An infant with combination gene mutations for Monogenic Diabetes of Youth (MODY) 2 and 4, presenting with Diabetes Mellitus Requiring Insulin (DMRI) at 8 months of age. Pediatr Diabetes 10, 550-553. 
Ohashi, Y., Mano, T., ,, Umemoto, M., Hositani, H., Tamada, R., Tano, Y., Matsuda, M., Fukuda, M., Manabe, R., 1986. The effects of aldose reductase inhibitor (CT112) on diabetic keratoepitheliopathy, in: Sakamoto, N., Kinoshita, J.H., kador, P.F., Hotta, N. (Eds.), Polyol Pathway and its Role in Diabetic Complications. Excerpta Medica, Kaskikojima, Japan, pp. 231-236.

Ohashi, Y., Matsuda, M., Hosotani, H., Tano, Y., Ishimoto, I., Fukuda, M., Manabe, R., 1988. Aldose reductase inhibitor (CT-112) eyedrops for diabetic corneal epitheliopathy. Am J Ophthalmol 105, 233-238.

Ohguro, N., Matsuda, M., Ohashi, Y., Fukuda, M., 1995. Topical aldose reductase inhibitor for correcting corneal endothelial changes in diabetic patients. $\mathrm{Br} \mathrm{J}$ Ophthalmol 79, 1074-1077.

Oka, S., Hsu, C.P., Sadoshima, J., 2012. Regulation of cell survival and death by pyridine nucleotides. Circ Res 111, 611-627.

Oliver, J.A., Clark, L., Corletto, F., Gould, D.J., 2010. A comparison of anesthetic complications between diabetic and nondiabetic dogs undergoing phacoemulsification cataract surgery: a retrospective study. Vet Ophthalmol 13, 244250.

Olmos, P., Acosta, A.M., Schiaffino, R., Diaz, R., Alvarado, D., O'Brien, A., Munoz, X., Arriagada, P., Claro, J.C., Vega, R., Vollrath, V., Velasco, S., Emmerich, M., Maiz, A., 1999. [Aldose reductase gene polymorphism and rate of appearance of retinopathy in non insulin dependent diabetics]. Rev Med Chil 127, 399-409.

Olmos, P., Futers, S., Acosta, A.M., Siegel, S., Maiz, A., Schiaffino, R., Morales, P., Diaz, R., Arriagada, P., Claro, J.C., Vega, R., Vollrath, V., Velasco, S., Emmerich, M., 2000. (AC)23 [Z-2] polymorphism of the aldose reductase gene and fast progression of retinopathy in Chilean type 2 diabetics. Diabetes Res Clin Pract 47, 169-176.

Organization, A.V.M., 2007. U.S. Pet Ownership \& Demographics Sourcebook (2007 Edition). AVMA.

Orts Vila, P., Devesa Torregrosa, P., Belmonte Martinez, J., 2003. [Juvenile Diabetic cataract. A rare finding which lead us to the diagnosis of this illness]. Arch Soc Esp Oftalmol 78, 389-391.

Pacher, P., Szabo, C., 2005. Role of poly(ADP-ribose) polymerase-1 activation in the pathogenesis of diabetic complications: endothelial dysfunction, as a common underlying theme. Antioxid Redox Signal 7, 1568-1580.

Paques, M., Massin, P., Gaudric, A., 1997. Growth factors and diabetic retinopathy. Diabetes Metab 23, 125-130.

Park, H.K., Ahn, C.W., Lee, G.T., Kim, S.J., Song, Y.D., Lim, S.K., Kim, K.R., Huh, K.B., Lee, H.C., 2002. (AC)(n) polymorphism of aldose reductase gene and diabetic microvascular complications in type 2 diabetes mellitus. Diabetes Res Clin Pract 55, 151-157. 
Patterson, J.W., 1954. Hyperglycemia and galactose cataract. Am. J. Physiol. 165, 541-543.

Patz, A., Maumenee, A.E., 1962. Studies on diabetic retinopathy. I. Retinopathy in a dog with spontaneous diabetes mellitus. Am J Ophthalmol 54, 532-541.

Perry, H.D., Foulks, G.N., Thoft, R.A., Tolentino, F.I., 1978. Corneal complications after closed vitrectomy through the pars plana. Arch Ophthalmol 96, 1401-1403.

Peterson, M.J., Page, M.G., Just, L.J., Aldinger, C.E., Malone, J.I., 1986. Applicability of red blood cell sorbitol measurements to monitor the clinical activity of sorbinil. Metabolism 35, 93-95.

PetMD, 2011. Diabetes in Dogs.

Petropoulos, I.N., Alam, U., Fadavi, H., Marshall, A., Asghar, O., Dabbah, M.A., Chen, X., Graham, J., Ponirakis, G., Boulton, A.J., Tavakoli, M., Malik, R.A., 2014. Rapid automated diagnosis of diabetic peripheral neuropathy with in vivo corneal confocal microscopy. Invest Ophthalmol Vis Sci 55, 2071-2078.

Petrovic, M.G., Peterlin, B., Hawlina, M., Petrovic, D., 2005. Aldose reductase (AC)n gene polymorphism and susceptibility to diabetic retinopathy in Type 2 diabetes in Caucasians. J Diabetes Complications 19, 70-73.

Pfeifer, M.A., Schumer, M.P., Gelber, D.A., 1997. Aldose reductase inhibitors: the end of an era or the need for different trial designs? Diabetes 46 Suppl 2, S82-89.

Piatigorsky, J., Fukui, H.N., Kinoshita, J.H., 1978. Differential metabolism and leakage of protein in an inherited cataract and a normal lens cultured with ouabain. Nature 274, 558-562.

Polydefkis, M., Arezzo, J., Nash, M., Bril, V., Shaibani, A., Gordon, R.J., Bradshaw, K.L., Junor, R.W., Ranirestat Study, G., 2015. Safety and efficacy of ranirestat in patients with mild-to-moderate diabetic sensorimotor polyneuropathy. J Peripher Nerv Syst 20, 363-371.

Quadrado, M.J., Popper, M., Morgado, A.M., Murta, J.N., Van Best, J.A., 2006. Diabetes and corneal cell densities in humans by in vivo confocal microscopy. Cornea 25, 761-768.

Rabbani, N., Thornalley, P.J., 2012. Methylglyoxal, glyoxalase 1 and the dicarbonyl proteome. Amino Acids 42, 1133-1142.

Rand, J.S., Fleeman, L.M., Farrow, H.A., Appleton, D.J., Lederer, R., 2004. Canine and feline diabetes mellitus: nature or nurture? J Nutr 134, 2072S-2080S.

Randazzo, J., Zhang, P., Makita, J., Blessing, K., Kador, P.F., 2011. Orally active multifunctional antioxidants delay cataract formation in streptozotocin (type 1) diabetic and gamma-irradiated rats. PLoS One 6, e18980.

Richeti, F., Noronha, R.M., Waetge, R.T., de Vasconcellos, J.P., de Souza, O.F., Kneipp, B., Assis, N., Rocha, M.N., Calliari, L.E., Longui, C.A., Monte, O., de Melo, M.B., 2007. Evaluation of $A C(n)$ and $C(-106) T$ polymorphisms of the aldose 
reductase gene in Brazilian patients with DM1 and susceptibility to diabetic retinopathy. Mol Vis 13, 740-745.

Richter, M., Guscetti, F., Spiess, B., 2002. Aldose reductase activity and glucoserelated opacities in incubated lenses from dogs and cats. Am J Vet Res 63, 15911597.

Robison, W.G., Jr., Houlder, N., Kinoshita, J.H., 1990a. The role of lens epithelium in sugar cataract formation. Exp Eye Res 50, 641-646.

Robison, W.G., Jr., Kador, P.F., Kinoshita, J.H., 1983. Retinal capillaries: basement membrane thickening by galactosemia prevented with aldose reductase inhibitor. Science 221, 1177-1179.

Robison, W.G., Jr., Tillis, T.N., Laver, N., Kinoshita, J.H., 1990b. Diabetes-related histopathologies of the rat retina prevented with an aldose reductase inhibitor. Exp Eye Res 50, 355-366.

Sato, S., Lin, L.R., Reddy, V.N., Kador, P.F., 1993. Aldose reductase in human retinal pigment epithelial cells. Exp Eye Res 57, 235-241.

Sato, S., Mori, K., Wyman, M., Kador, P.F., 1998. Dose-dependent prevention of sugar cataracts in galactose-fed dogs by the aldose reductase inhibitor M79175. Exp Eye Res 66, 217-222.

Sato, S., Takahashi, Y., Wyman, M., Kador, P.F., 1991. Progression of sugar cataract in the dog. Invest Ophthalmol Vis Sci 32, 1925-1931.

Schleicher, E.D., Weigert, C., 2000. Role of the hexosamine biosynthetic pathway in diabetic nephropathy. Kidney Int Suppl 77, S13-18.

Schultz, R.O., Matsuda, M., Yee, R.W., Edelhauser, H.F., Schultz, K.J., 1984. Corneal endothelial changes in type I and type II diabetes mellitus. Am J Ophthalmol 98, 401-410.

Segal, S., 2004. Another aspect of the galactosemia enigma. Mol Genet Metab 81, 253-254; author reply 255-257.

Shah, V.O., Scavini, M., Nikolic, J., Sun, Y., Vai, S., Griffith, J.K., Dorin, R.I., Stidley, C., Yacoub, M., Vander Jagt, D.L., Eaton, R.P., Zager, P.G., 1998. Z-2 microsatellite allele is linked to increased expression of the aldose reductase gene in diabetic nephropathy. J Clin Endocrinol Metab 83, 2886-2891.

Sharma, P., Vasavada, A.R., 2001. Acute transient bilateral diabetic posterior subcapsular cataracts(1). J Cataract Refract Surg 27, 789-794.

Sima, A.A., 1994. Pathological definition and evaluation of diabetic neuropathy and clinical correlations. Can J Neurol Sci 21, S13-17.

Simpson, R.G., Moshirfar, M., Edmonds, J.N., Christiansen, S.M., 2012. Laser in-situ keratomileusis in patients with diabetes mellitus: a review of the literature. Clin Ophthalmol 6, 1665-1674.

Skarbez, K., Priestley, Y., Hoepf, M., Koevary, S.B., 2010. Comprehensive Review of the Effects of Diabetes on Ocular Health. Expert Rev Ophthalmol 5, 557-577. 
Sorbinil Retinopathy Trial Research Group, 1990. A randomized trial of sorbinil, an aldose reductase inhibitor, in diabetic retinopathy. . Arch Ophthalmol 108, 12341244.

Spielberg, S.P., Shear, N.H., Cannon, M., Hutson, N.J., Gunderson, K., 1991. In-vitro assessment of a hypersensitivity syndrome associated with sorbinil. Ann Intern Med 114, 720-724.

Suzuki, Y., Atsumi, Y., Matsuoka, K., Suzuki, Y., Nishimaki, K., Ohta, S., Suzuki, Y., Taniyama, M., Suzuki, Y., Muramatsu, T., Suzuki, Y., 2004. Acute metabolic cataract as a first manifestation of diabetes mellitus in a 12-year-old girl. Diabetologia 47, 592-593.

Takahashi, Y., Augustin, W., Wyman, M., Kador, P.F., 1993. Quantitative analysis of retinal vessel changes in galactose-fed dogs. J Ocul Pharmacol 9, 257-269.

Takahashi, Y., Wyman, M., Ferris, F., 3rd, Kador, P.F., 1992. Diabeteslike preproliferative retinal changes in galactose-fed dogs. Archives of ophthalmology 110, 1295-1302.

Takamura, Y., Kubo, E., Tsuzuki, S., Akagi, Y., 2003. Apoptotic cell death in the lens epithelium of rat sugar cataract. Exp Eye Res 77, 51-57.

Takamura, Y., Sugimoto, Y., Kubo, E., Takahashi, Y., Akagi, Y., 2000. Immunohistochemical Study of Apoptosis of Lens Epithelial Cells in Human and Diabetic Rat Cataracts. Jpn J Ophthalmol 44, 569-570.

van Gerven, J.M., Boot, J.P., Lemkes, H.H., van Best, J.A., 1994. Effects of aldose reductase inhibition with tolrestat on diabetic retinopathy in a six months double blind trial. Doc Ophthalmol 87, 355-365.

Van Heyningen, R., 1959. Formation of polyols in the lens of the rat with "sugar" cataract. Nature 184, 194-195.

Vanderveen, D.K., 2008. Cataract update 2008: all you need to know about your pediatric cataract patients. Binocul Vis Strabismus Q 23, 145-158.

Varma, S.D., Kinoshita, J.H., 1974. The absence of cataracts in mice with congenital hyperglycemia. Exp Eye Res 19, 577-582.

Varma, S.D., Schocket, S.S., Richards, R.D., 1979. Implications of aldose reductase in cataracts in human diabetes. Invest Ophthalmol Vis Sci 18, 237-241.

Vedantham, S., Thiagarajan, D., Ananthakrishnan, R., Wang, L., Rosario, R., Zou, Y.S., Goldberg, I., Yan, S.F., Schmidt, A.M., Ramasamy, R., 2014. Aldose reductase drives hyperacetylation of Egr-1 in hyperglycemia and consequent upregulation of proinflammatory and prothrombotic signals. Diabetes 63, 761-774.

Vinding, T., Nielsen, N.V., 1984. Two cases of acutely developed cataract in diabetes mellitus. Acta Ophthalmol (Copenh) 62, 373-377.

Vinores, S.A., Campochiaro, P.A., Williams, E.H., May, E.E., Green, W.R., Sorenson, R.L., 1988. Aldose reductase expression in human diabetic retina and retinal pigment epithelium. Diabetes 37, 1658-1664. 
Wahren, J., Larsson, C., 2015. C-peptide: new findings and therapeutic possibilities. Diabetes Res Clin Pract 107, 309-319.

Wang, Y., Luk, A.O., Ng, M.C., Pang, C.C., Lam, V., Lee, S.C., Lam, D.S., Choy, K.W., Ma, R.C., So, W.Y., Chan, J.C., 2014. Additive effect of aldose reductase Z-4 microsatellite polymorphism and glycaemic control on cataract development in type 2 diabetes. J Diabetes Complications 28, 147-151.

Wang, Y., Ng, M.C., Lee, S.C., So, W.Y., Tong, P.C., Cockram, C.S., Critchley, J.A., Chan, J.C., 2003. Phenotypic heterogeneity and associations of two aldose reductase gene polymorphisms with nephropathy and retinopathy in type 2 diabetes. Diabetes Care 26, 2410-2415.

Williamson, J.R., Chang, K., Frangos, M., Hasan, K.S., Ido, Y., Kawamura, T., Nyengaard, J.R., Enden, M.v.d., Kilo, C., Tilton, R.G., 1993. Hyperglycemic pseudohypoxia and diabetic complications. Diabetes 42, 801-813.

Yan, S.F., Ramasamy, R., Schmidt, A.M., 2010. The RAGE axis: a fundamental mechanism signaling danger to the vulnerable vasculature. Circ Res 106, 842-853.

Yang, B., Millward, A., Demaine, A., 2003. Functional differences between the susceptibility Z-2/C-106 and protective Z+2/T-106 promoter region polymorphisms of the aldose reductase gene may account for the association with diabetic microvascular complications. Biochim Biophys Acta 1639, 1-7.

Yang, S.K., Xiao, L., Li, J., Liu, F., Sun, L., 2014. Oxidative stress, a common molecular pathway for kidney disease: role of the redox enzyme p66Shc. Ren Fail 36, 313-320.

Yee, R.W., Matsuda, M., Kern, T.S., Engerman, R.L., Edelhauser, H.F., 1985. Corneal endothelial changes in diabetic dogs. Curr Eye Res 4, 759-766.

Yeh, L.A., Ashton, M.A., 1990. The increase in lipid peroxidation in diabetic rat lens can be reversed by oral sorbinil. Metabolism 39, 619-622.

Yokoi, N., Niiya, A., Komuro, A., Yokogaki, S., Naka, H., Awata, T., Honma, Y., Yamada, J., Tei, M., Kinoshita, S., 1997. Effects of aldose reductase inhibitor CT112 on the corneal epithelial barrier of galactose-fed rats. Curr Eye Res 16, 595-599.

Zatechka, D.S., Jr., Kador, P.F., Garcia-Castineiras, S., Lou, M.F., 2003. Diabetes can alter the signal transduction pathways in the lens of rats. Diabetes 52, 1014-1022.

Zhang, P., Xing, K., Randazzo, J., Blessing, K., Lou, M.F., Kador, P.F., 2012a. Osmotic stress, not aldose reductase activity, directly induces growth factors and MAPK signaling changes during sugar cataract formation. Exp Eye Res 101, 36-43.

Zhang, Z., Xing, K., Randazzo, J., Blessing, K., Lou, M.F., Kador, P.F., 2012b. Osmotic stress, not aldose reductase activity, directly induces growth factors and MAPK signaling changes during sugar cataract formation. Exp Eye Res 101, 36-43.

Zou X-M, Zhao H-L, Song H-J, Lu J-M, C-Y:, P., 2002. Association of the Z-2 and 2 allele of aldose reductase gene with its erythrocyte activity and diabetic microangiopathy in Chinese with type 2 diabetes. Diabetes Res. Clin. Pract., 57 (Suppl 1), S27-S28. 


\section{Legends:}

Table 1 Summary of ARI effects on retinal, lens and tissue biological markers observed in galactose-fed dogs. The values for pericyte ghosts and microaneurysms represent the time required in months to develop a $50 \%$ incidence of either pericyte ghosts or microaneurysms. Cataract severity (calculated as the mean score from 6-36 months) was subjectively classified on a scale of 0 to 4 , with 4 being the most advanced cataract according to the criteria: 1) an incipient cataract with some degree of vacuolization in the anterior or posterior cortex; 2) a progression of vacuoles and opacification to stria in the cortex with involvement of the sutures; 3 ) opacification of most of the visible cortex; and 4) a complete dense cataract. * calculated from 30-36 month values.

Figure 1. Summary of biochemical changes associated with increased Sorbitol Pathway activity. Increased "polyol" formation can result in cellular changes that result from osmotic stress, REDOX changes, the generation of ROS, and the induction of growth factors and signaling changes. The metabolism of sorbitol is linked to the activation, acetylation, and prolonged expression of Egr1 which leads to proinflammatory and prothrombotic changes. AC, acetylation; bFGF, basic fibroblast growth factor, DAG diacylglycerol; Erg 1, ETS-related gene-1; GSH glutathione, MMPs, matrix metalloproteinases; NAMPT, Nicotinamide phosphoribosyl transferase; Na/K-ATPase, sodium-potassium ATPase; PKc, protein kinase c; REDOX, reduction and oxidation; ROS, reactive oxygen species; Sirt1, NAD-dependent deacetylase sirtuin-1; TF, tissue factor; TGF $\beta$, transforming growth factor beta; TNF $\alpha$, tumor necrosis factor alpha; VEGF, vascular endothelial growth factor; VCAM, vascular cell adhesion molecule.

Figure 2 Relationship between osmotic changes resulting from sorbitol formation and the induction of growth factor and signaling changes, and the generation of ROS in the rat lens epithelial cell.

Figure 3. Structure of ARIs evaluated in galactose-fed dogs. 
Figure 4 Time-frame of retinal changes in 9 -month beagles fed $30 \%$ galactose diet. Retinopathy progresses from the early background stage to the advanced proliferative stage.

Figure 5 Comparison of retinal vascular changes in initially 2-month-old (diagonal bars) versus 9-month-old (vertical bars) male beagles fed a 30\% galactose diet for 36 months. Solid bars represent values obtained from 9-month old males fed only a control, fiber diet (values are the mean \pm standard error of the mean; $n 4-6) .{ }^{*}$ indicate significance $(p<$ $0.05)$ between groups.

Figure 6 Dose dependent effect of M79175 on pericyte ghost and microaneurysm formation and clinical appearance of dot and blot hemorrhages in 36-38 month galactosefed dogs.

Figure 7 Dose-dependent prevention of cataract formation correlates with the prevention of microaneurysms. The center graph shows the average cataract severity (5-36/38 months) calculated from graph at the left. At right, the dose-dependent reduction in microaneurysm formation correlated with the observed reduction in cataract severity (center).

Figure 8 Comparison of cataract formation in untreated (black) versus $30 \mathrm{mg}$ (red) and $180 \mathrm{mg}$ (green) FK366 treated dogs fed galactose for 36 months.

Figure 9 Analysis of galactitol (right) and FK366 levels (left) in select tissues from 30 month galactose-fed dogs. Red represents the $30 \mathrm{mg} / \mathrm{kg}$ dose and green represents the $180 \mathrm{mg} / \mathrm{kg}$ dose of FK366. The percent reduction of galactitol levels was calculated by comparing galactitol levels in tissues from drug treated dogs to galactitol levels from similar untreated dogs. Mean \pm SEM.

Figure 10 Effect of galactose diet removal on changes in endothelial cell to pericyte ratio, microaneurysm formation, and acellular vessel formation observed in the eyes from 
control $(\bullet)$, continuously galactose diet $(\square)$, galactose diet removed at 24 months $\left({ }^{\wedge}\right)$ and galactose diet removed at 31 months $\left({ }^{\nabla}\right)$ dogs. Results are from quantification of histological changes with each point representing $n=4-5$ eyes, mean \pm SD. Symbols indicate significant differences between the continuous galactose-fed group and all other groups at the $* p<0.01$ and $\ddagger p<0.05$ level. No significant differences between the control and either galactose-removed group were observed.

Figure 11 Fluorescein angiograms illustrating the development of retinal areas of nonperfusion in continuous galactose-fed dogs. Beginning at 36 months, focal areas of hyperfluorescence (arrows) developed (left) followed by areas of nonperfusion (arrows) that are characterized by a decreased amount of fluorescein leakage (center). This area of nonperfusion increases with the duration of galactose feeding (right).

Figure 12 Fluorescein angiograms illustrating the presence of proliferative changes in the retina of continuous galactose-fed dogs. The fundus photograph taken near the optic disc $(A)$ demonstrates in the early $(B)$ and late $(C)$ angiograms massive fluorescein leakage around the optic disc after the injection of fluorescein that is typically indicative of neovascularization. New vessel formation was subsequently confirmed by histology.

Figure 13 Estimated probability of progression to any retinal nonperfusion (top left), progression to nonperfusion $\geq 1 / 2$ field (top right), and progression to neovascularization (bottom right) among the control (black), continuous galactose fed (red), galactose withdrawal at 36 months (blue) and M79175-treated galactose withdrawal at 34 months (green) groups of dogs. The table (bottom left) lists the estimated month to outcome values for each group of dogs.

Figure 14 Appearance of retinal capillaries isolated from transgenic mice and comparison of retinal and lens polyol levels obtained from these mice. Left $A$ shows the confocal appearance of the isolated retinal vasculature from a SMAA-GFP mouse under white light and B fluorescence indicating intense GFP localization in pericytes. Similarly, immunohistochemical staining of isolated capillaries from C57BL/6 control (C) and 
SMAA-GFP-HAR (D) mice with red staining Texas red conjugate of AR antibody from human placental AR (Akagi et al., 1983; Hohman et al., 1989) showed staining in pericytes. The capillaries from control mice $(C)$ showed minimal immunohistochemical staining with $A R$ antibodies from either human or rat, indicating low levels of $A R$ present. The graph on the right shows that when crossed with the naturally diabetic Akita mouse, significantly higher levels of sorbitol $(p<0.05)$ accumulate in the neural retina

Figure 15 Appearance and changes of isolated retinal capillaries from 18 week nondiabetic SMAA-GFP-hAR mice and diabetic AK-SMAA-GFP-hAR mice treated with or without the hydantoin ARI AL1576 or carboxylic acid ARI statil and 10 week diabetic rats treated with or without the same ARIs. The representative appearances of retinal vessels from SMAA-GFP-hAR mice (A), AK-SMAA-GFP-hAR mice (B) and AK-SMAA-GFP-hAR mice treated with AL1576 (C), control rat (D), diabetic rat (E) and diabetic rat treated with Al1575 (F) are shown. The red arrow indicates acellular vessels. The capillary cell density expressed as capillary nuclei per $100 \mu \mathrm{m}$ of capillary length for the mice and rats is summarized in $(\mathbf{G})$ showing a small decrease in the number of nuclei per capillary length in the diabetic AK-SMAA-GFP-hAR mice compared to either the SMAA-GFP-hAR mice or AK-SMAA-GFP-hAR mice treated with AL1576. In the 10 week diabetic rats, the untreated diabetic rats showed a significant reduction in retinal capillary nuclei compared to either non-diabetic controls or diabetic rats treated with ARIs AL1576 or statil. The percent of acellular capillaries present in the examined neural retinal capillaries is summarized in $(\mathbf{H})$. A small, but significant increase in the percent acellular vessels present in the diabetic AK-SMAA-GFP-hAR mice compared to either AK-SMAA-GFPhAR mice treated with AL1576 ( $p<0.007)$ or non-diabetic SMAA-GFP-hAR $(p=0.03)$ mice. Mean \pm S.E.M. ${ }^{*} p<0.05$ compared to SMAA-GFP-hAR. ${ }^{* *} p<0.05$ compared to

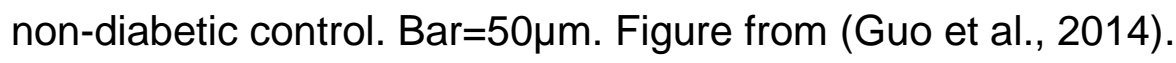

Figure 16 Dose-dependent reduction of cataract formation in galactose-fed dogs by oral administration of 2-MS (M79175). The retro-illumination (A) and slit lamp (B) photograph of a lens from a galactose-fed dog administered 2-MS and receiving 30\% galactose diet 
for 38 months shows the absence of opacities. There is no demarcation line, confirming that cortical changes had not developed and that cataract formation had been arrested.

Figure 17. Representative appearance of lenses from dilated eyes from two beagles fed $30 \%$ galactose diet treated with or without Kinostat $^{\circledR}$. The appearance 1 week prior to start of treatment (15 weeks), 9 weeks after treatment with vehicle (25 weeks) and the isolated lens at the termination of the study (26 weeks) is shown for the vehicle treated dogs in $\mathbf{A}$ and Kinostat $^{\circledR}$ treated dogs in $\mathbf{B}$. Graph in $\mathbf{C}$ compares the means of the weighted average integrated optical density per $\mathrm{mm}^{2}$ area analyzed for the lenses from each group. ${ }^{*} P<0.05$. Mean $\pm S D$, vehicle treated $n=4$; Kinostat-treated $n=6$.

Figure 18 Cataract grading scale employed ranged from: 0 no lens opacity; 1 equatorial vacuoles only / punctate cortical opacities; 2 equatorial and cortical vacuoles / diffuse cortical opacities; 3 late immature to mature cataract. Suture accentuation was given a score of 0.5 .

Figure 19 Osmotic lens changes observed in a placebo treated diabetic dog. While initially clear at the onset of the study, vacuoles rapidly developed resulting the appearance of a mature cataract within 6 months.

Figure 20 Comparison of mean cataract scores at the onset and at 12 months of placebo (vehicle, red) and Kinostat ${ }^{\circledR}$ (blue) treated diabetic dogs. The placebo treated group was composed of 24 eyes from 12 dogs and the Kinostat ${ }^{\circledR}$ treated dog was composed of 56 eyes from 28 dogs. (Mean \pm SEM) ${ }^{*} \mathrm{P} \leq 0.0016$.

Figure 21 Wax and waning of osmotic lens changes in a Kinostat ${ }^{\circledR}$ treated diabetic dog. While equatorial vacuoles formed and receded over the 12 month study period, the agerelated anterior and posterior cortical opacities which were present from the onset of study did not progress and remained unchanged after 12 months. 
Figure 22 Appearance of the lens from a diabetic Cocker Spaniel where equatorial vacuoles were noted at $360^{\circ}$. These disappeared after 29 months and the lens remained clear with continued topical treatment of Kinostat ${ }^{\circledR}$ until the dog's death at 4 years.

Figure 23 Number of dogs enrolled in long-term Kinostat ${ }^{\circledR}$ treatment following completion of the Proof of Concept trial.

Figure 24 Effect of 2-MS particle size on lens uptake. Levels of 2-MS measured in the lenses of rats after 21 days of topical TID treatment. Mean $\pm S D * p<0.05$ compared to $14 \mu \mathrm{m}$ diameter.

Figure 25 Immunohistochemical localization and specific activity of AR in rat, dog and human lenses. AR specific antibodies against rat lens, dog lens and human placental AR were used to demonstrate that the enzyme is primarily present in lens epithelium and superficial cortical fibers at the equator. From (Kador, 2010)

Figure 26 Diabetic corneal changes linked to AR activity include morphological changes in the epithelium and endothelium as well as nerve changes. ARIs have been clinically observed to reduce these changes. Illustrated here are the clinical effects of the ARI CT112 which has been shown to (A) reduce Superficial Punctate Keratitis (SPK) and surface defects (Hosotani et al., 1986) as well as (B) significantly reduce diabetes induced epithelial cell morphology measured by specular microscopy (mean \pm SE; dashed line represents range; $n=39$ patients) (Hosotani et al., 1995). (C) illustrates that CT-112 treatment resulted in significant improvement of corneal sensitivity in patients compared to placebo ( $n=39$ patients $\# p<0.0001$ ) (Hosotani et al., 1995). CT-112 treatment also reduced the corneal endothelial cell coefficient of variation (D) and increased the percent hexagonality (E) measured in diabetic patients by specular microscopy. (F) Persistent corneal edema observed to significantly increase in diabetics $(\# p<0,01)$ following cataract surgery was also reduced in similar patients treated with CT-112 $(n=21)$ (Awata et al., 1990). 